\title{
Multivalent elastin-like glycopolypeptides: subtle chemical structure modifications with high impact on lectin binding affinity
}

Marie Rosselin, Zoeisha S. Chinoy, Lourdes Mónica Bravo Anaya, Sébastien Lecommandoux and Elisabeth Garanger*

Univ. Bordeaux, CNRS, Bordeaux INP, LCPO, UMR 5629, Pessac, F-33600, France.

\section{EXPERIMENTAL SECTION}

\section{Materials.}

All reagents and solvents were purchased from commercial sources. Glycidyl propargyl ether, glacial acetic acid, hexafluoroisopropanol (HFIP), acetic anhydride, anhydrous 1,2dichloroethane, pyridine, boron trifluoride diethyl etherate, $N, N, N^{\prime}, N^{\prime \prime}, N^{\prime \prime}$ pentamethyldiethylenetriamine (PMDETA) and Trizma® were obtained from Sigma-Aldrich (FR). Anhydrous $\mathrm{CH}_{2} \mathrm{Cl}_{2}$ was obtained using PureSolv MD-5 solvent purification system from Innovative Technology. Ultrapure water $(18 \mathrm{M} \Omega-\mathrm{cm})$ was obtained by using a Millipore Milli-Q Biocel A10 purification unit. Cuprisorb ${ }^{\mathrm{TM}}$ was from Seachem (USA). Ethanol $(96.0 \%, \mathrm{EtOH})$, methanol $(98.5 \%, \mathrm{MeOH})$, acetonitrile $(99.9 \%, \mathrm{ACN})$ and $\mathrm{CuSO}_{4} .5 \mathrm{H}_{2} \mathrm{O}$ were obtained from VWR international. $\mathrm{NaCl}(99 \%)$ was purchased from Alfa Aesar (FR). $\beta$ D-galactopyranosyl azide $\left(\beta-\mathrm{Gal}_{3} \mathrm{~N}_{3}\right), \quad \alpha$-D-mannopyranosyl azide $\left(\alpha-\mathrm{Man}-\mathrm{N}_{3}\right), \quad \beta$-Dgalactopyranosyl pentaacetate, and D-mannose were obtained from Carbosynth (UK). Ammonium acetate, ammonium pyrrolidinedithiocarbamate (APDC) and sodium ascorbate were obtained from Fisher Scientific (FR). Unconjugated Ricinus Communis Agglutinin I $\left(\right.$ RCA $\left._{120}\right)$ from Vector Labs was purchased from Eurobio Scientific (FR). Amicon ${ }^{\circledR}$ ultra-15 centrifugal filter tubes (3,000 MWCO) were obtained from Merck Millipore (FR). Tris buffer was prepared with $0.05 \mathrm{M}$ Trizma- $\mathrm{HCl}$ and $0.15 \mathrm{M} \mathrm{NaCl}$ in ultrapure water, and the $\mathrm{pH}$ of the solution was adjusted to 7.6 with $0.1 \mathrm{M} \mathrm{NaOH}$.

Synthetic procedures.

Synthesis of 3-azidopropyl- $\beta$-D-galactopyranoside ( $\beta$-Gal-link-N3) and 3-azidopropyl- $\alpha$ D-mannopyranoside ( $\alpha$-Man-link-N3).

1,2,3,4,6-Penta- $\boldsymbol{O}$-acetyl-D-mannopyranose. Acetic anhydride $(10 \mathrm{~mL})$ was added to a solution of mannose $(2 \mathrm{~g}, 11.1 \mathrm{mmol})$ in pyridine $(15 \mathrm{~mL})$ and the resulting reaction mixture 
was left to stir for $18 \mathrm{~h}$. The solution was diluted with ethyl acetate (EtOAc), washed with a saturated solution of $\mathrm{NaHCO}_{3}$ and a solution of $\mathrm{CuSO}_{4}$, dried over $\mathrm{MgSO}_{4}$, filtered and the filtrate was concentrated in vacuo. The resulting residue was purified by flash chromatography on silica gel (petroleum ether:EtOAc, 6:4, v:v) to afford 1,2,3,4,6-Penta- $O$ acetyl-D-mannopyranose (4.3 g, $\beta: \alpha=4: 1$, quantitative yield) as an oil ${ }^{1} \mathrm{H}$ NMR (400 MHz; $\left.\mathrm{CDCl}_{3}\right): \delta 2.00-2.16(\mathrm{~m}, 15 \mathrm{H}, 5 \times \mathrm{OAc}), 3.80(\mathrm{ddd}, J=9.9,5.4,2.4 \mathrm{~Hz}, 0.19 \mathrm{H}, \mathrm{H}-5 \alpha), 4.03-$

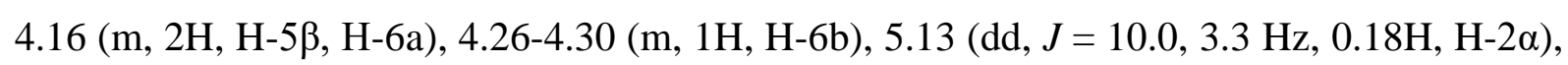

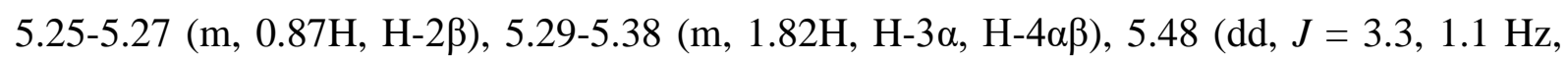
$0.19 \mathrm{H}, \mathrm{H}-3 \beta), 5.86$ (d, $J=1.2 \mathrm{~Hz}, 0.19 \mathrm{H}, \mathrm{H}-1 \alpha), 6.09$ (d, $J=1.7 \mathrm{~Hz}, 0.81 \mathrm{H}, \mathrm{H}-1 \beta) .{ }^{13} \mathrm{C} \mathrm{NMR}$ assigned from HSQC (100 MHz, $\left.\mathrm{CDCl}_{3}\right): \delta 20.39(5 \times), 61.80,65.36,67.95,68.27,68.59(\mathrm{C}-$

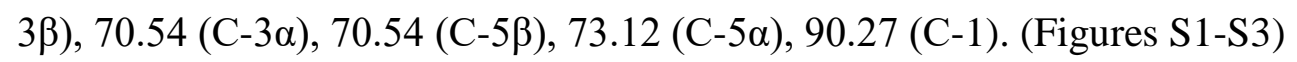

3-Azidopropyl (2,3,4,6-tetra- $\boldsymbol{O}$-acetyl- $\alpha$-D-mannopyranoside. To a cooled $\left(0{ }^{\circ} \mathrm{C}\right)$ solution of 3-azido-1-propanol $(520 \mu \mathrm{L}, 5.63 \mathrm{mmol})$ and 1,2,3,4,6-penta- $O$-acetyl-D-mannopyranose (733 mg, $1.88 \mathrm{mmol})$ in anhydrous $\mathrm{CH}_{2} \mathrm{Cl}_{2}(5 \mathrm{~mL})$, boron trifluoride diethyl etherate $(1.16$ $\mathrm{mL}, 9.4 \mathrm{mmol}$ ) was added and the reaction left to stir, while warming to room temperature, for $18 \mathrm{~h}$. The reaction mixture was diluted with $\mathrm{CH}_{2} \mathrm{Cl}_{2}$ and washed with a saturated solution of $\mathrm{NaHCO}_{3}$, and then water till the $\mathrm{pH}$ was neutral, filtered through celite, The organic layers were combined, dried over $\mathrm{MgSO}_{4}$, filtered and concentrated in vacuo. The resulting residue was purified by flash chromatography on silica gel (petroleum ether:EtOAc, 6:4, v:v), to give 3-azidopropyl (2,3,4,6-tetra- $O$-acetyl- $\alpha$-D-mannopyranoside $(331 \mathrm{mg}, 41 \%)$ as an oil. ${ }^{1} \mathrm{H}$ NMR (400 MHz; $\left.\mathrm{CDCl}_{3}\right): \delta$ 1.87-1.93 (m, 2H, L2-CH $), 2.00$ (s, 3H, OAc), 2.05 (s, 3H, OAc), 2.11 (s, 3H, OAc), 2.16 (s, 3H, OAc), 3.43 (t, $J=6.5 \mathrm{~Hz}, 2 \mathrm{H}, \mathrm{L} 3-\mathrm{CH}_{2}$ ), 3.49-3.56 (m, 1H, L1-CHH), 3.79-3.85 (m, 1H, L1-CHH), 3.97 (ddd, $J=9.3,5.5,2.5 \mathrm{~Hz}, 1 \mathrm{H}, \mathrm{H}-5$ ), 4.12 (dd, $J=12.2,2.5 \mathrm{~Hz}, 1 \mathrm{H}, \mathrm{H}-6 \mathrm{a}), 4.28$ (dd, $J=12.2,5.4 \mathrm{~Hz}, 1 \mathrm{H}, \mathrm{H}-6 \mathrm{~b}), 4.82$ (d, $J=1.7 \mathrm{~Hz}$, $1 \mathrm{H}, \mathrm{H}-1), 5.24$ (dt, $J=3.4,1.8 \mathrm{~Hz}, 1 \mathrm{H}, \mathrm{H}-2), 5.28-5.34$ (m, 2H, H-3, H-4). ${ }^{13} \mathrm{C}$ NMR assigned from HSQC (100 MHz, $\left.\mathrm{CDCl}_{3}\right)$ : $\delta 20.39$ (5×), 28.48, 47.89, 62.45, 64.71, 66.01, 68.59 (C-5), 68.59 (C-2), 69.24, 97.39. MALDI-MS: $[\mathrm{M}+\mathrm{Na}]^{+} \mathrm{C}_{17} \mathrm{H}_{25} \mathrm{~N}_{3} \mathrm{NaO}_{10}$, calcd 454.14, obsd 454.46. (Figures S4-S6)

3-Azidopropyl- $\alpha$-D-mannopyranoside. 3-Azidopropyl (2,3,4,6-tetra- $O$-acetyl- $\alpha$-Dmannopyranoside $(204 \mathrm{mg})$ was dissolved in $20 \mathrm{mM} \mathrm{NaOMe}(8 \mathrm{~mL})$, and the reaction left to stir at room temperature for $4 \mathrm{~h}$. The reaction was neutralized with Dowex $50 \mathrm{WX} 8 \mathrm{H}^{+}$resin, filtered, concentrated and azeotropically dried with toluene $(4 \times 5 \mathrm{~mL})$ to afford the product 3-azidopropyl- $\alpha$-D-mannopyranoside (130 mg, quantitative yield). ${ }^{1} \mathrm{H}$ NMR (400 MHz; $\mathrm{D}_{2} \mathrm{O}$ ): 
$\delta$ 1.90-1.94 (m, 2H, L2-CH $), 3.46\left(\mathrm{td}, J=6.6,2.1 \mathrm{~Hz}, 2 \mathrm{H}, \mathrm{L} 3-\mathrm{CH}_{2}\right), 3.58-3.66(\mathrm{~m}, 3 \mathrm{H}, \mathrm{H}-4$, H-5, L1-CHH), 3.74-3.85 (m, 3H, H-6a, H-3, L1-CHH), 3.90 (dd, J = 12.1, 1.8 Hz, 1H, H6b), 3.96 (dd, $J=3.4,1.8 \mathrm{~Hz}, 1 \mathrm{H}, \mathrm{H}-2), 4.87$ (d, $J=1.8 \mathrm{~Hz}, 1 \mathrm{H}, \mathrm{H}-1) .{ }^{13} \mathrm{C}$ NMR assigned from HSQC (100 MHz, $\left.\mathrm{D}_{2} \mathrm{O}\right): \delta$ 27.83, 48.21, 60.83, 64.71, 66.65, 69.89, 70.54, 72.80, 99.65. MALDI-MS: $[\mathrm{M}+\mathrm{Na}]^{+} \mathrm{C}_{9} \mathrm{H}_{17} \mathrm{~N}_{3} \mathrm{NaO}_{6}$, calcd 286.10, obsd 286.31. (Figures S7-S9)

3-Azidopropyl $\left(\mathbf{2 , 3 , 4 , 6}\right.$-tetra- $\boldsymbol{O}$-acetyl- $\boldsymbol{\beta}$-D-galactopyranoside. To a cooled $\left(0{ }^{\circ} \mathrm{C}\right)$ solution of 3-azido-1-propanol $(720 \mu \mathrm{L}, 7.84 \mathrm{mmol})$ and $\beta$-D-galactopyranosyl pentaacetate $(1.02 \mathrm{~g}$, $2.61 \mathrm{mmol})$ in anhydrous 1,2-dichloroethane $(8 \mathrm{~mL})$, boron trifluoride diethyl etherate (640 $\mu \mathrm{L}, 5.22 \mathrm{mmol}$ ) was added and the reaction left to stir, while warming to room temperature, for $18 \mathrm{~h}$. The reaction mixture was diluted with $\mathrm{CH}_{2} \mathrm{Cl}_{2}$ and washed with a saturated solution of $\mathrm{NaHCO}_{3}$, and then water till the $\mathrm{pH}$ was neutral, filtered through celite, The organic layers were combined, dried over $\mathrm{MgSO}_{4}$, filtered and concentrated in vacuo. The resulting residue was purified by flash chromatography on silica gel (petroleum ether:EtOAc, 7:3, v:v), to give 3-azidopropyl (2,3,4,6-tetra- $O$-acetyl- $\beta$-D-galactopyranoside $(380 \mathrm{mg}, 34 \%)$ as an oil. ${ }^{1} \mathrm{H}$ NMR (400 MHz; $\mathrm{CDCl}_{3}$ ): $\delta$ 1.75-1.84 (m, 2H, L2-CH $), 1.92$ (s, 3H, OAc), 1.99 (d, J = 6.8 $\mathrm{Hz}, 6 \mathrm{H}, 2 \times \mathrm{OAc}), 2.09$ (s, 3H, OAc), 3.29-3.33 (m, 2H, L3-CH $\mathrm{CH}_{2}, 3.50-3.57$ (m, 1H, L1$\mathrm{CH} H$ ), 3.83-3.92 (m, 2H, H-5, L2-CHH), 4.04-4.14 (m, 2H, H-6a, H-6b), 4.40 (d, J = 7.9 Hz, 1H, H-1), 4.95 (dd, $J=10.5,3.4 \mathrm{~Hz}, 1 \mathrm{H}, \mathrm{H}-3), 5.13$ (dd, $J=10.5,7.9 \mathrm{~Hz}, 1 \mathrm{H}, \mathrm{H}-2), 5.33$ (dd, $J=3.4,1.0 \mathrm{~Hz}, 1 \mathrm{H}, \mathrm{H}-4) .{ }^{13} \mathrm{C}$ NMR assigned from HSQC $\left(100 \mathrm{MHz}, \mathrm{D}_{2} \mathrm{O}\right): \delta 20.71(\times 4)$, 28.80, 47.57, 61.15, $66.33(\times 2), 68.59,70.54,70.86$, 101.27. MALDI-MS: $[\mathrm{M}+\mathrm{Na}]^{+}$ $\mathrm{C}_{17} \mathrm{H}_{25} \mathrm{~N}_{3} \mathrm{NaO}_{10}$, calcd 454.14, obsd 454.35. (Figures S10-S12)

3-Azidopropyl- $\beta$-D-galactopyranoside. $\quad 3$-azidopropyl $\quad(2,3,4,6$-tetra- $O$-acetyl- $\beta$-Dgalactopyranoside $(241 \mathrm{mg})$ was dissolved in $20 \mathrm{mM} \mathrm{NaOMe}(10 \mathrm{~mL})$, and the reaction left to stir at room temperature for $3 \mathrm{~h}$. The reaction was neutralized with Dowex $50 \mathrm{WX} 8 \mathrm{H}^{+}$resin, filtered, concentrated and azeotropically dried with toluene $(4 \times 5 \mathrm{~mL})$ to afford 3azidopropyl- $\beta$-D-galactopyranoside $\left(152 \mathrm{mg}\right.$, quantitative yield) as an oil. ${ }^{1} \mathrm{H}-\mathrm{NMR}$ (400 $\mathrm{MHz} ; \mathrm{D}_{2} \mathrm{O}$ ): $\delta 1.92$ (quintet, $J=6.5 \mathrm{~Hz}, 2 \mathrm{H}, \mathrm{L} 2-\mathrm{CH}_{2}$ ), 3.54-3.46 (m, 3H, L3-CH,$\left.~ H-2\right), 3.65$ (dd, $J=9.9,3.5 \mathrm{~Hz}, 1 \mathrm{H}, \mathrm{H}-2), 3.70$ (ddd, $J=7.8,4.4,0.9 \mathrm{~Hz}, 1 \mathrm{H}, \mathrm{H}-5), 3.80-3.73$ (m, 3H, L1-CHH, H-6a, H-6b), 3.93 (dd, $J=3.4,0.7$ Hz, 1H, H-4), 4.01 (dt, $J=10.4,6.2$ Hz, 1H, L1$\mathrm{CHH}), 4.40(\mathrm{~d}, J=7.9 \mathrm{~Hz}, 1 \mathrm{H}, \mathrm{H}-1) .{ }^{13} \mathrm{C}$ NMR assigned from HSQC (100 MHz, $\left.\mathrm{D}_{2} \mathrm{O}\right): \delta$ 27.83, 47.57, 60.83, 66.98, 68.27, 70.54, 72.48, 75.07, 102.89. MALDI-MS: $[\mathrm{M}+\mathrm{Na}]^{+}$ $\mathrm{C}_{9} \mathrm{H}_{17} \mathrm{~N}_{3} \mathrm{NaO}_{6}$, calcd 286.10, obsd 286.31. (Figures S13-S15) 


\section{Synthesis of glycopolypeptides.}

ELP $\left[\mathrm{M}_{1} \mathrm{~V}_{3}-20\right]$ and ELP $\left[\mathrm{M}_{1} \mathrm{~V}_{3}-40\right]$ (Figure 1A) were produced recombinantly in Esherichia coli bacteria and purified by inverse transition cycling (1999_ Nat.Biotechnol_Meyer_ A. Purification of Recombinant Proteins by Fusion with Thermally-Responsive Polypeptides) following established procedures. (2010_Chem.Biol._Basle',_Protein Chemical Modification on Endogenous Amino Acids, Biomacromol Rosine 2017, 2017_Bioconjugate_Petitdemange) These two ELPs were chemoselectively thioalkylated with glycidyl propargyl ether (Figure $1 \mathrm{~B}$, step $i$ ), and part of the purified products were demethylated (Figure 1B, step ii) in $75 \%$ $\mathrm{EtOH}(\mathrm{aq})$ with ammonium pyrrolidinedithiocarbamate (APDC) as described in a previous contribution (2017_Bioconjugate_Petitdemange, ACS MacroLetters Rosselin). Both series of sulfonium- and thioether-containing derivatives were subsequently functionalized by copper catalyzed azide-alkyne cycloaddition (CuAAC) using $\beta$-D-galactopyranosyl azide $\left(\beta-\mathrm{Gal}_{-} \mathrm{N}_{3}\right)$, $\alpha$-D-mannopyranosyl azide ( $\alpha \square$ Man- $\mathrm{N}_{3}$ ), 3-azidopropyl- $\beta$-D-galactopyranoside ( $\beta$-Gal-link$\mathrm{N}_{3}$ ) or 3-azidopropyl- $\alpha$-D-mannopyranoside ( $\alpha \square$ Man-link-N 3 ) to give compounds $\underline{\mathbf{1 a}-\mathbf{c}}, \underline{\mathbf{2 a}-\mathbf{d}}$, $\underline{\mathbf{3 a}-\mathbf{d}}$ and $\underline{\mathbf{4 a}-\mathbf{d}}$. (Figure 1B, step iii)

General procedure for ELP thioalkylation: synthesis of ELP[M(Alk)1 V $\left._{3}-20\right]$ (1) and $\operatorname{ELP}\left[M(A l k)_{1} V_{3}-40\right](\underline{2})$.

$\operatorname{ELP}\left[\mathrm{M}_{1} \mathrm{~V}_{3}-n\right](n=20$ or 40$)$ was dissolved in AcOH/HFIP mixture (9/1, v/v) at $20 \mathrm{mg} / \mathrm{mL}$. The solution was degassed with Ar and glycidyl propargyl ether was added to the mixture (10 equiv. per Met residue). After $24 \mathrm{~h}$ stirring, a second portion of glycidyl propargyl ether (10 equiv. per Met residue) was added and the reaction was stirred for a total of $48 \mathrm{~h}$ at room temperature and under Ar atmosphere. The reaction mixture was transferred into a 3,000 MWCO Amicon® ultra-15 centrifugal filter tube, washed with $40 \mathrm{~mL}$ ultrapure water and freeze-dried. Derivatives $\underline{\mathbf{1}}$ and $\underline{\mathbf{2}}$ were characterized by NMR spectroscopy. (Figures S18 and S44-45, respectively).

General procedure for ELP demethylation: synthesis of $\operatorname{ELP}\left[\mathrm{M}\left(\operatorname{Dem} \mathrm{Alk}_{1} \mathrm{~V}_{3}-20\right](\underline{3})\right.$ and $\operatorname{ELP}\left[M(\operatorname{Dem} A l k)_{1} V_{3}-20\right](\underline{4})$.

To a solution of ELP[M(Alk) $\left.)_{1} \mathrm{~V}_{3}-n\right](n=20$ or 40$)$ in $75 \%$ EtOH(aq) was added ammonium pyrrolidinedithiocarbamate (APDC) (5.0 equiv per Met residue). The solution was stirred under Ar for $24 \mathrm{~h}$ at room temperature. The reaction mixture was transferred to a $1 \mathrm{kDa}$ MWCO dialysis tubing and dialyzed against $50 \% \mathrm{MeOH}(\mathrm{aq})$ during $24 \mathrm{~h}$ with 3 solvent 
changes, followed by $8 \mathrm{~h}$ dialysis against ultrapure water with 3 changes. The solution was then lyophilized. Derivatives $\underline{\mathbf{3}}$ and $\underline{\mathbf{4}}$ were characterized by NMR spectroscopy. (Figures S2829, and S56-57, respectively).

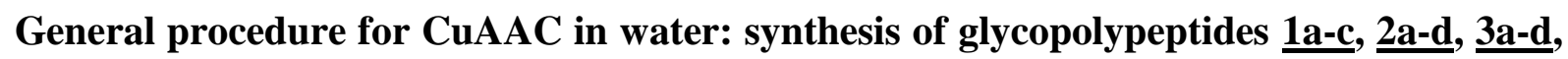
4a-d.

To a solution of $\operatorname{ELP}\left[\mathrm{M}(\mathrm{Alk})_{1} \mathrm{~V}_{3}-n\right]$ or $\operatorname{ELP}\left[\mathrm{M}(\operatorname{DemAlk})_{1} \mathrm{~V}_{3}-n\right](n=20$ or 40$)$ derivative in degassed water $(5 \mathrm{mg} / \mathrm{mL})$ under Ar Atmosphere, the desired azido-containing monosaccharide derivative (1.5 equiv. per alkyne) was added. A solution of $\mathrm{Cu}(\mathrm{I})$ was prepared by addition of sodium ascorbate (1.3 equiv. per alkyne) to a degassed solution of $\mathrm{Cu}(\mathrm{II}) \mathrm{SO}_{4}$ (0.26 equiv. per alkyne) and pentamethyldiethylenetriamine (0.26 equiv. per alkyne) in Milli-Q water. The fresh $\mathrm{Cu}(\mathrm{I})$ solution was then transferred to the reaction mixture with a syringe. The reaction was stirred under Ar at room temperature for $72 \mathrm{~h}$. Cuprisorb was added to remove copper by shaking overnight. Few drops of an aqueous solution of EDTA $(0.15 \mathrm{M})$ were added and the solution was purified by ultracentrifugation with Amicon ${ }^{\circledR} 3000$ MWCO ultra-centrifugal filter tube against Milli-Q water $(40 \mathrm{~mL})$. The remaining mixture was lyophilized. All products were characterized by NMR. (Spectra provided in SI) Yields and functionalization degrees are provided in Table 1.

NMR Spectrometry Analysis. ${ }^{1} \mathrm{H}$ NMR analyses were performed in $\mathrm{D}_{2} \mathrm{O}$ at $298 \mathrm{~K}$ on a Bruker AVANCE III HD 400 apparatus equipped with a 5 mm Bruker multinuclear z-gradient direct probe operating at $400.2 \mathrm{MHz}$. The solvent signal was used as the reference signal $(\delta=$ $4.79 \mathrm{ppm})$. HSQC analyses were performed on a Bruker AVANCE NEO 400 spectrometer operating at $100.7 \mathrm{MHz}$, equipped with a $5 \mathrm{~mm}$ Bruker multinuclear z-gradient direct cryoprobe-head operating at $298 \mathrm{~K}$. Data processing was performed using Bruker Topspin Software.

Size-exclusion Chromatography (SEC). Measurements in aqueous solvent were performed on an Ultimate 3000 system from Thermoscientific equipped with diode array detector DAD. The system also includes a multi-angles light scattering detector MALS and differential refractive index detector dRI from Wyatt technology. Glycopolypeptides were separated on two TOSOH successive columns (one G4000PWXL $(7.8 * 300)$ column with exclusion limits from $2000 \mathrm{Da}$ to $300,000 \mathrm{Da}$ and one G3000PWXL (7.8*300) column with exclusion limit below 40,000 Da). Measurements were performed at a flow rate of $0.6 \mathrm{~mL} / \mathrm{min}$ and columns temperature was held at $26^{\circ} \mathrm{C}$. Aqueous solvent composed by acetic acid ( $\left.\mathrm{AcOH}\right) 0.3 \mathrm{M}$, 
ammonium acetate $0.2 \mathrm{M}$ and $\mathrm{ACN}(6.5 / 3.5, \mathrm{v} / \mathrm{v})$ was used as the eluent. Ethylene glycol was used as flow marker.

\section{Micro-Scale Thermophoresis (MST).}

MST experiments were conducted in triplicate on a Monolith NT.115 system (NanoTemper Technologies) using Auto Red laser power and medium MST power with temperature set at $22^{\circ} \mathrm{C}$. The buffer containing $\mathrm{RCA}_{120}$ was exchanged for Tris buffer (pH 7.6) and $\mathrm{RCA}_{120}$ was fluorescently labeled using a Monolith protein labeling kit "RED-NHS 2nd generation" (amine reactive) provided by NanoTemper (DE). Tris buffer ( $\mathrm{pH} 7.6)$ containing $0.05 \%$ of Tween ${ }^{\circledR}-20$ and $20 \mathrm{mM} \mathrm{MgCl}$ was used for all binding assays.

Lectin binding tests. All compounds were screened in the same conditions. Glycopolypeptides were previously solubilized in Tris buffer at $4{ }^{\circ} \mathrm{C}$ at the maximum concentration corresponding to their respective limit of solubility (around $10 \mathrm{mg} \cdot \mathrm{mL}^{-1}$ ), i.e. 1 $\mathrm{mM}$ for the series of ELP-[M $\left[\mathrm{M}_{1} \mathrm{~V}_{3}-20\right]$ derivatives (series $\underline{\mathbf{1}}$ and $\underline{\mathbf{3}}$ ) and $0.5 \mathrm{mM}$ for the series of ELP- $\left[\mathrm{M}_{1} \mathrm{~V}_{3}-40\right]$ derivatives (series $\underline{\mathbf{2}}$ and $\underline{\mathbf{4}}$ ). Serial 2-fold dilutions were prepared with $\mathrm{RCA}_{120}(5 \mathrm{nM})$ in Tris buffer. Thermophoresis was measured using "Auto Red laser power" and medium "MST power". MO Analysis software (NanoTemper Technologies, DE) was used to analyze data and calculate dissociation constants. For each sample, experimental data points were plotted on a graph representing the normalized fluorescence intensity as function of glycopolypeptide molar concentration. Experimental data were fitted with a sigmoidal curve model and the dissociation constant $\left(\mathrm{K}_{\mathrm{D}}\right)$ was extracted (inflection point of fitted curve). Results are summarized in Table 2. 
Table S1. List of NMR spectra provided for all compounds.

\begin{tabular}{|c|c|c|}
\hline Figure \# & Compound & NMR analysis \\
\hline $\mathrm{S} 1$ & \multirow{3}{*}{$1,2,3,4,6$-penta- $O$-acetyl-D-mannopyranose } & ${ }^{1} \mathrm{H}$ \\
\hline S2 & & COSY \\
\hline S3 & & HSQC \\
\hline $\mathrm{S} 4$ & \multirow{3}{*}{ 3-azidopropyl (2,3,4,6-tetra- $O$-acetyl- $\alpha$-D-mannopyranoside } & ${ }^{1} \mathrm{H}$ \\
\hline S5 & & COSY \\
\hline S6 & & HSQC \\
\hline S7 & \multirow{3}{*}{ 3-azidopropyl- $\alpha$-D-mannopyranoside } & ${ }^{1} \mathrm{H}$ \\
\hline S8 & & COSY \\
\hline S9 & & HSQC \\
\hline S10 & \multirow{3}{*}{ 3-azidopropyl (2,3,4,6-tetra- $O$-acetyl- $\beta$-D-galactopyranoside } & ${ }^{1} \mathrm{H}$ \\
\hline S11 & & COSY \\
\hline S12 & & HSQC \\
\hline S13 & \multirow{3}{*}{ 3-Azidopropyl- $\beta$-D-galactopyranoside } & ${ }^{1} \mathrm{H}$ \\
\hline S14 & & COSY \\
\hline S15 & & HSQC \\
\hline S16 & \multirow{2}{*}{$\mathrm{ELP}\left[\mathrm{M}_{1} \mathrm{~V}_{3}-20\right]$} & ${ }^{1} \mathrm{H}$ \\
\hline S17 & & HSQC \\
\hline S18 & 1 & ${ }^{1} \mathrm{H}$ \\
\hline S19 & \multirow{3}{*}{$\underline{\mathbf{1 a}}$} & ${ }^{1} \mathrm{H}$ \\
\hline S20 & & ${ }^{1} \mathrm{H}(\mathrm{zoom})$ \\
\hline S21 & & HSQC \\
\hline S22 & \multirow{3}{*}{$\underline{\mathbf{1 b}}$} & ${ }^{1} \mathrm{H}$ \\
\hline $\mathrm{S} 23$ & & ${ }^{1} \mathrm{H}($ zoom) \\
\hline $\mathrm{S} 24$ & & HSQC \\
\hline S25 & \multirow{3}{*}{$\underline{1 c}$} & ${ }^{1} \mathrm{H}$ \\
\hline S26 & & ${ }^{1} \mathrm{H}(\mathrm{zoom})$ \\
\hline S27 & & HSQC \\
\hline S28 & \multirow{2}{*}{$\underline{\mathbf{3}}$} & ${ }^{1} \mathrm{H}$ \\
\hline S29 & & HSQC \\
\hline S30 & \multirow{3}{*}{$\underline{\mathbf{3 a}}$} & ${ }^{1} \mathrm{H}$ \\
\hline S31 & & ${ }^{1} \mathrm{H}($ zoom) \\
\hline S32 & & HSQC \\
\hline S33 & \multirow{3}{*}{$\underline{3 \mathbf{b}}$} & ${ }^{1} \mathrm{H}$ \\
\hline S34 & & ${ }^{1} \mathrm{H}$ (zoom) \\
\hline S35 & & HSQC \\
\hline S36 & \multirow{3}{*}{$\underline{3 c}$} & ${ }^{1} \mathrm{H}$ \\
\hline S37 & & ${ }^{1} \mathrm{H}$ (zoom) \\
\hline S38 & & HSQC \\
\hline S39 & \multirow{3}{*}{$\underline{\mathbf{3 d}}$} & ${ }^{1} \mathrm{H}$ \\
\hline S40 & & ${ }^{1} \mathrm{H}$ (zoom) \\
\hline S41 & & HSQC \\
\hline S42 & \multirow{2}{*}{$\operatorname{ELP}\left[\mathrm{M}_{1} \mathrm{~V}_{3}-40\right]$} & ${ }^{1} \mathrm{H}$ \\
\hline S43 & & HSQC \\
\hline S44 & \multirow[b]{2}{*}{$\underline{2}$} & ${ }^{1} \mathrm{H}$ \\
\hline S45 & & HSQC \\
\hline S46 & \multirow{3}{*}{$\underline{2 a}$} & ${ }^{1} \mathrm{H}$ \\
\hline S47 & & ${ }^{1} \mathrm{H}$ (zoom) \\
\hline S48 & & HSQC \\
\hline S49 & \multirow{2}{*}{$\underline{2 b}$} & ${ }^{1} \mathrm{H}$ \\
\hline S50 & & ${ }^{1} \mathrm{H}$ (zoom) \\
\hline S51 & \multirow[b]{2}{*}{$\underline{2 c}$} & ${ }^{1} \mathrm{H}$ \\
\hline S52 & & HSQC \\
\hline S53 & \multirow{3}{*}{$\underline{2 d}$} & ${ }^{1} \mathrm{H}$ \\
\hline S54 & & ${ }^{1} \mathrm{H}$ (zoom) \\
\hline S55 & & HSQC \\
\hline
\end{tabular}




\begin{tabular}{|c|c|c|}
\hline S56 & \multirow[b]{2}{*}{$\underline{4}$} & ${ }^{1} \mathrm{H}$ \\
\hline S57 & & HSQC \\
\hline S58 & \multirow{3}{*}{$\underline{4 a}$} & ${ }^{1} \mathrm{H}$ \\
\hline S59 & & ${ }^{1} \mathrm{H}$ (zoom) \\
\hline S60 & & HSQC \\
\hline S61 & \multirow{3}{*}{$\underline{4 b}$} & ${ }^{1} \mathrm{H}$ \\
\hline S62 & & ${ }^{1} \mathrm{H}$ (zoom) \\
\hline S63 & & HSQC \\
\hline S64 & \multirow{3}{*}{$\underline{4 c}$} & ${ }^{1} \mathrm{H}$ \\
\hline S65 & & ${ }^{1} \mathrm{H}$ (zoom) \\
\hline S66 & & HSQC \\
\hline S67 & \multirow{3}{*}{$\underline{4 d}$} & ${ }^{1} \mathrm{H}$ \\
\hline S68 & & ${ }^{1} \mathrm{H}$ (zoom) \\
\hline S69 & & HSQC \\
\hline
\end{tabular}




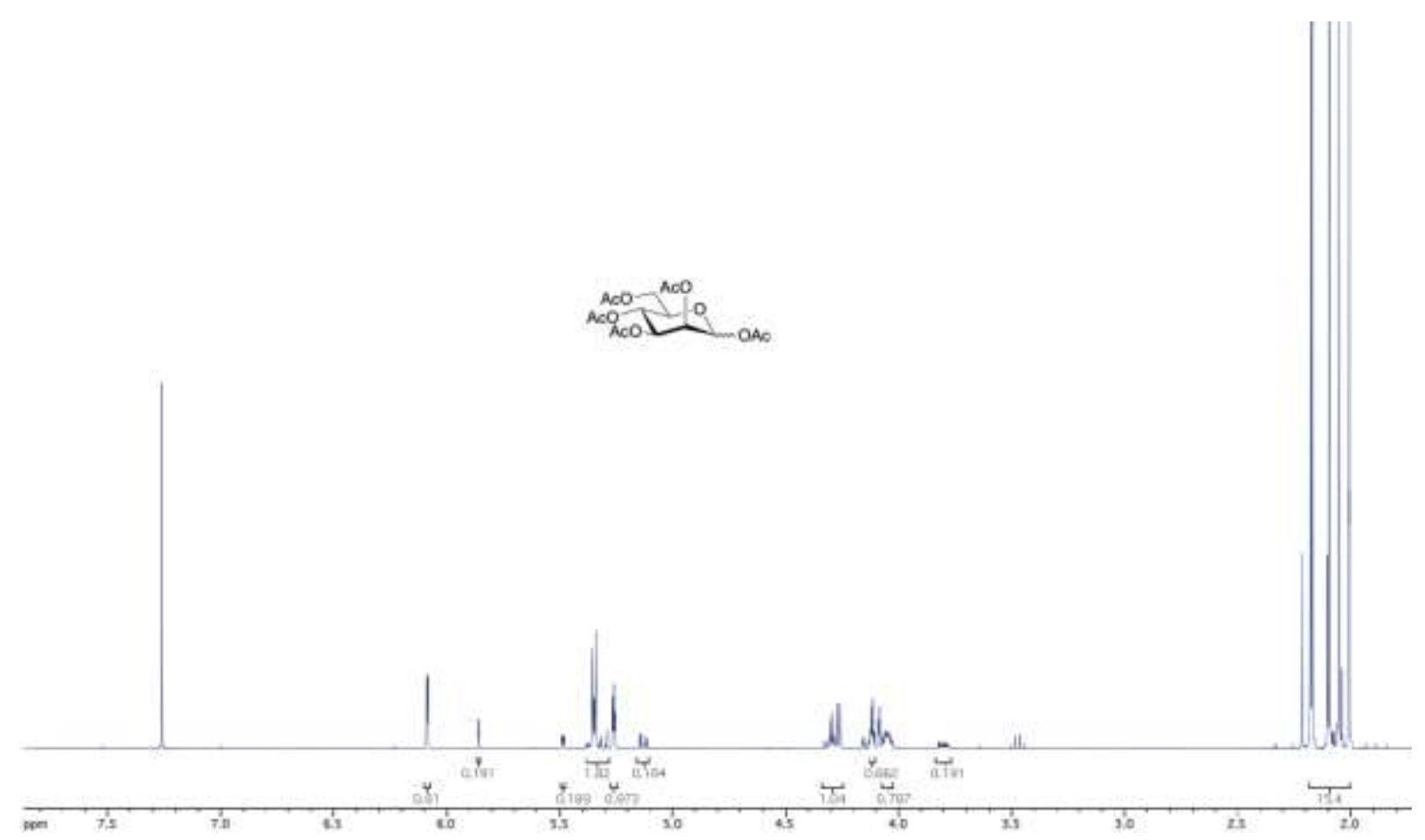

Figure S1. ${ }^{1} \mathrm{H}$ NMR spectrum of 1,2,3,4,6-penta- $O$-acetyl-D-mannopyranose in $\mathrm{CDCl}_{3}$.

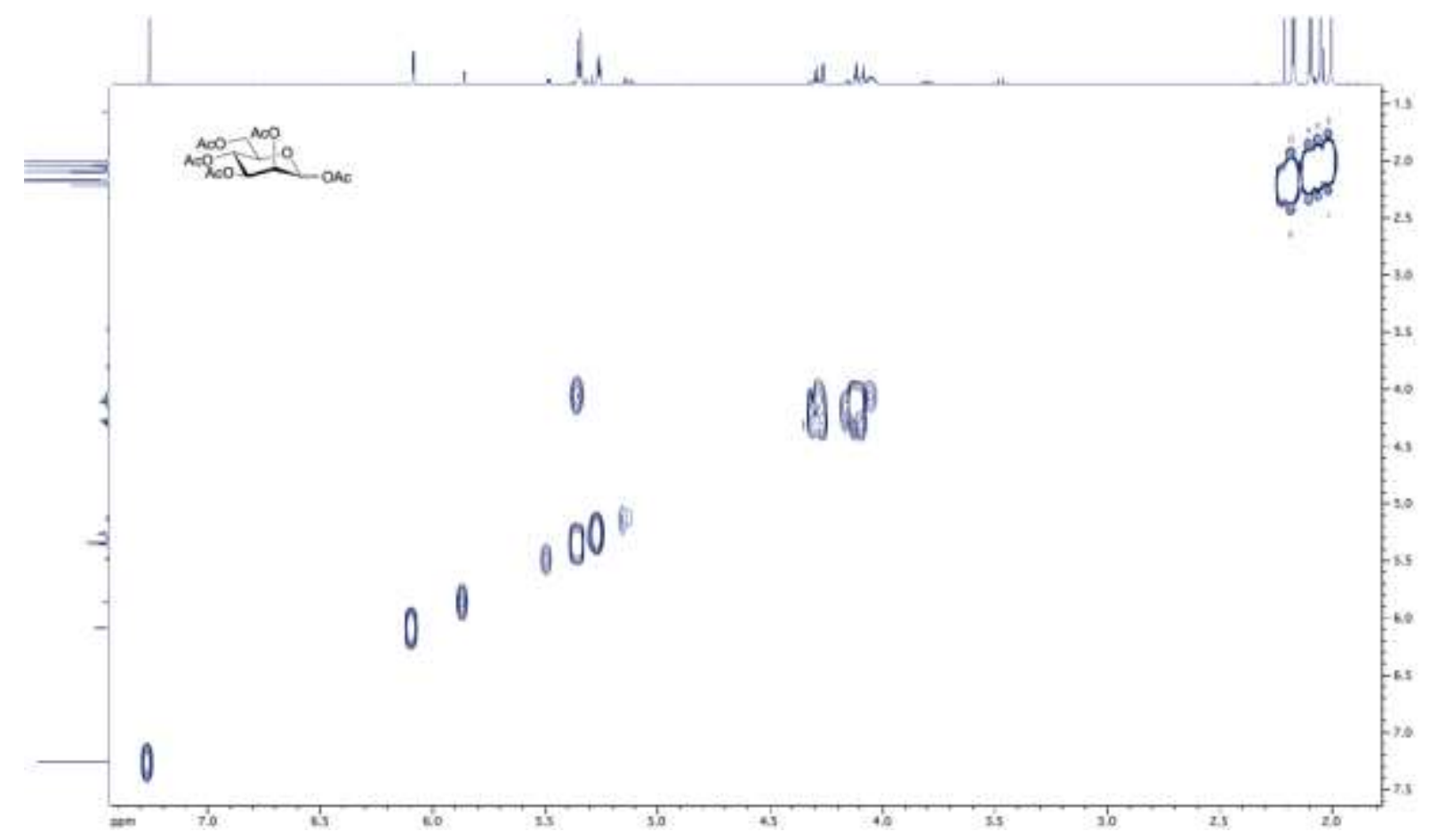

Figure S2. COSY NMR spectrum of compound 1,2,3,4,6-penta- $O$-acetyl-D-mannopyranose in $\mathrm{CDCl}_{3}$. 


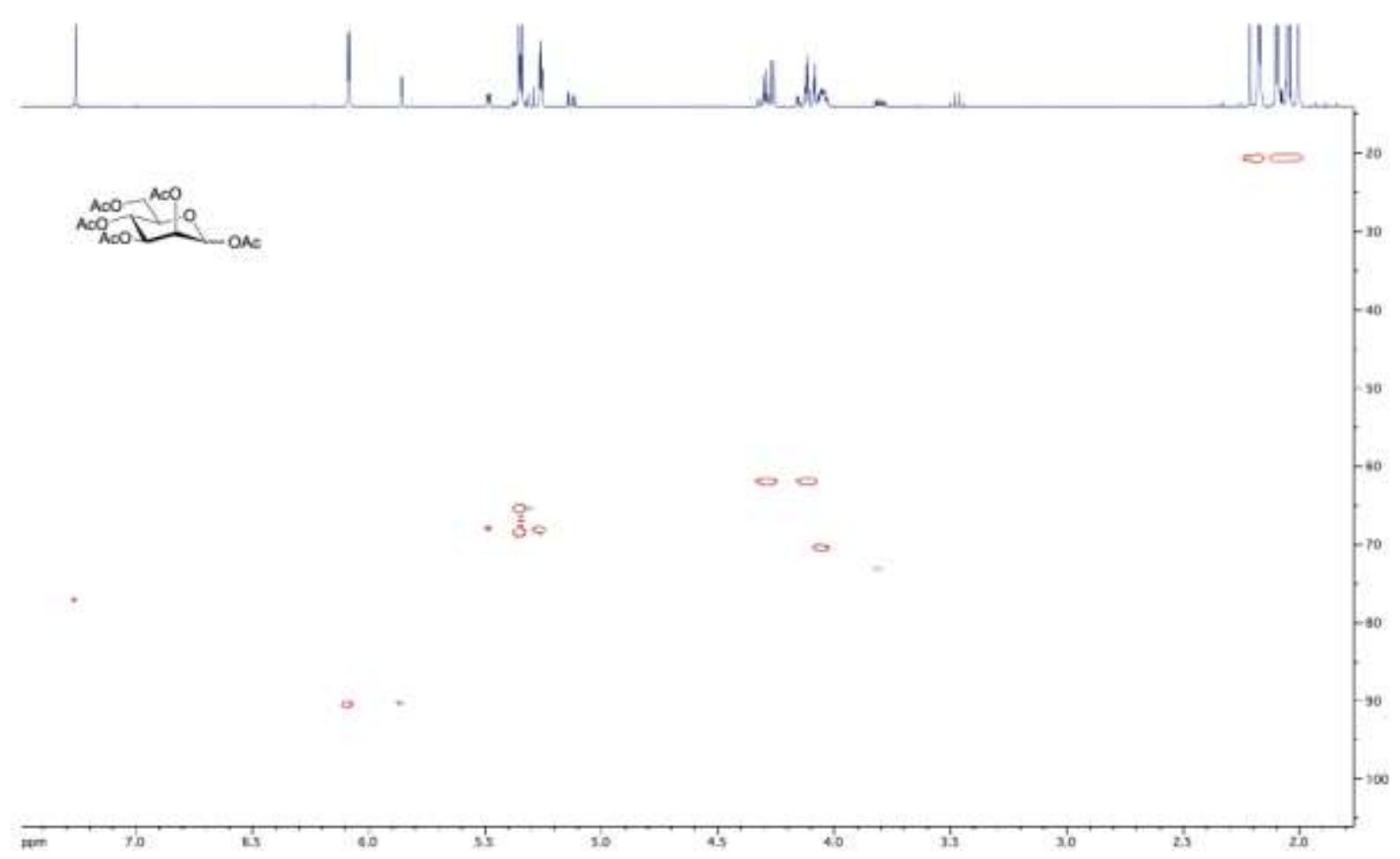

Figure S3. HSQC NMR spectrum of 1,2,3,4,6-penta- $O$-acetyl-D-mannopyranose in $\mathrm{CDCl}_{3}$.

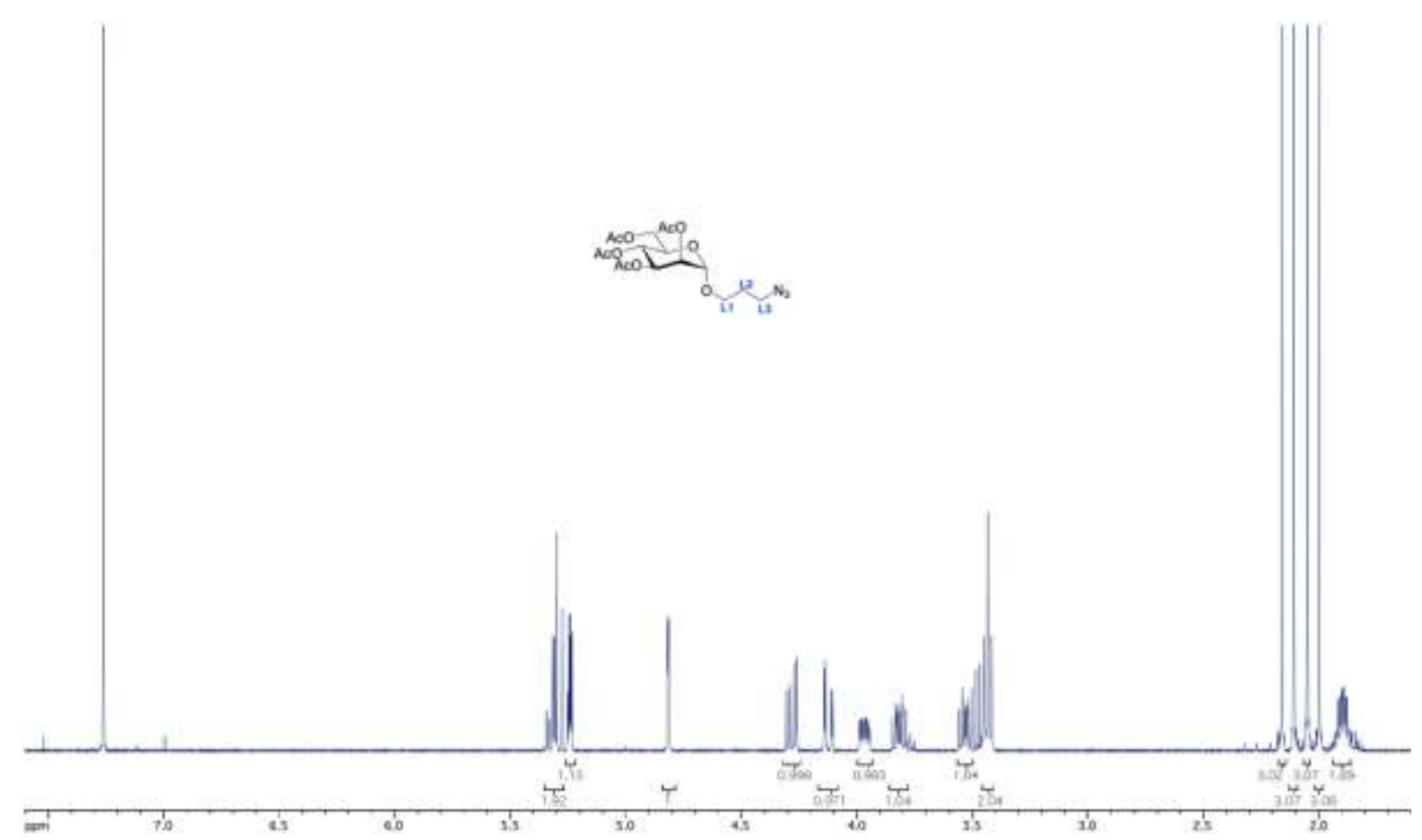

Figure S4. ${ }^{1} \mathrm{H}$ NMR spectrum of 3-azidopropyl (2,3,4,6-tetra- $O$-acetyl- $\alpha$-D-mannopyranoside in $\mathrm{CDCl}_{3}$. 


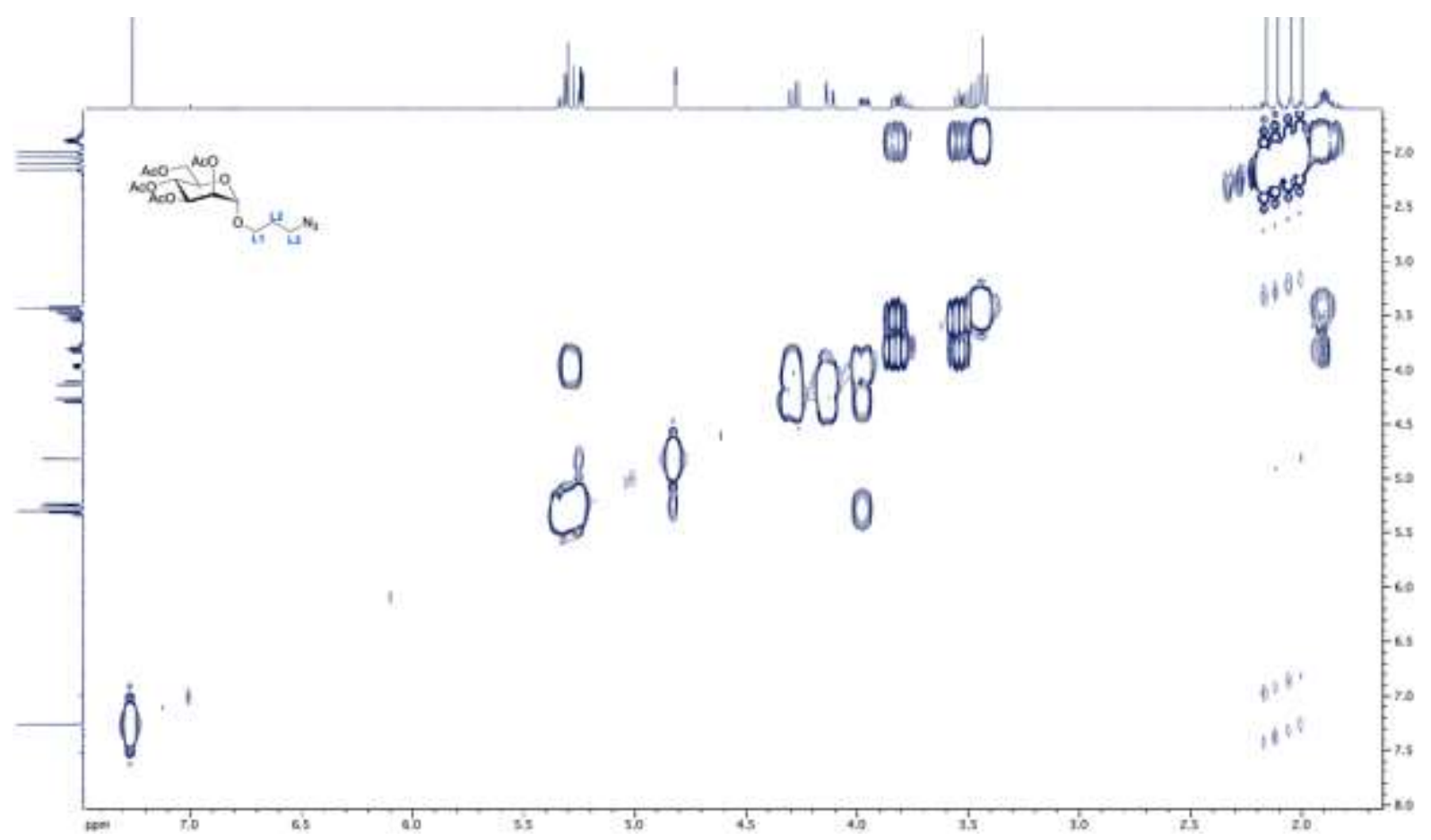

Figure S5. COSY NMR spectrum of 3-azidopropyl (2,3,4,6-tetra- $O$-acetyl- $\alpha$-Dmannopyranoside in $\mathrm{CDCl}_{3}$.

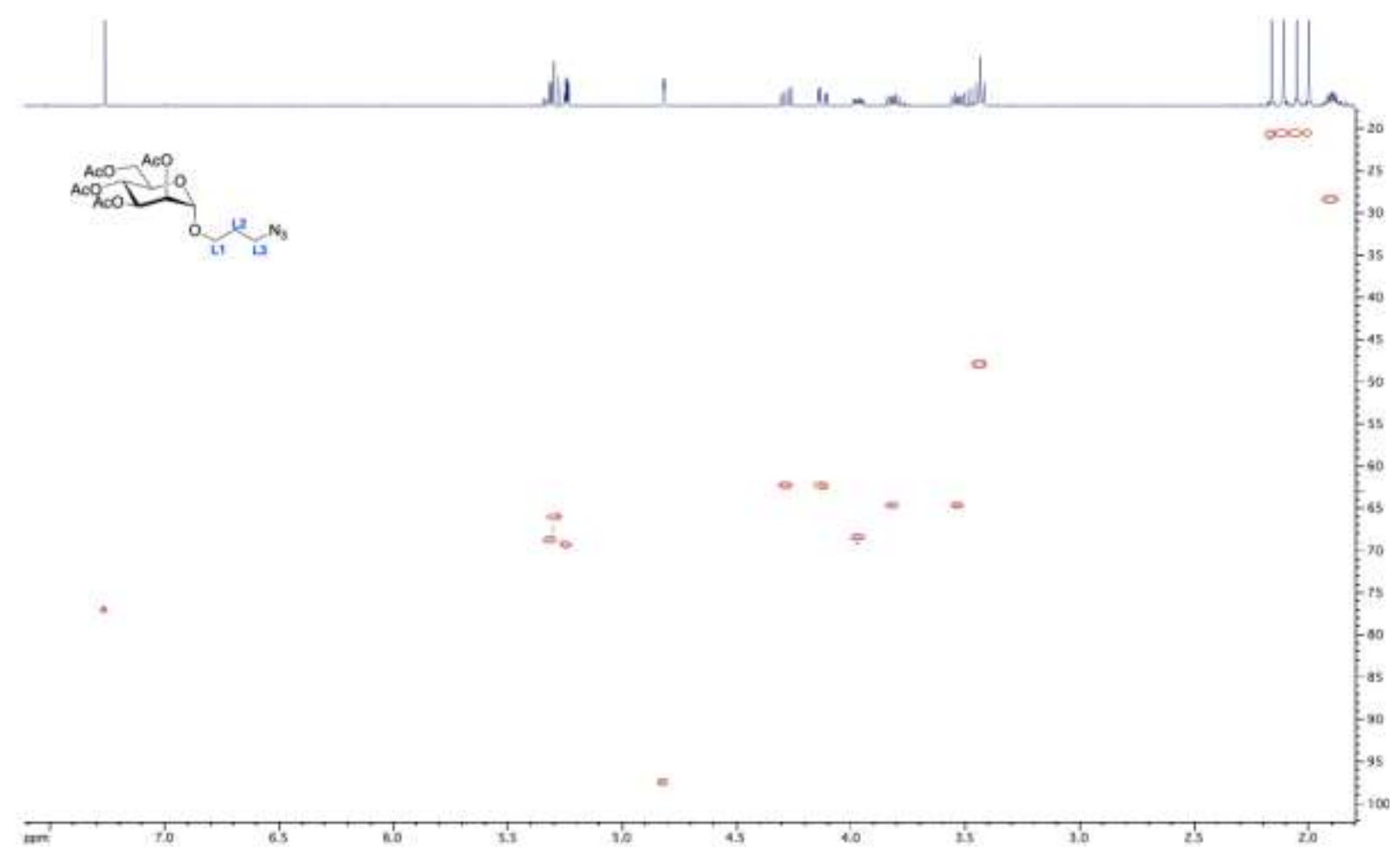

Figure S6. HSQC NMR spectrum of 3-azidopropyl (2,3,4,6-tetra- $O$-acetyl- $\alpha$-Dmannopyranoside in $\mathrm{CDCl}_{3}$. 


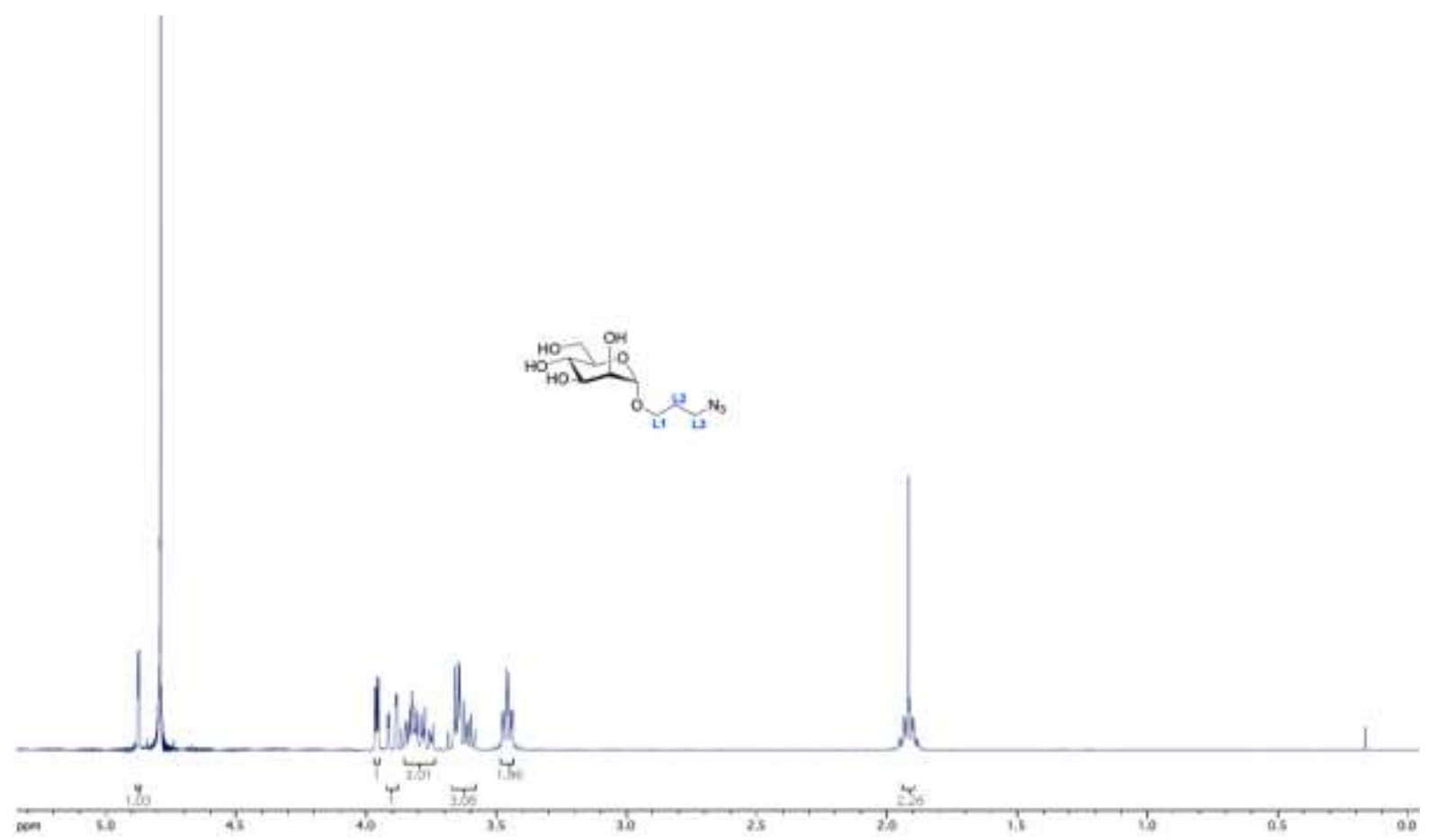

Figure S7. ${ }^{1} \mathrm{H}$ NMR spectrum of 3-azidopropyl- $\alpha$-D-mannopyranoside in $\mathrm{D}_{2} \mathrm{O}$.

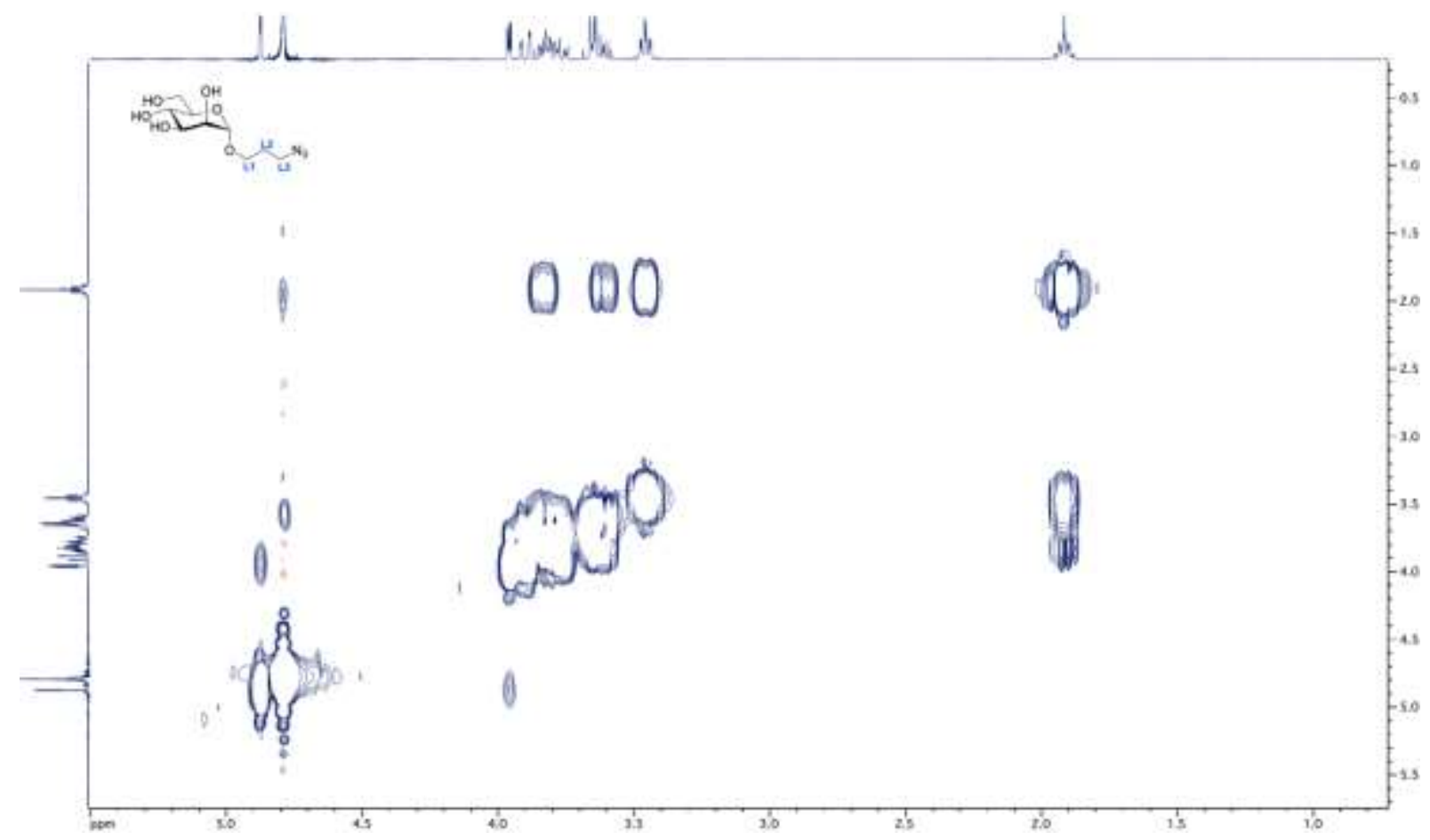

Figure S8. COSY NMR spectrum of 3-azidopropyl- $\alpha$-D-mannopyranoside in $\mathrm{D}_{2} \mathrm{O}$. 


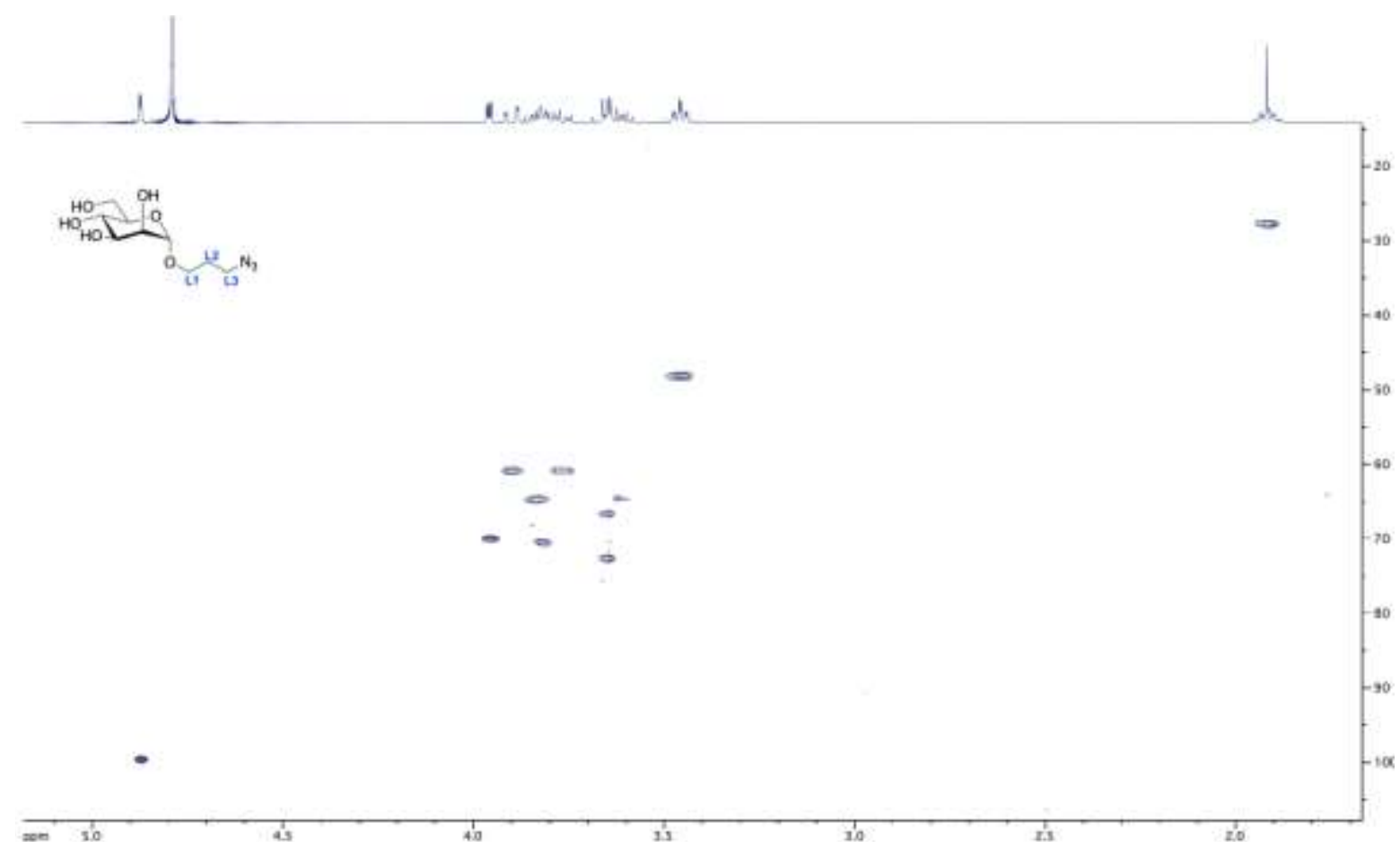

Figure S9. HSQC NMR spectrum of 3-azidopropyl- $\alpha$-D-mannopyranoside in $\mathrm{D}_{2} \mathrm{O}$.

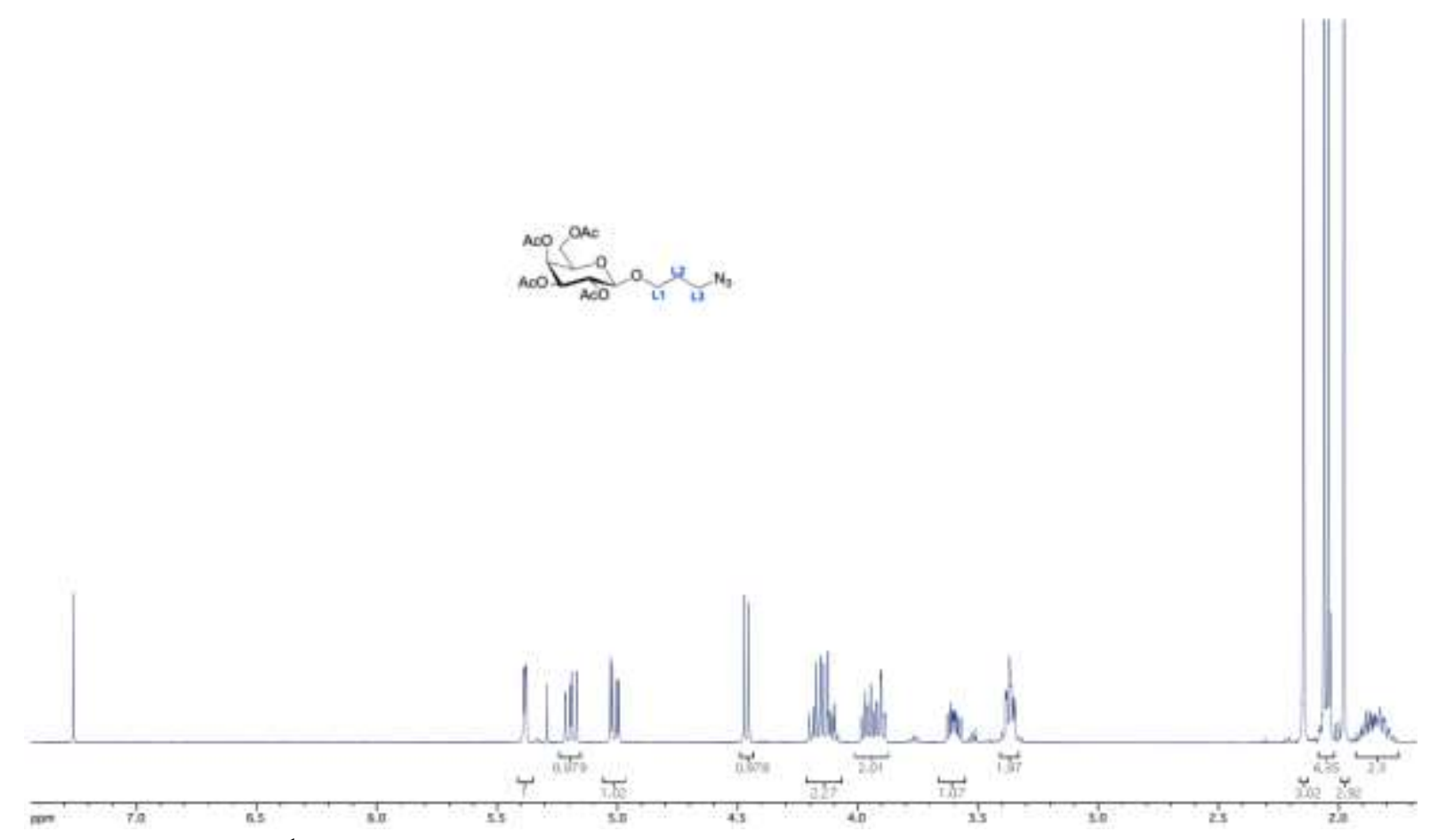

Figure S10. ${ }^{1} \mathrm{H} \quad \mathrm{NMR}$ spectrum of 3-azidopropyl (2,3,4,6-tetra- $O$-acetyl- $\beta$-Dgalactopyranoside in $\mathrm{CDCl}_{3}$. 


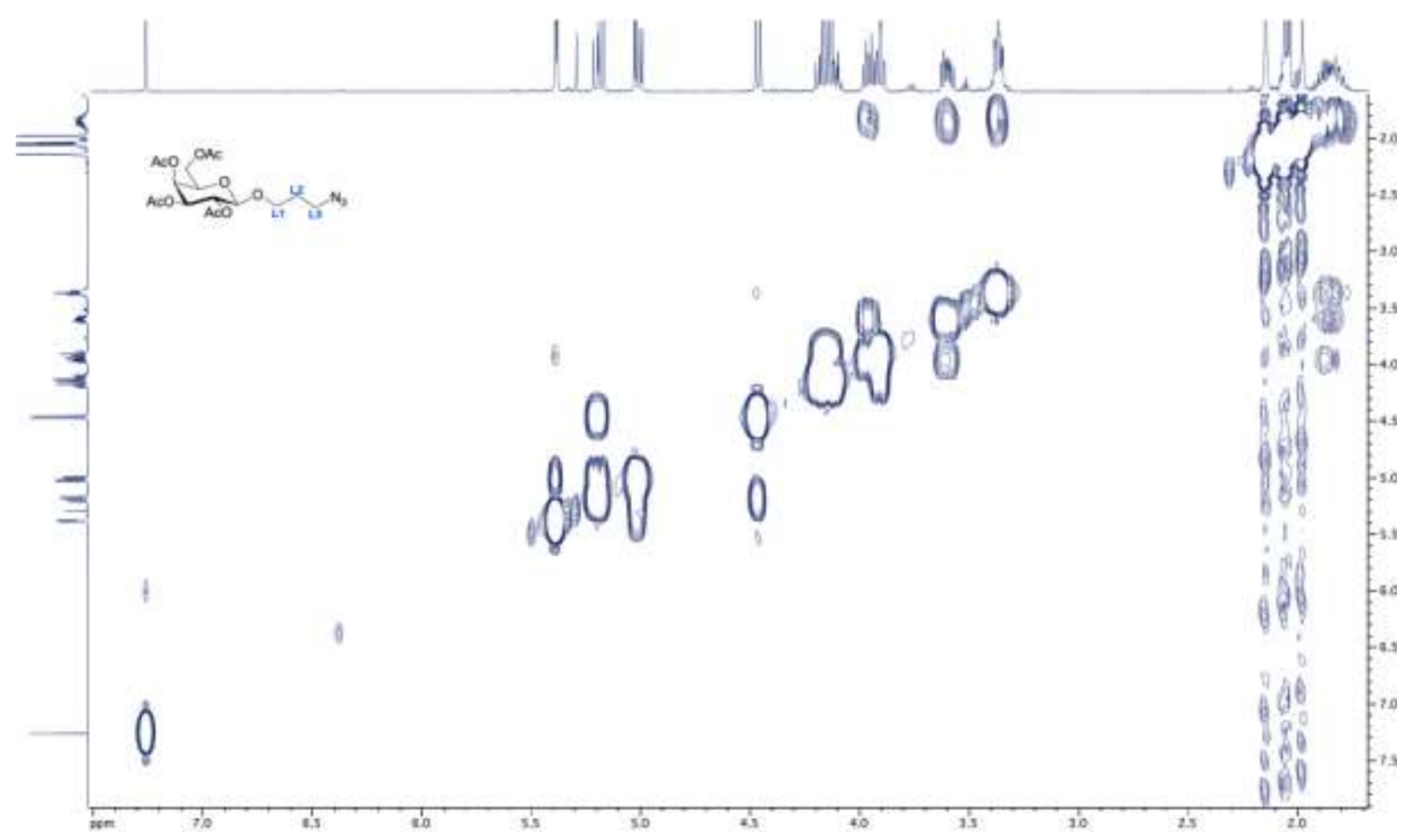

Figure S11. COSY NMR spectrum of 3-azidopropyl (2,3,4,6-tetra- $O$-acetyl- $\beta$-Dgalactopyranoside in $\mathrm{CDCl}_{3}$.

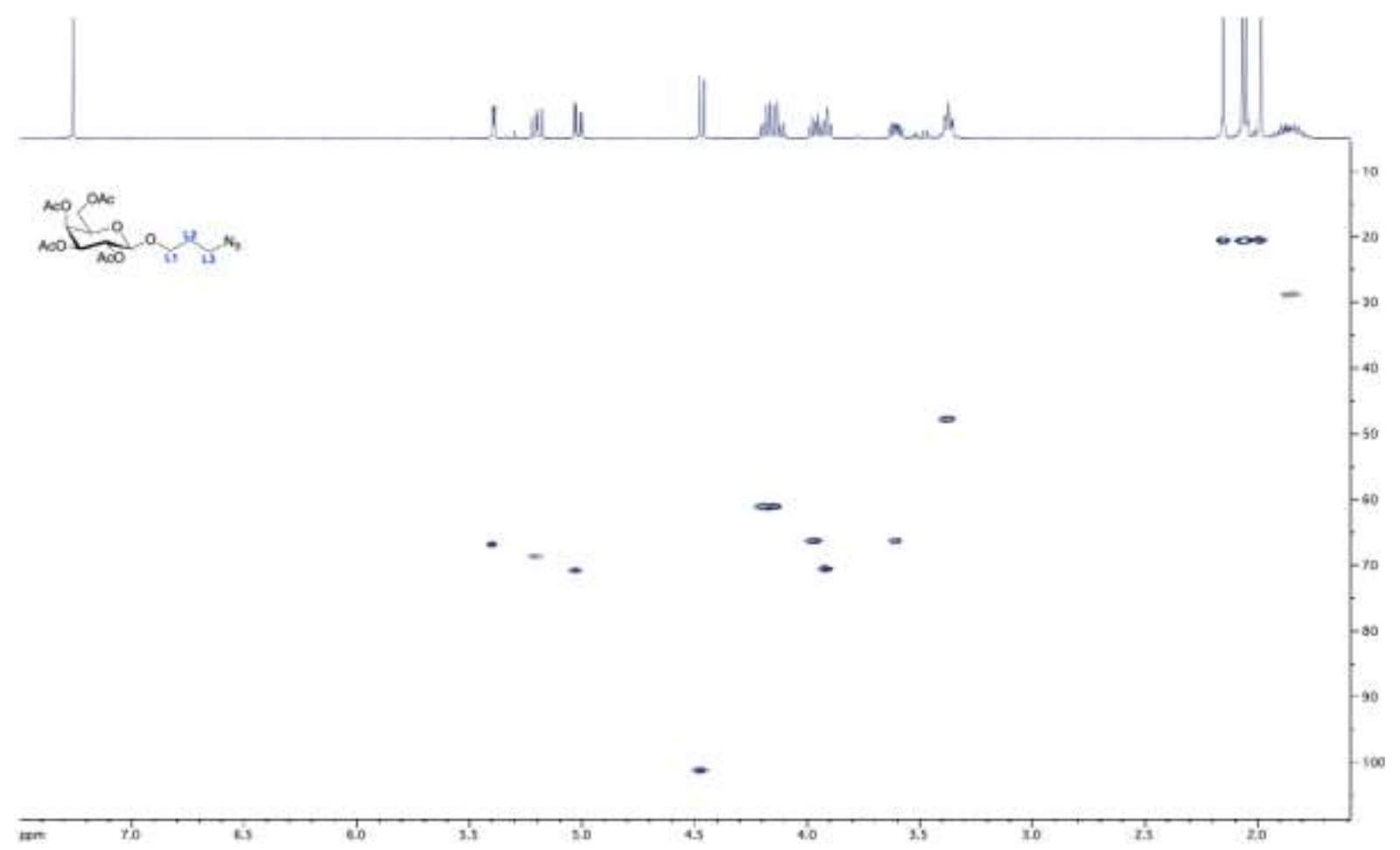

Figure S12. HSQC NMR spectrum of 3-azidopropyl (2,3,4,6-tetra- $O$-acetyl- $\beta$-Dgalactopyranoside in $\mathrm{CDCl}_{3}$. 


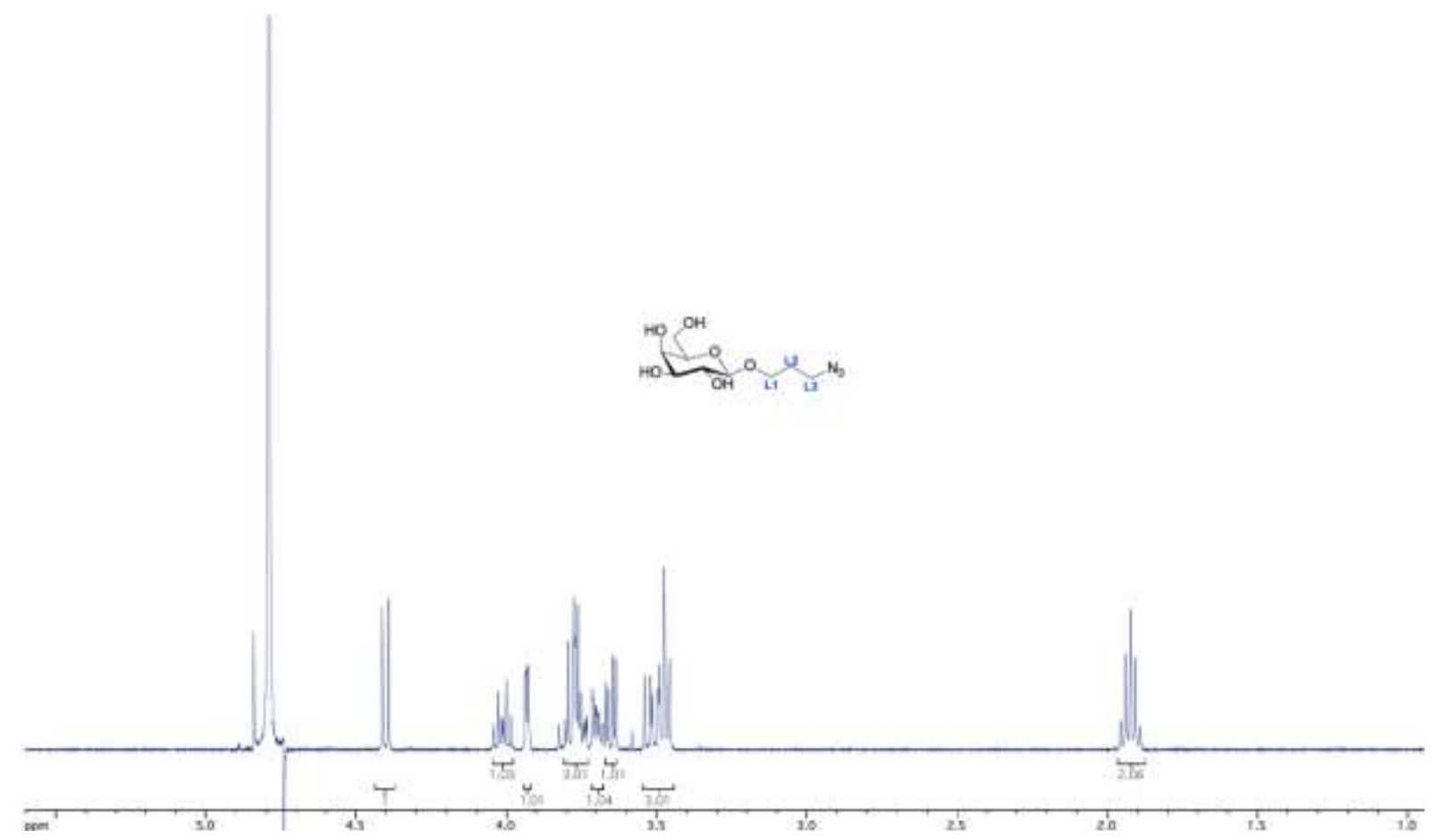

Figure S13. ${ }^{1} \mathrm{H}$ NMR spectrum of 3-azidopropyl- $\beta$-D-galactopyranoside in $\mathrm{D}_{2} \mathrm{O}$.

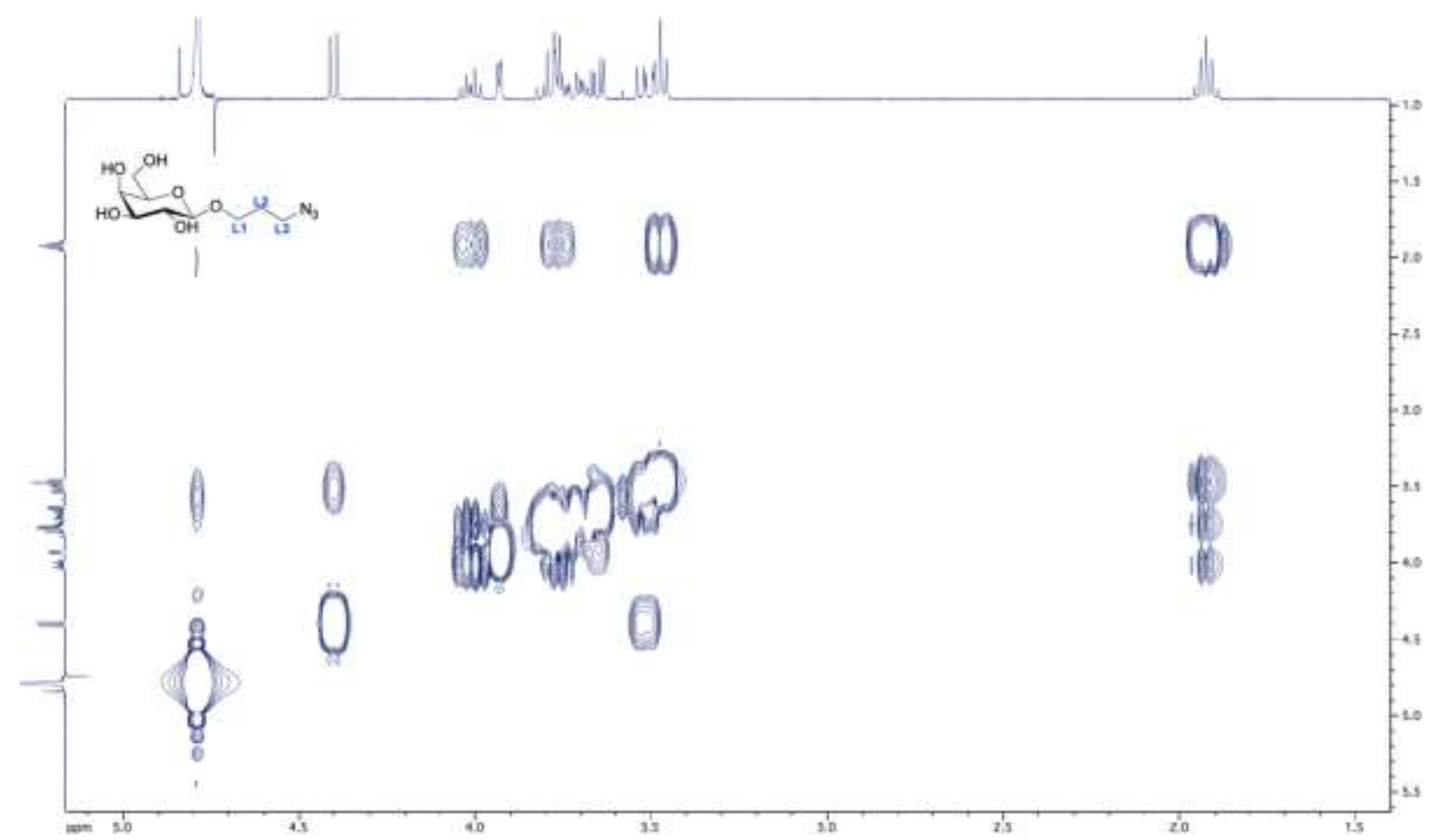

Figure S14. COSY NMR spectrum of 3-azidopropyl- $\beta$-D-galactopyranoside in $\mathrm{D}_{2} \mathrm{O}$. 


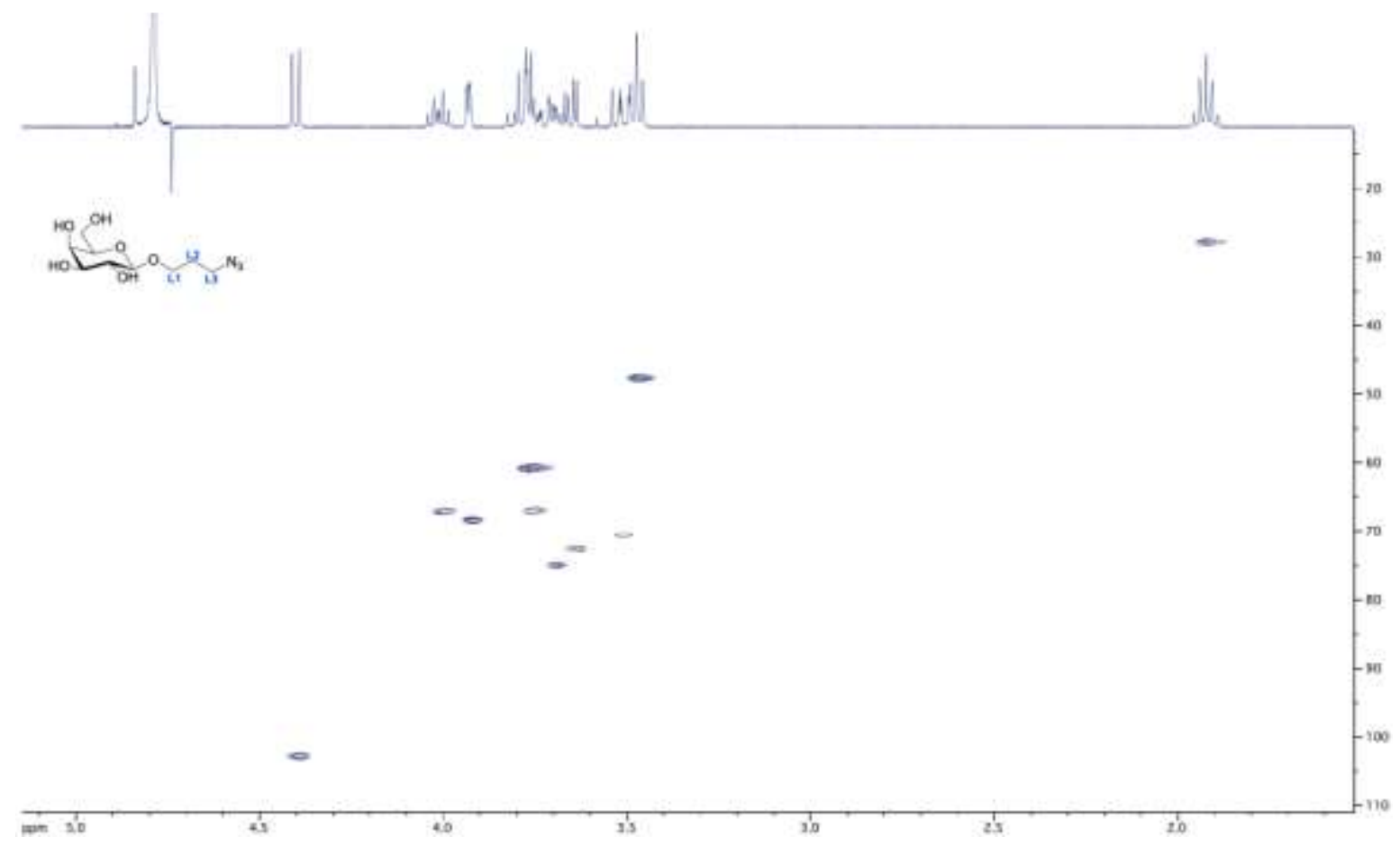

Figure S15. HSQC NMR spectrum of compound 3-azidopropyl- $\beta$-D-galactopyranoside in $\mathrm{D}_{2} \mathrm{O}$. 


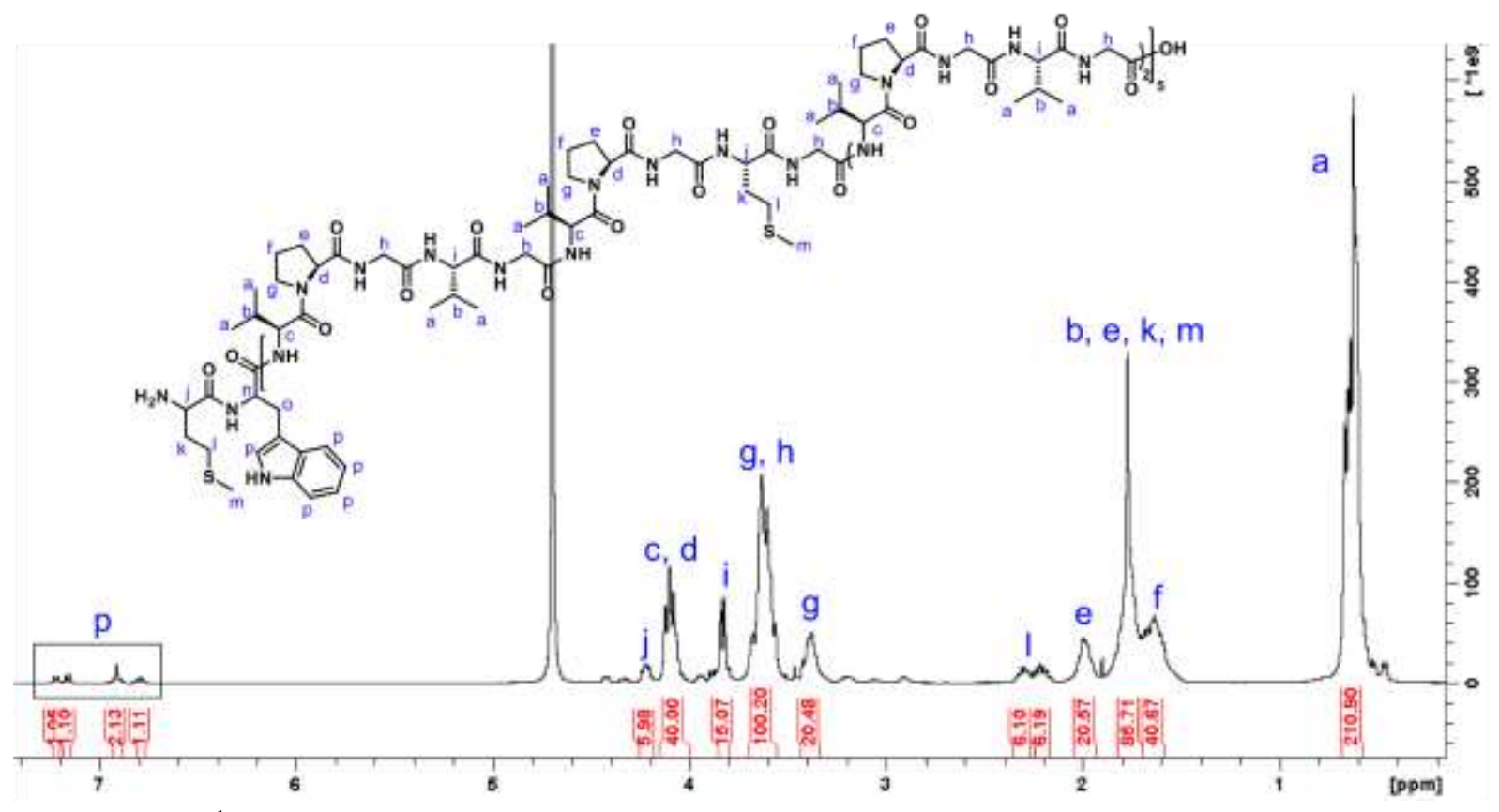

Figure S16. ${ }^{1} \mathrm{H}$ NMR spectrum of $\operatorname{ELP}\left[\mathrm{M}_{1} \mathrm{~V}_{3}-20\right]$ in $\mathrm{D}_{2} \mathrm{O}$.

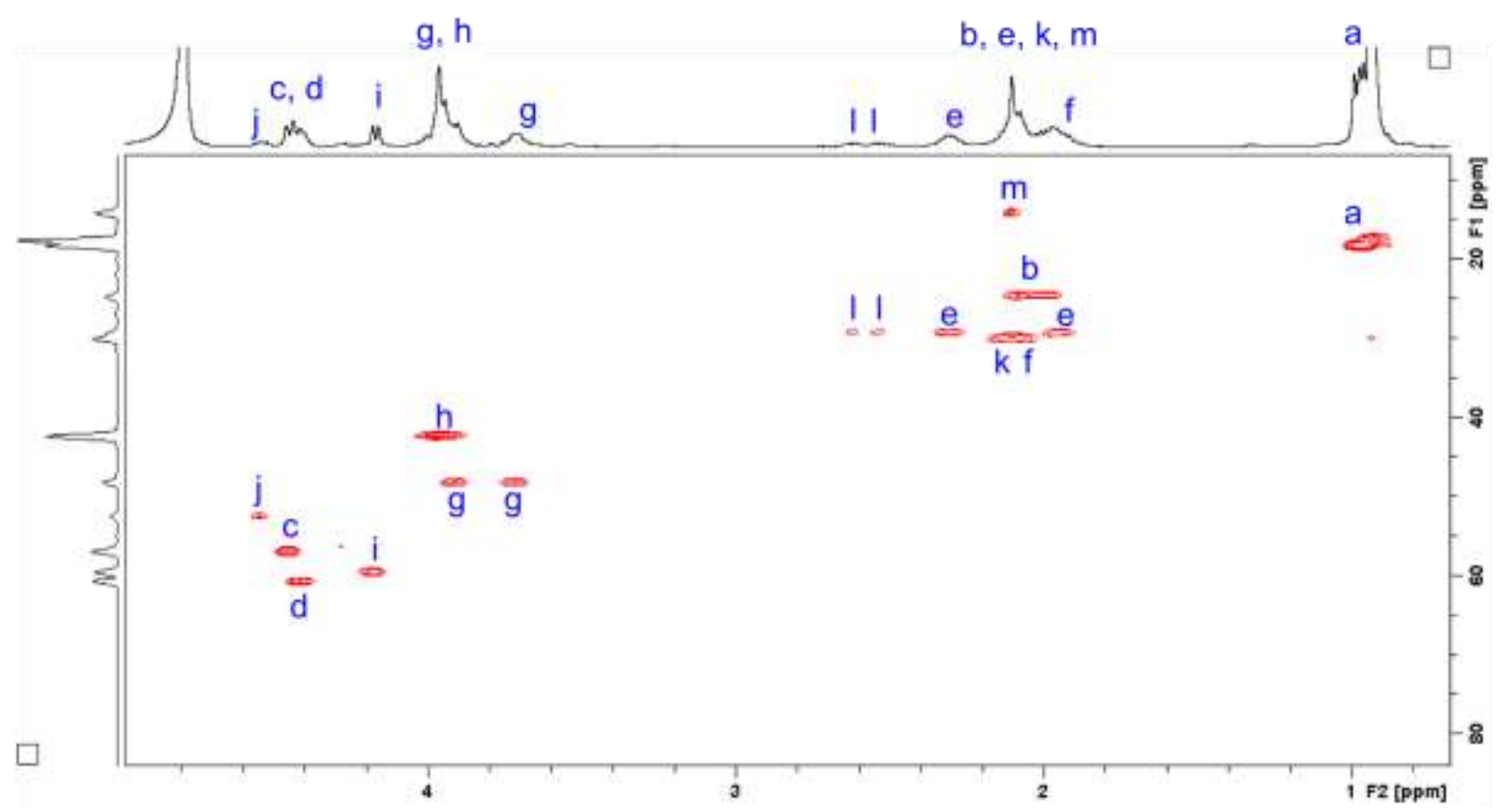

Figure S17. 2D NMR spectrum of ELP $\left[\mathrm{M}_{1} \mathrm{~V}_{3}-20\right]$ in $\mathrm{D}_{2} \mathrm{O}$, HSQC. 


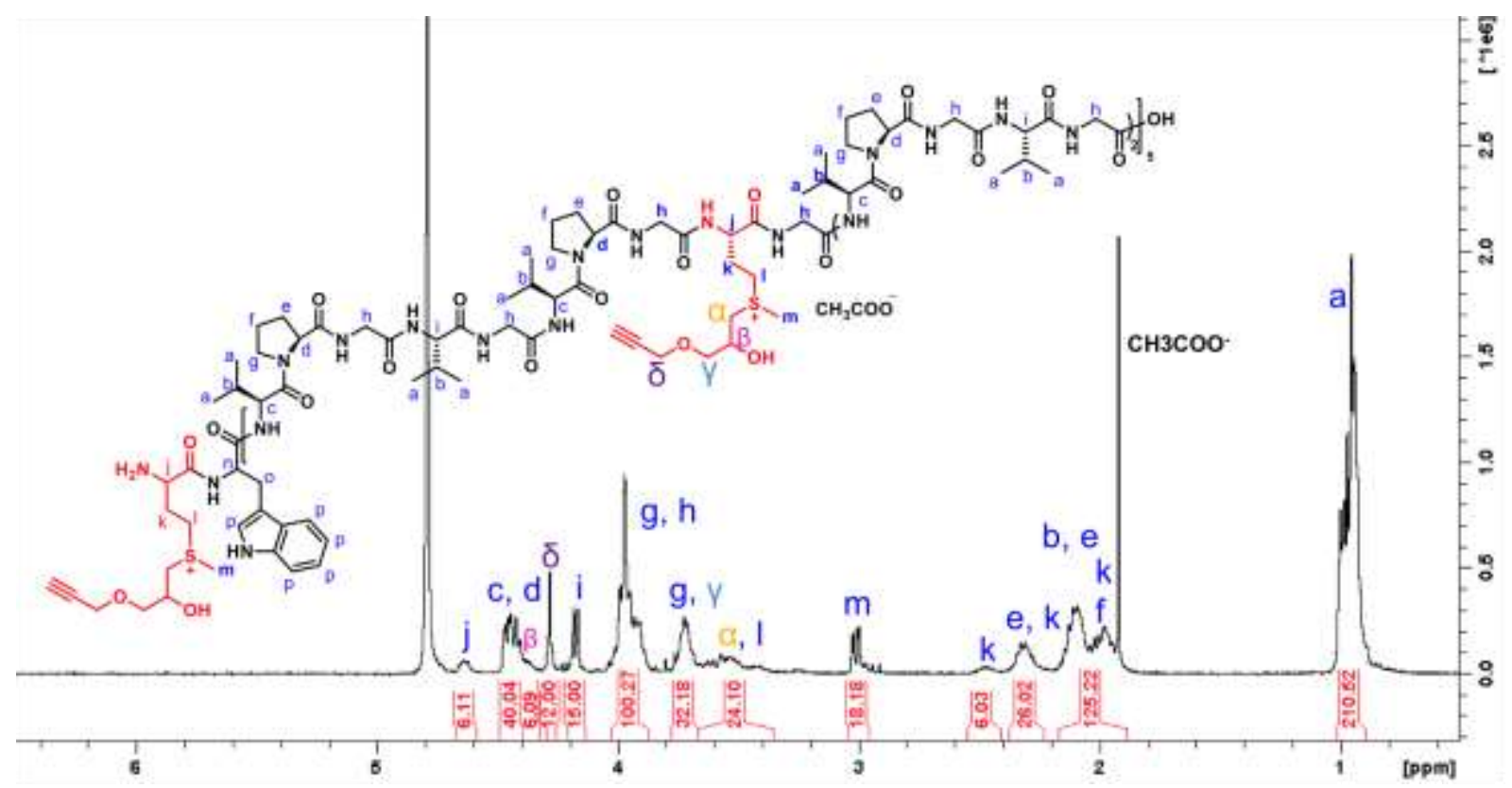

Figure S18. ${ }^{1} \mathrm{H}$ NMR spectrum of $\operatorname{ELP}\left[\mathrm{M}(\mathrm{Alk})_{1} \mathrm{~V}_{3}-20\right]$, $\underline{\mathbf{1}}$, in $\mathrm{D}_{2} \mathrm{O}$.

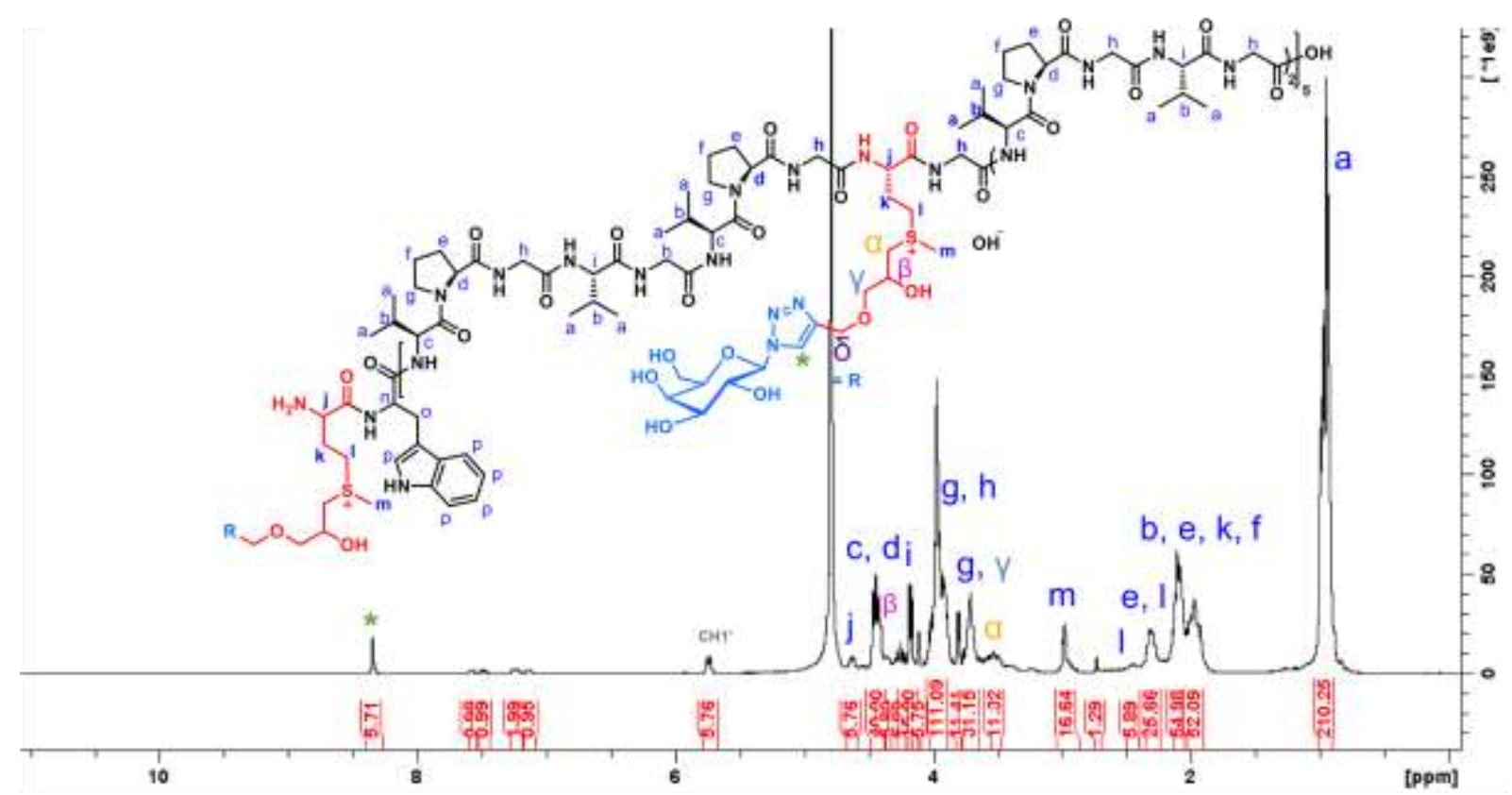

Figure S19. ${ }^{1} \mathrm{H}$ NMR spectrum of compound $\underline{\mathbf{1 a}}$ in $\mathrm{D}_{2} \mathrm{O}$. 


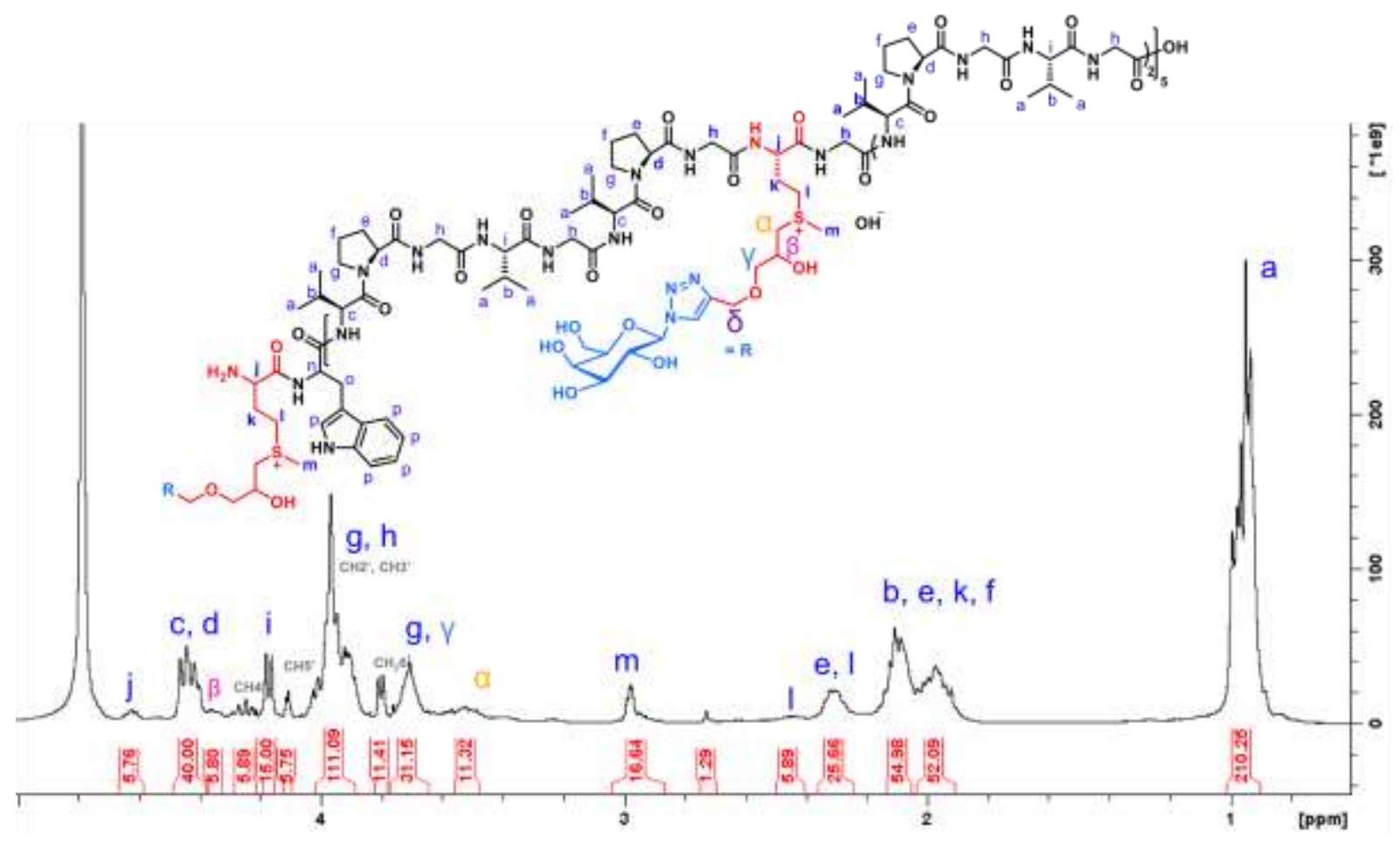

Figure S20. ${ }^{1} \mathrm{H}$ NMR spectrum of compound $\underline{\mathbf{1 a}}$ (zoom) in $\mathrm{D}_{2} \mathrm{O}$.

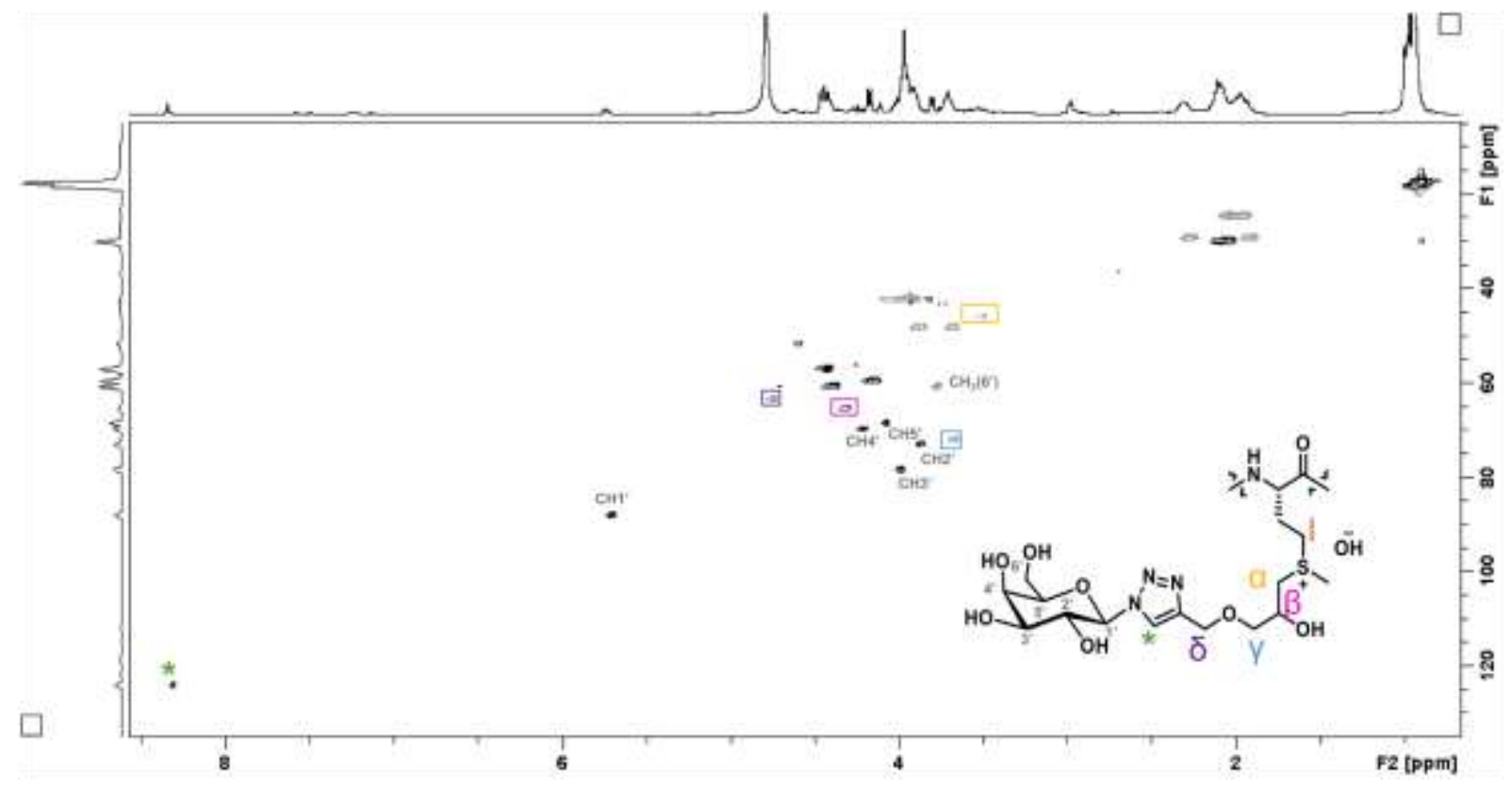

Figure S21. 2D NMR spectrum of compound $\underline{\mathbf{1 a}}$ in $\mathrm{D}_{2} \mathrm{O}$, HSQC. 


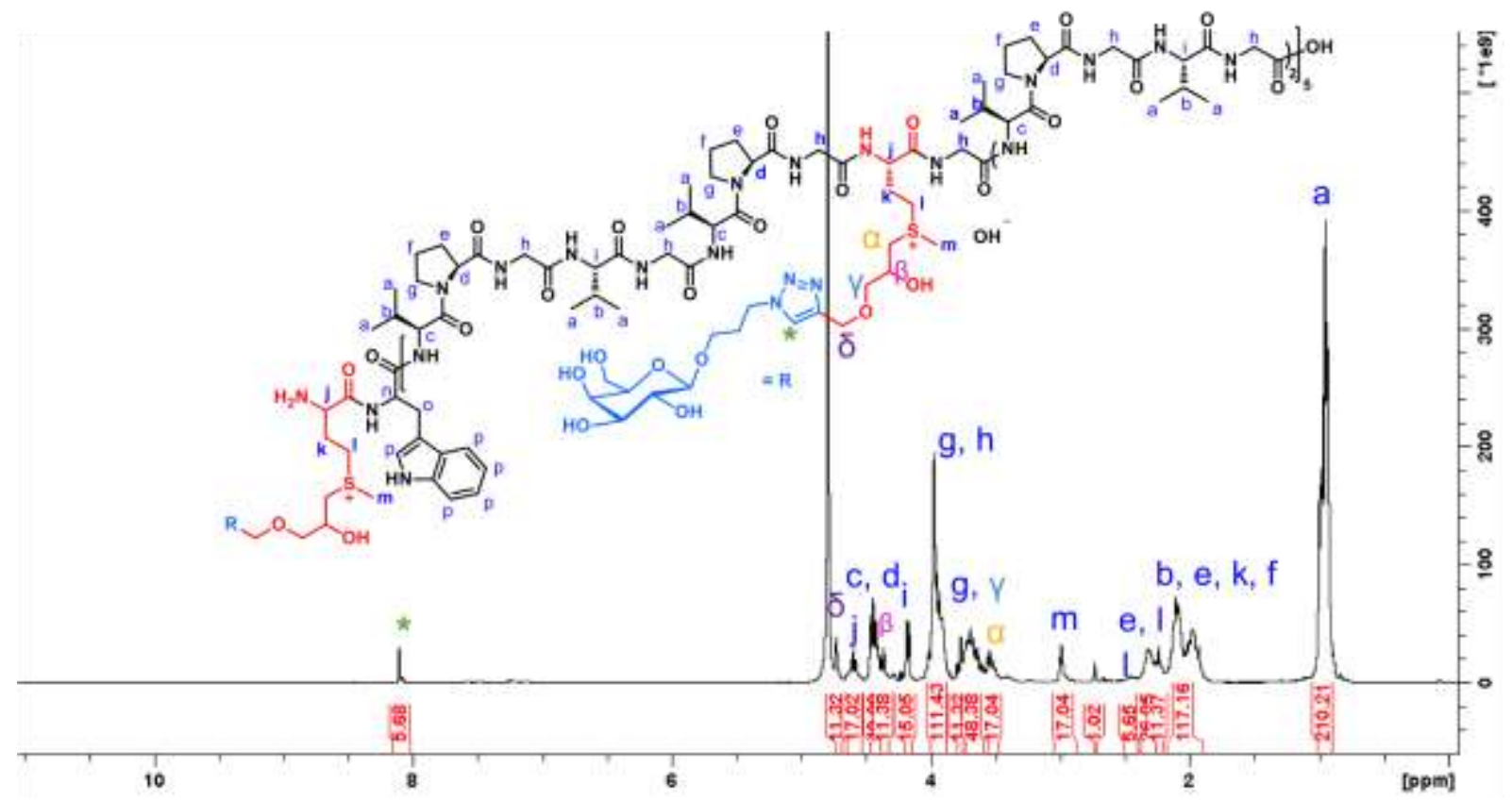

Figure S22. ${ }^{1} \mathrm{H}$ NMR spectrum of compound $\underline{\mathbf{1 b}}$ in $\mathrm{D}_{2} \mathrm{O}$.

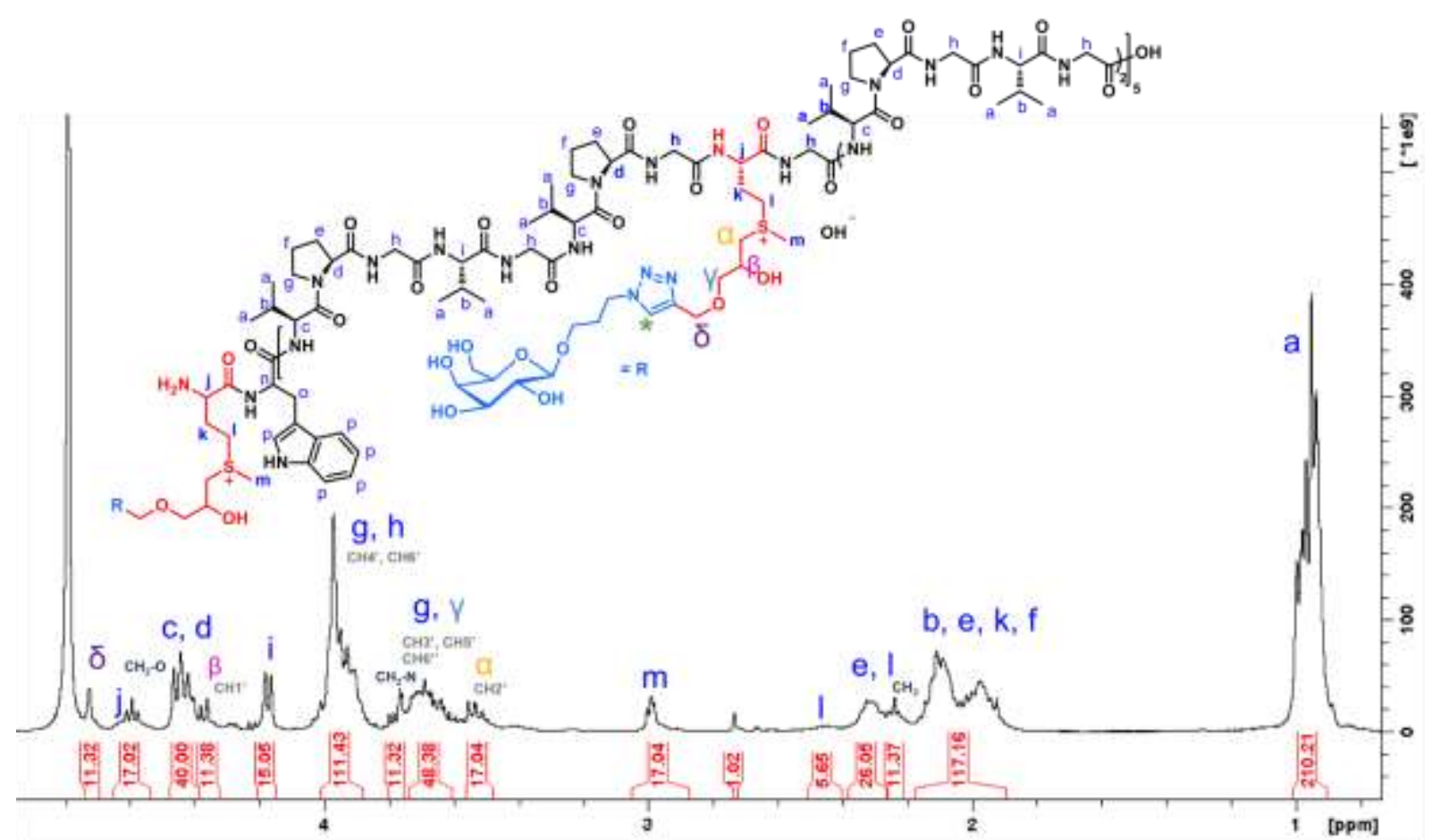

Figure S23. ${ }^{1} \mathrm{H}$ NMR spectrum of compound $\underline{\mathbf{1 b}}$ (zoom) in $\mathrm{D}_{2} \mathrm{O}$. 


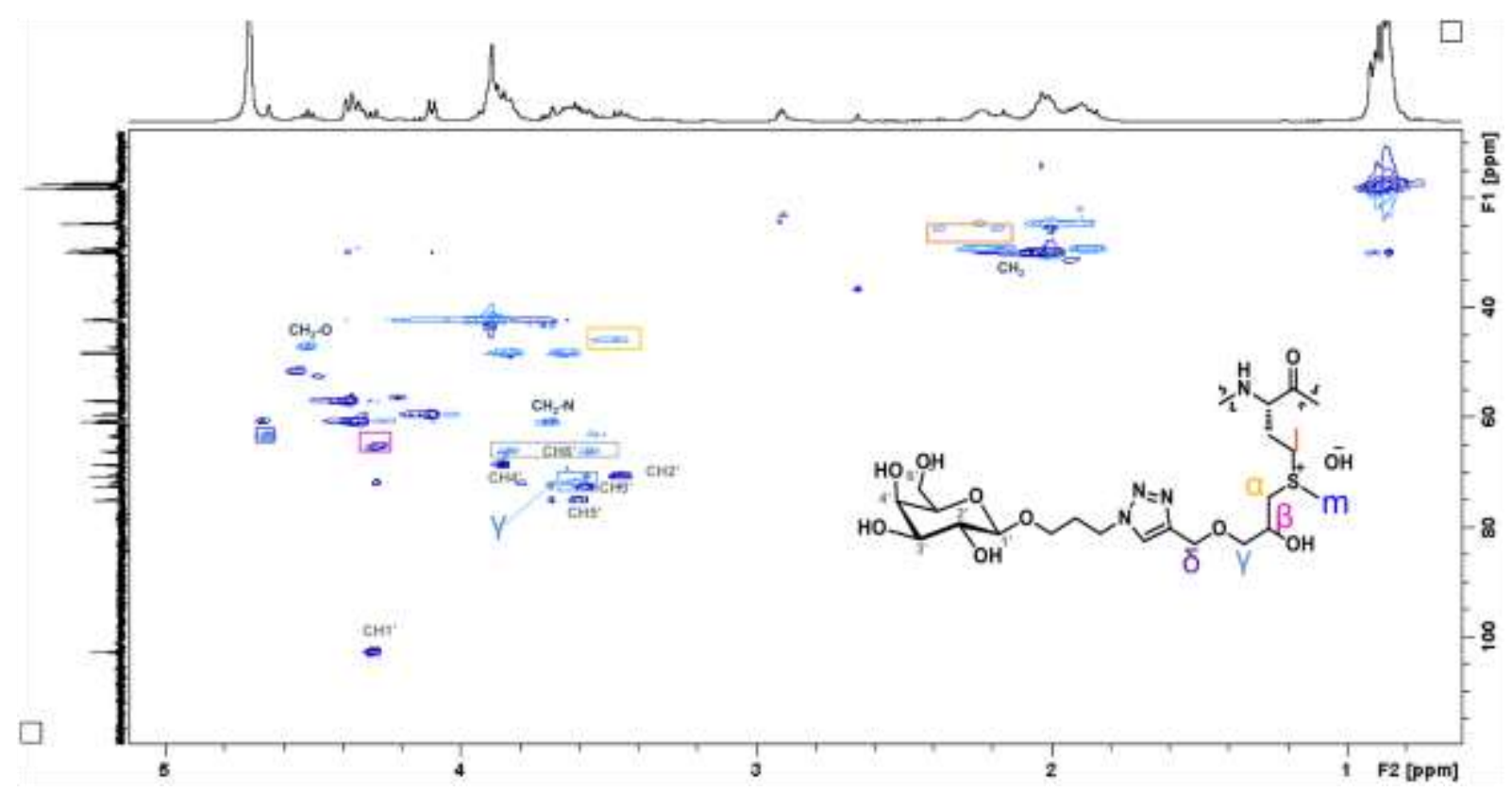

Figure S24. 2D NMR spectrum of compound $\underline{\mathbf{1 b}}$ in $\mathrm{D}_{2} \mathrm{O}, \mathrm{HSQC}$.

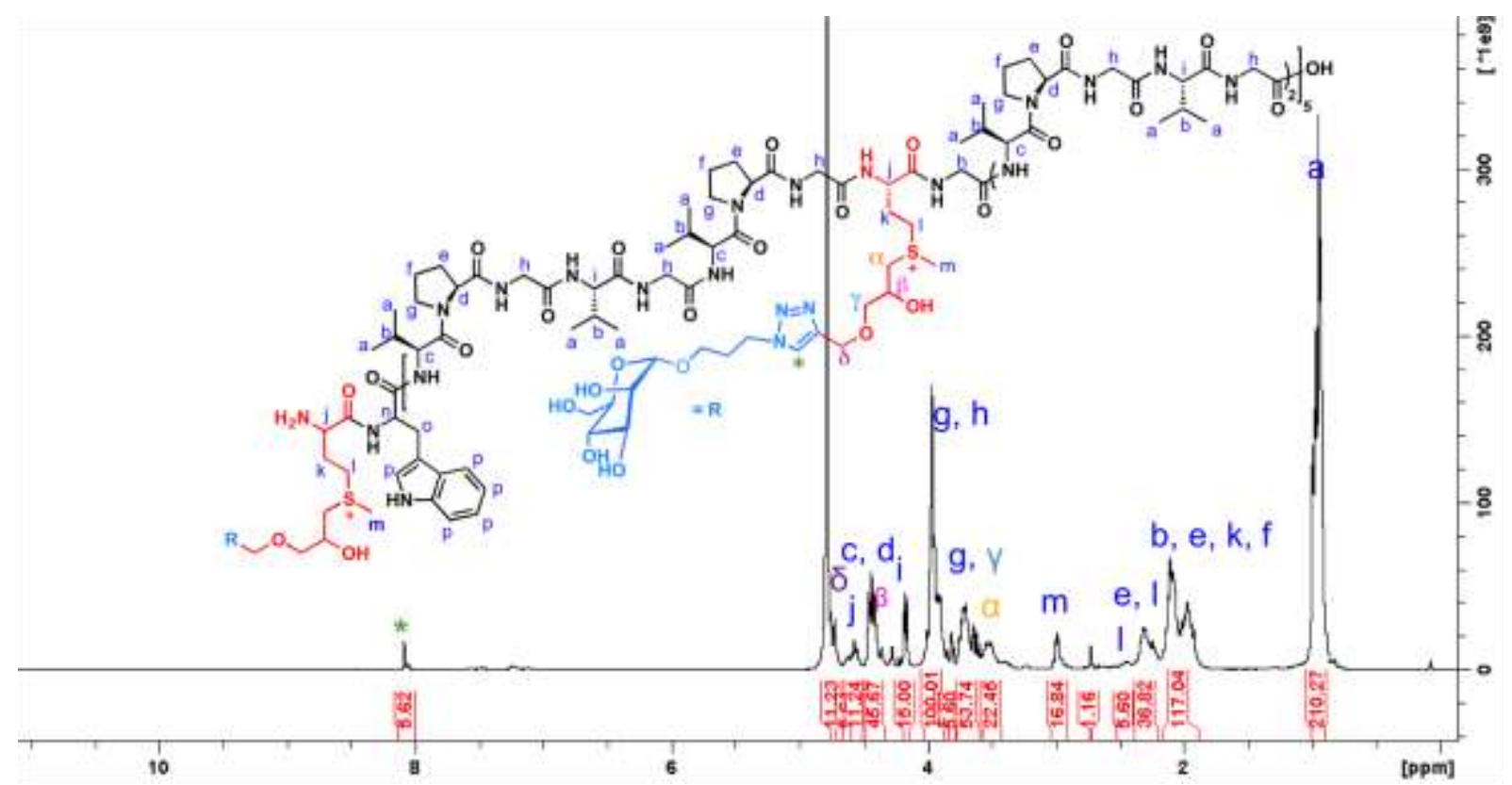

Figure S25. ${ }^{1} \mathrm{H}$ NMR spectrum of compound $\underline{\mathbf{1 c}}$ in $\mathrm{D}_{2} \mathrm{O}$. 


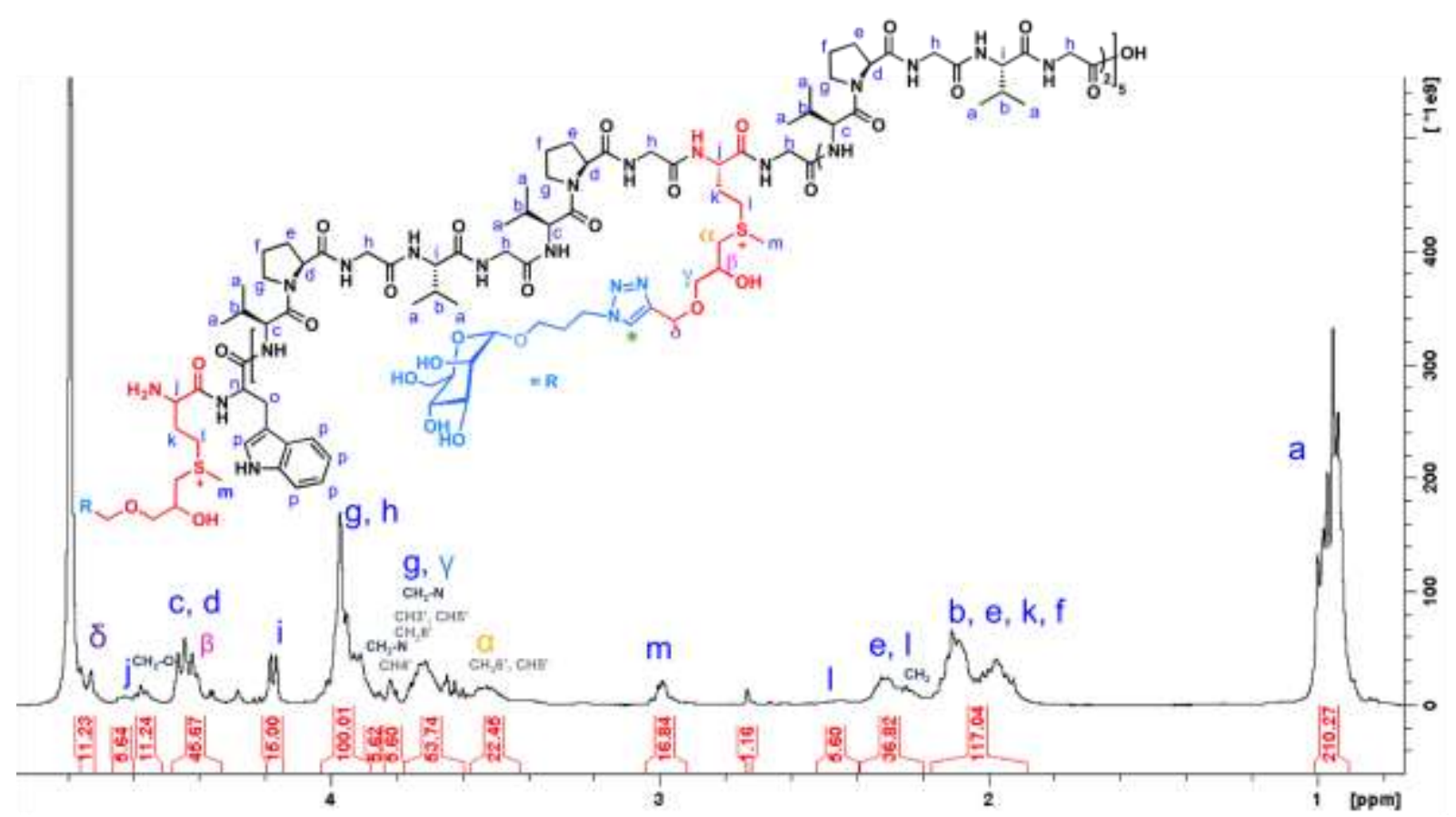

Figure S26. ${ }^{1} \mathrm{H}$ NMR spectrum of compound $\underline{\mathbf{1 c}}$ (zoom) in $\mathrm{D}_{2} \mathrm{O}$.

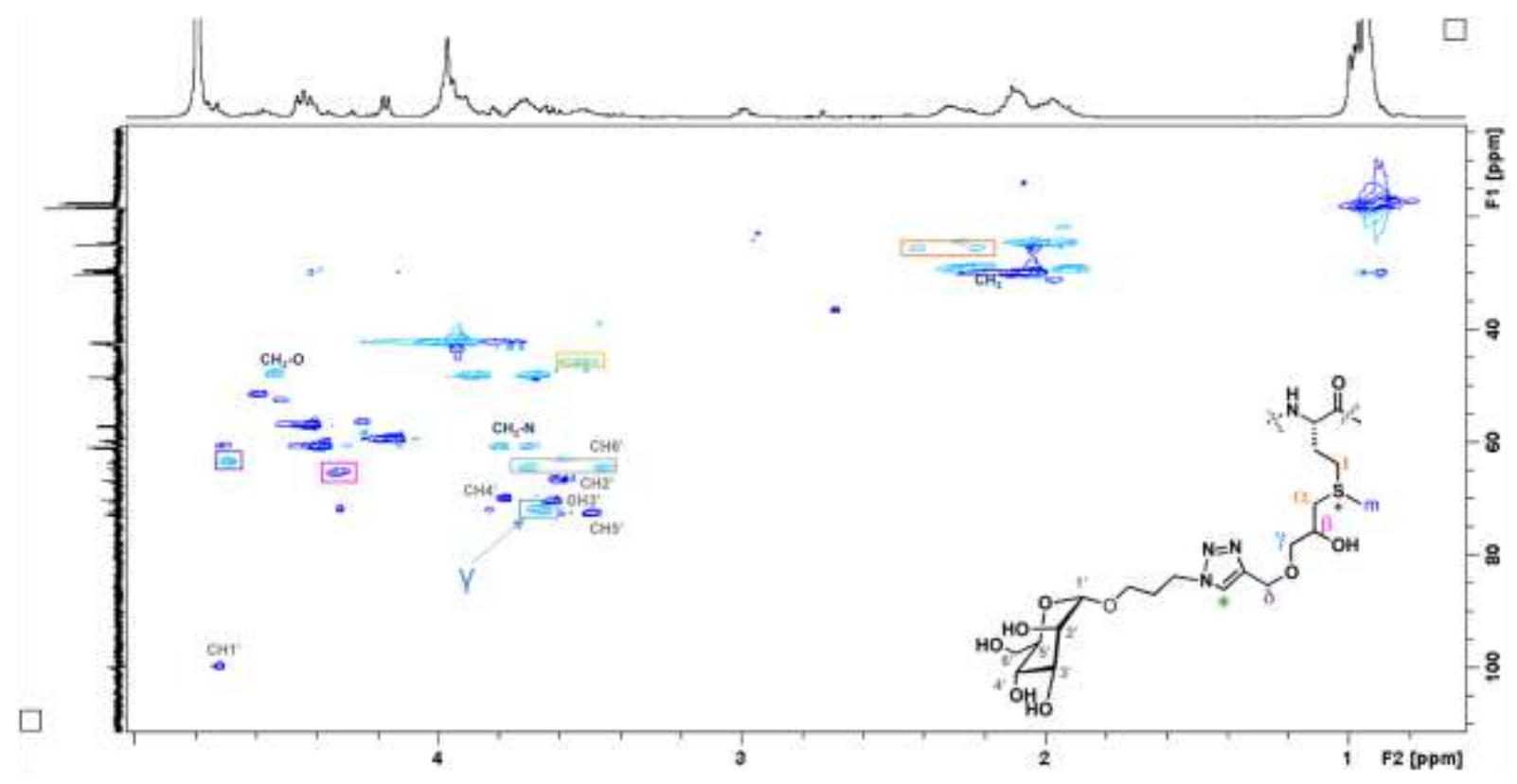

Figure S27. 2D NMR spectrum of compound $\underline{1 \mathrm{c}}$ in $\mathrm{D}_{2} \mathrm{O}, \mathrm{HSQC}$. 


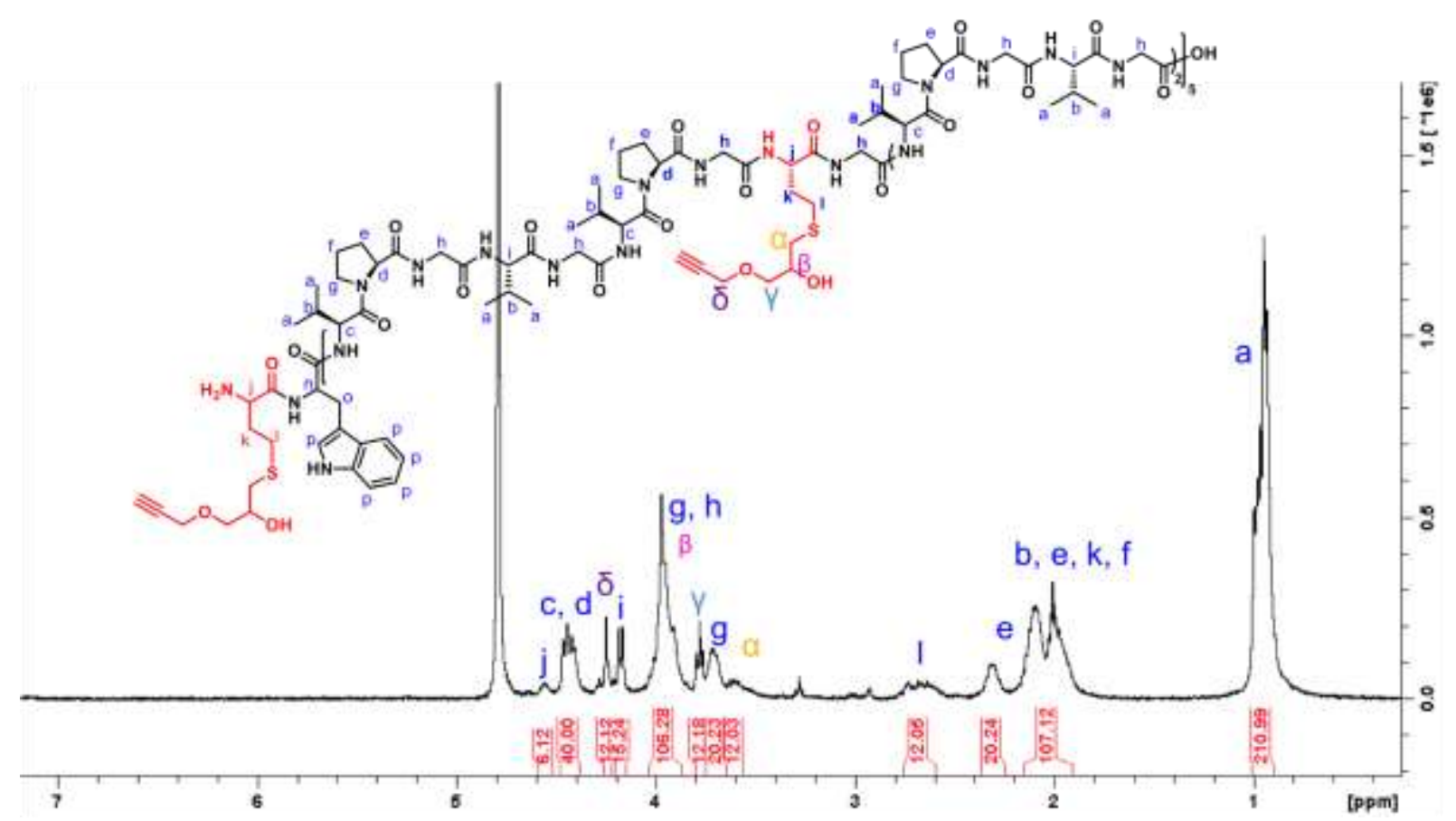

Figure S28. ${ }^{1} \mathrm{H}$ NMR spectrum of $\operatorname{ELP}\left[\mathrm{M}(\text { DemAlk })_{1} \mathrm{~V}_{3}-20\right]$, $\underline{\mathbf{3}}$, in $\mathrm{D}_{2} \mathrm{O}$.

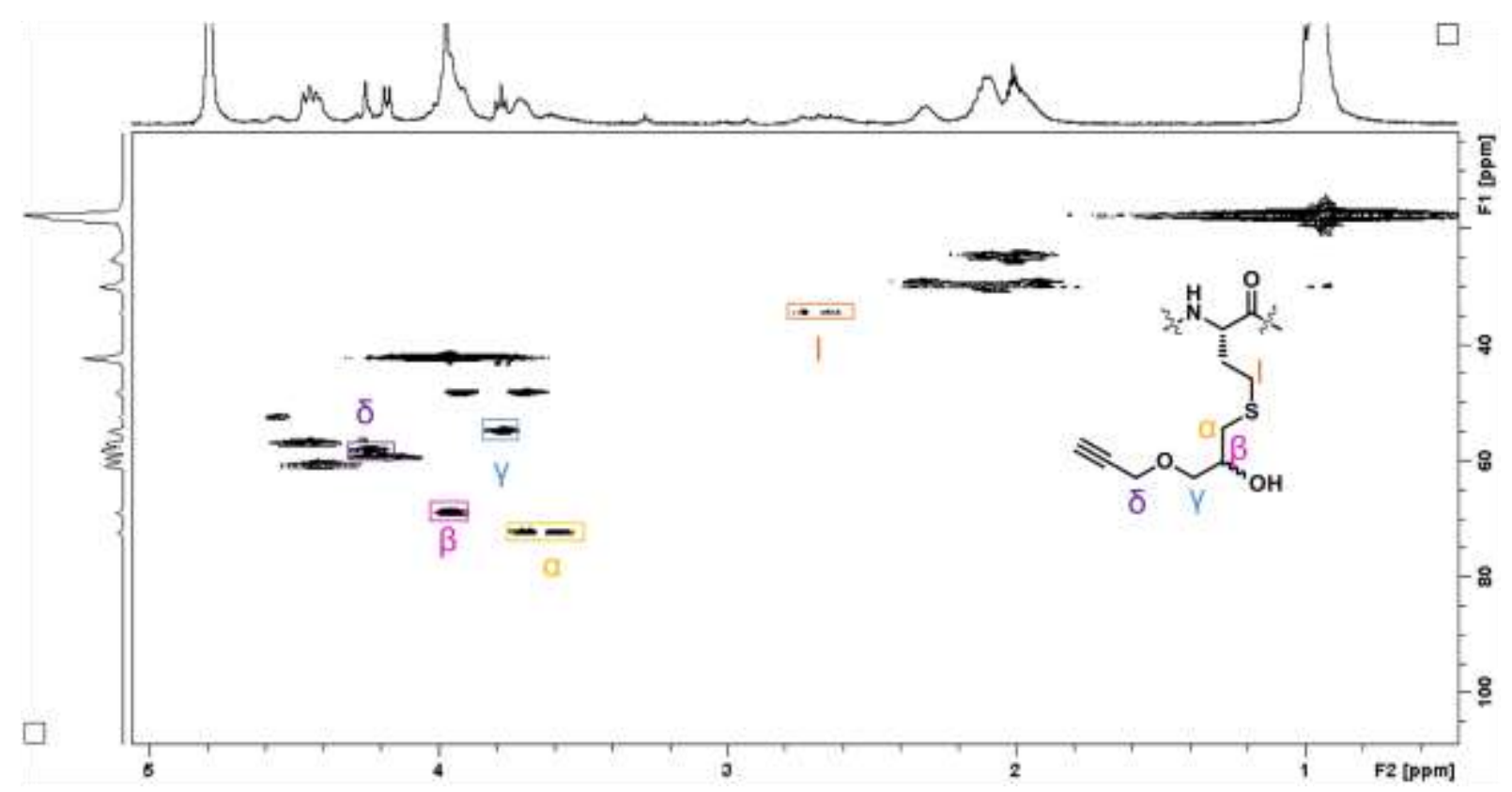

Figure S29. 2D NMR spectrum of $\operatorname{ELP}\left[\mathrm{M}(\text { Dem } A l k)_{1} \mathrm{~V}_{3}-20\right]$, $\underline{\mathbf{3}}$, in $\mathrm{D}_{2} \mathrm{O}$, HSQC. 


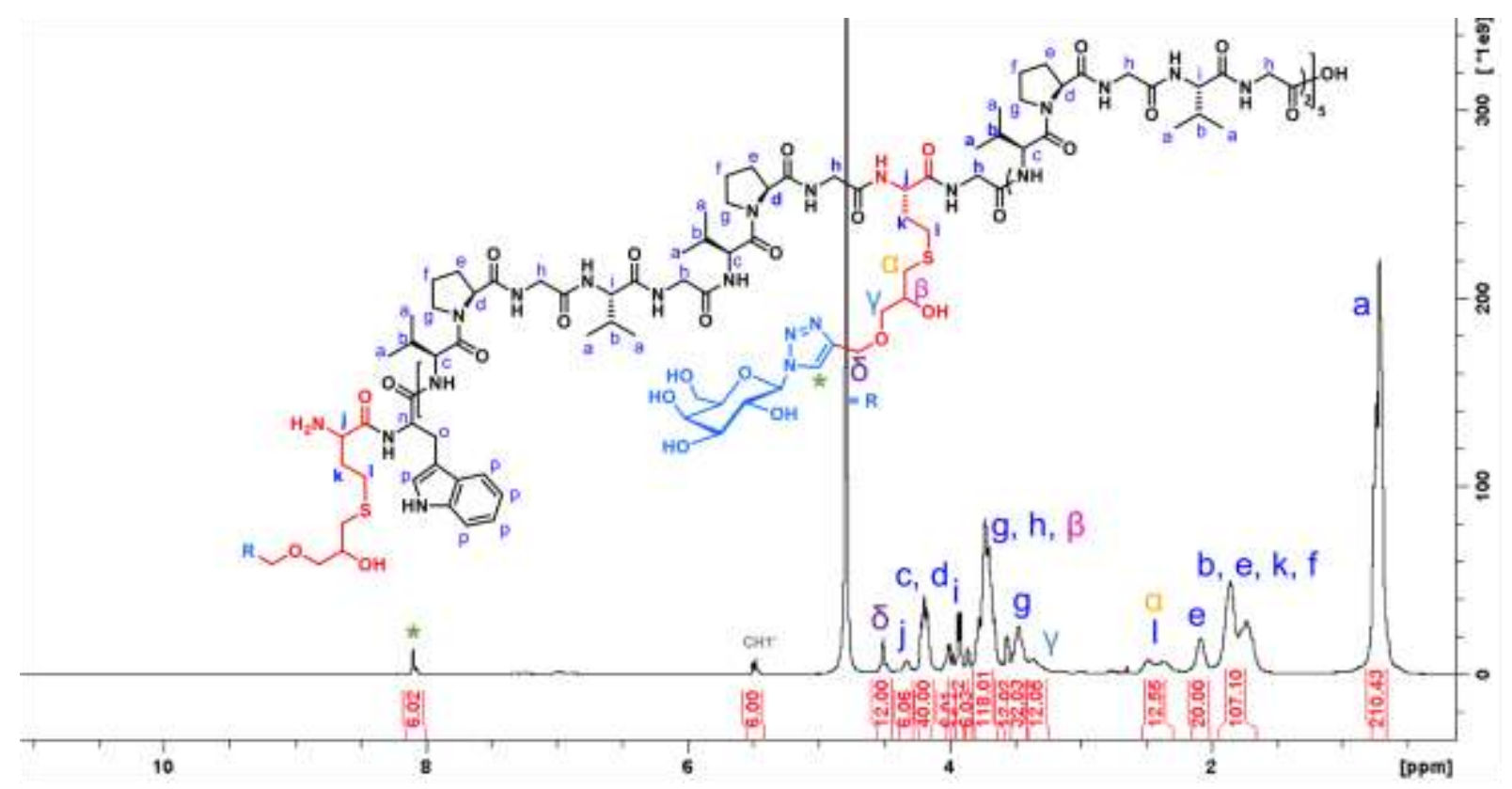

Figure S30. ${ }^{1} \mathrm{H}$ NMR spectrum of compound $\underline{\mathbf{3 a}}$ in $\mathrm{D}_{2} \mathrm{O}$.

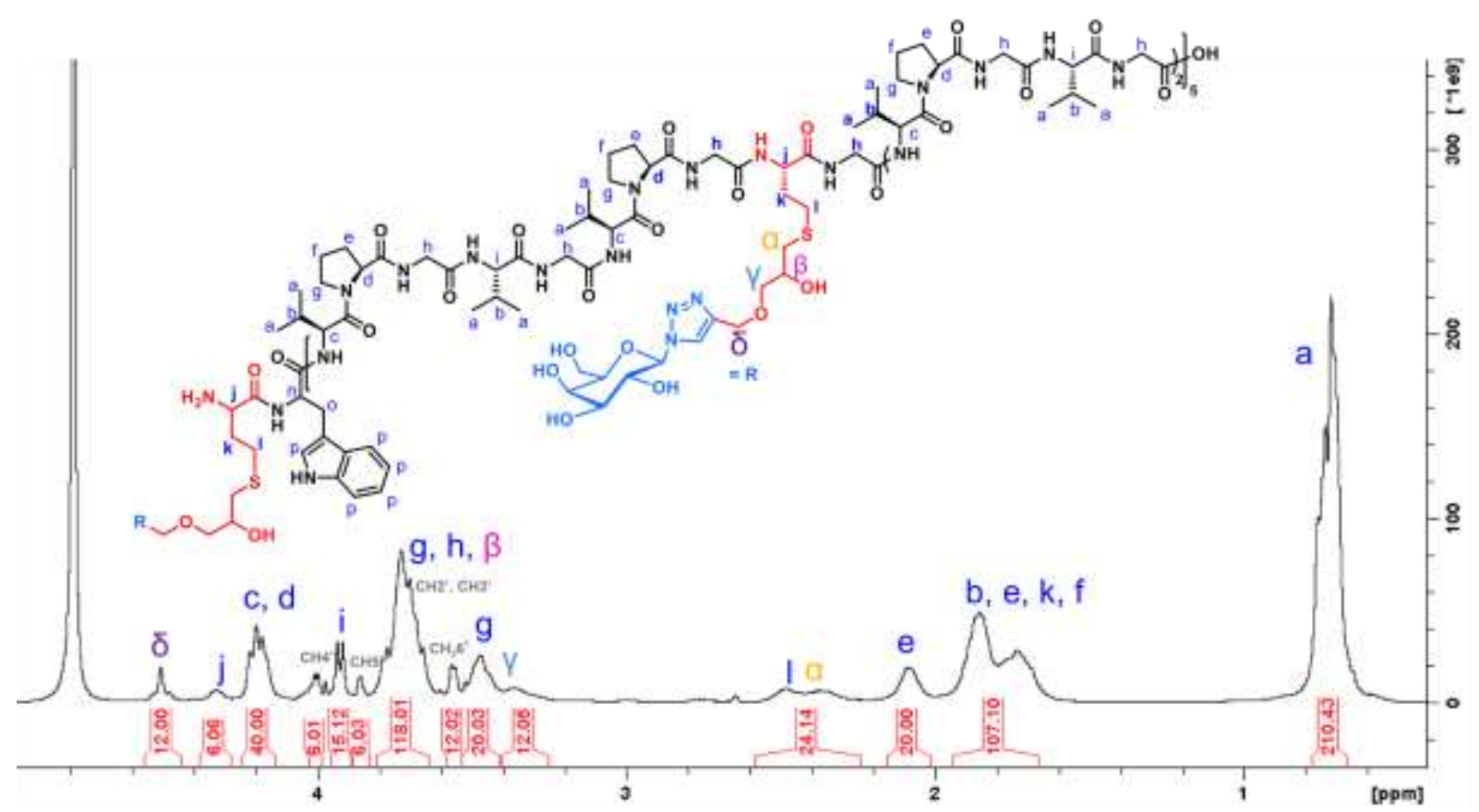

Figure S31. ${ }^{1} \mathrm{H}$ NMR spectrum of compound $\underline{\mathbf{3 a}}$ (zoom) in $\mathrm{D}_{2} \mathrm{O}$. 


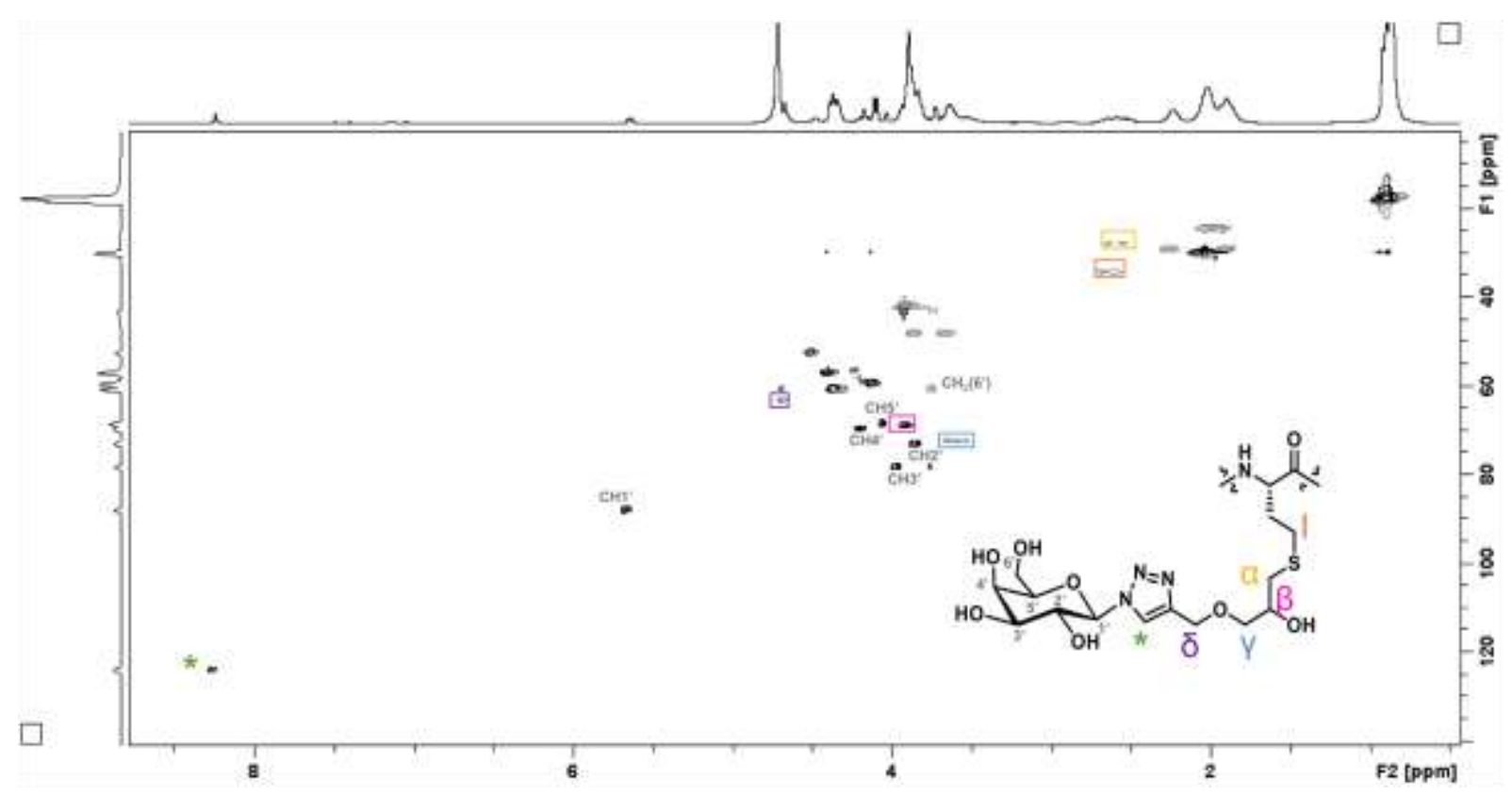

Figure S32. 2D NMR spectrum of compound $\underline{\mathbf{3 a}}$ in $\mathrm{D}_{2} \mathrm{O}$, HSQC.

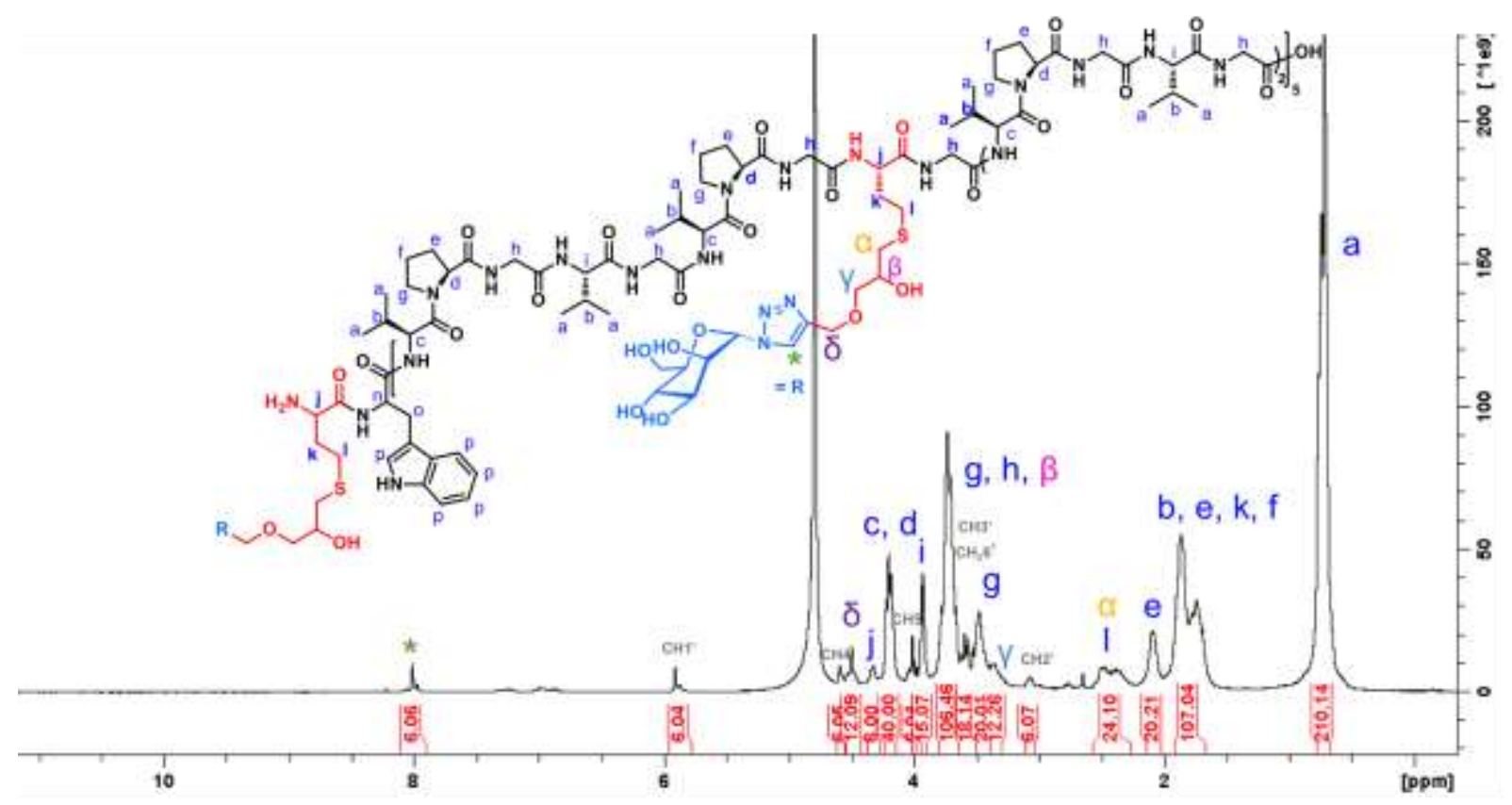

Figure S33. ${ }^{1} \mathrm{H}$ NMR spectrum of compound $\underline{\mathbf{3 b}}$ in $\mathrm{D}_{2} \mathrm{O}$. 


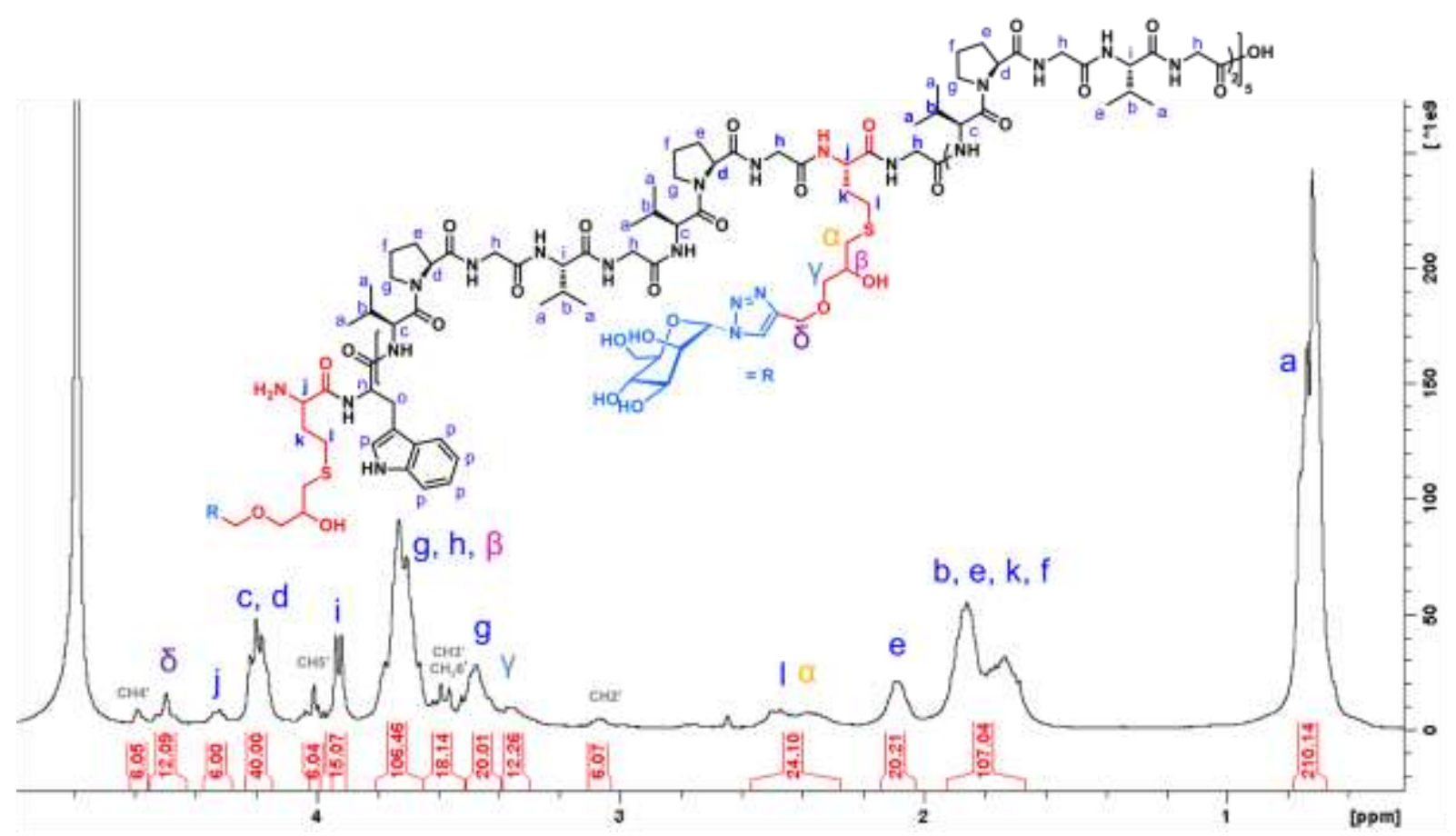

Figure S34. ${ }^{1} \mathrm{H}$ NMR spectrum of compound $\underline{\mathbf{3 b}}$ (zoom) in $\mathrm{D}_{2} \mathrm{O}$.

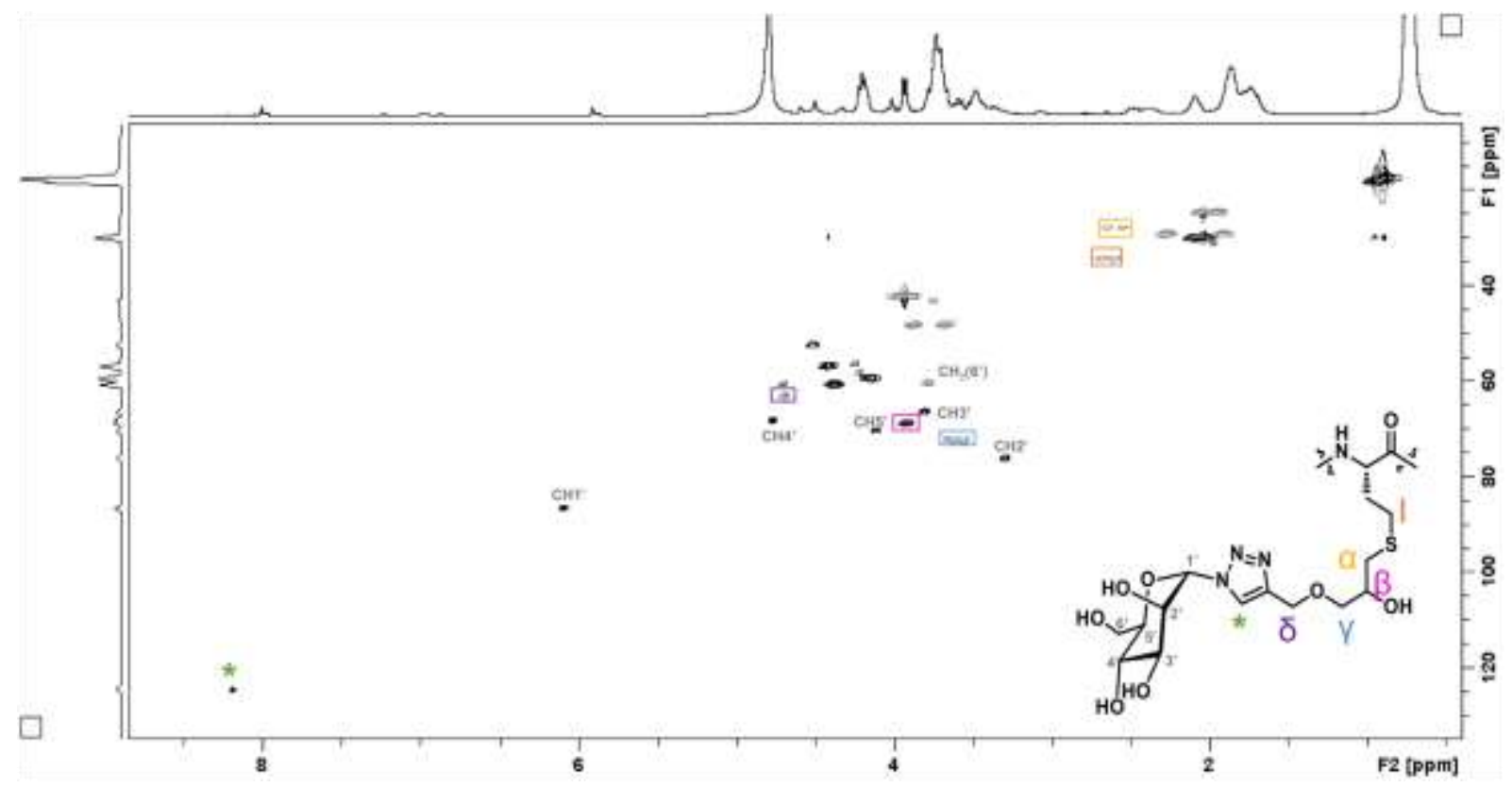

Figure S35. 2D NMR spectrum of compound $\underline{\mathbf{3 b}}$ in $\mathrm{D}_{2} \mathrm{O}$, HSQC. 


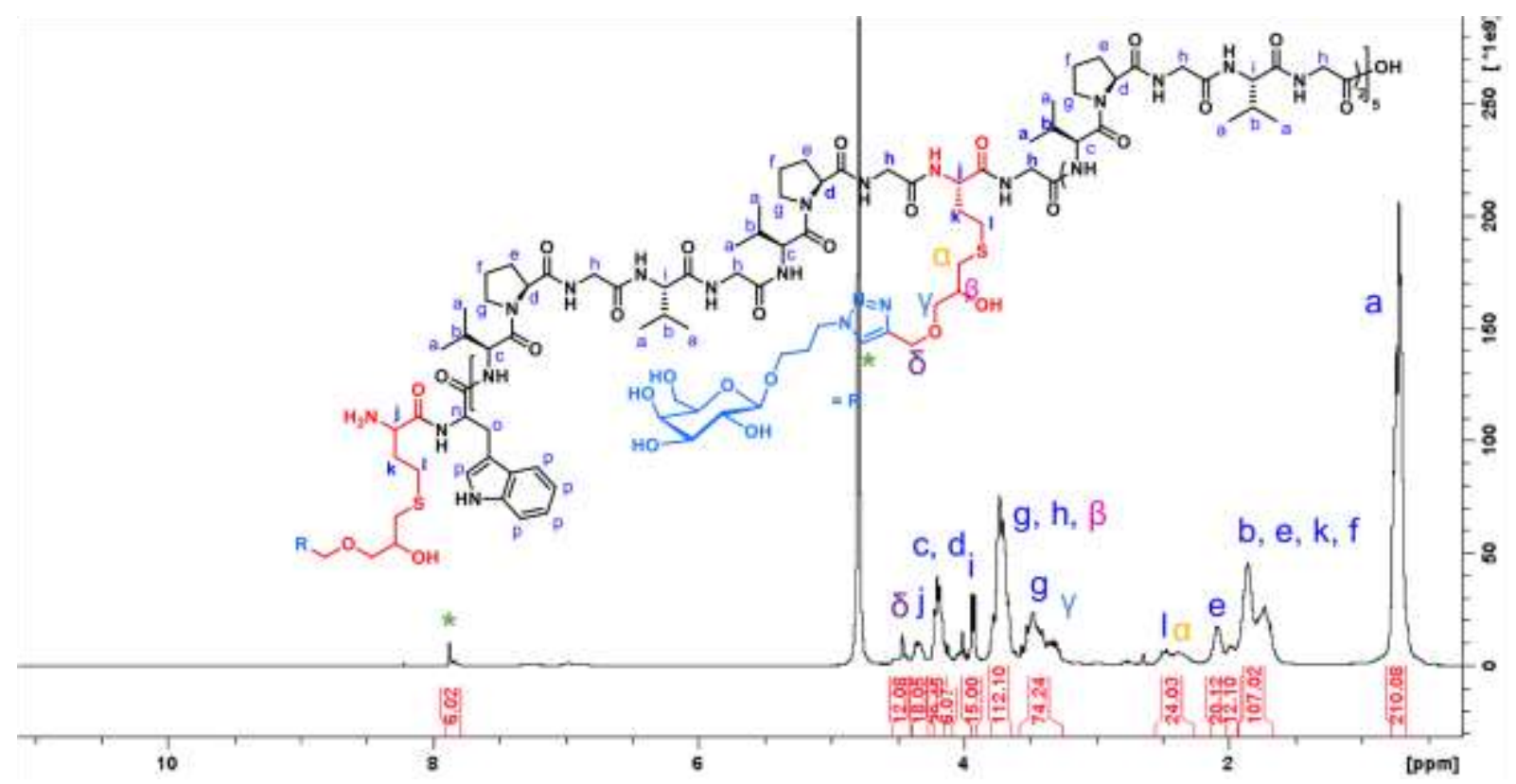

Figure S36. ${ }^{1} \mathrm{H}$ NMR spectrum of compound $\underline{\mathbf{3 c}}$ in $\mathrm{D}_{2} \mathrm{O}$.

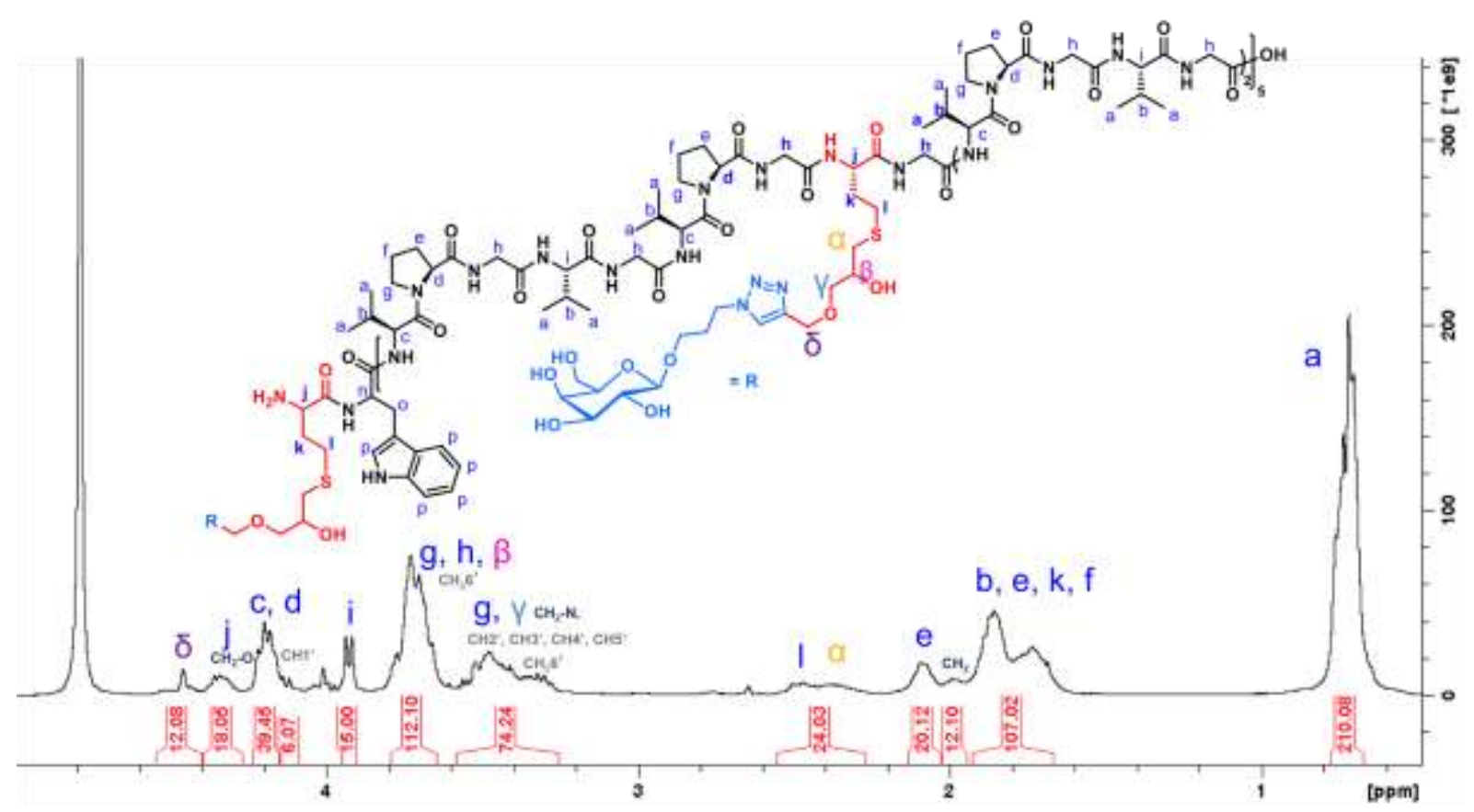

Figure S37. ${ }^{1} \mathrm{H}$ NMR spectrum of compound $\underline{\mathbf{3 c}}$ (zoom) in $\mathrm{D}_{2} \mathrm{O}$. 


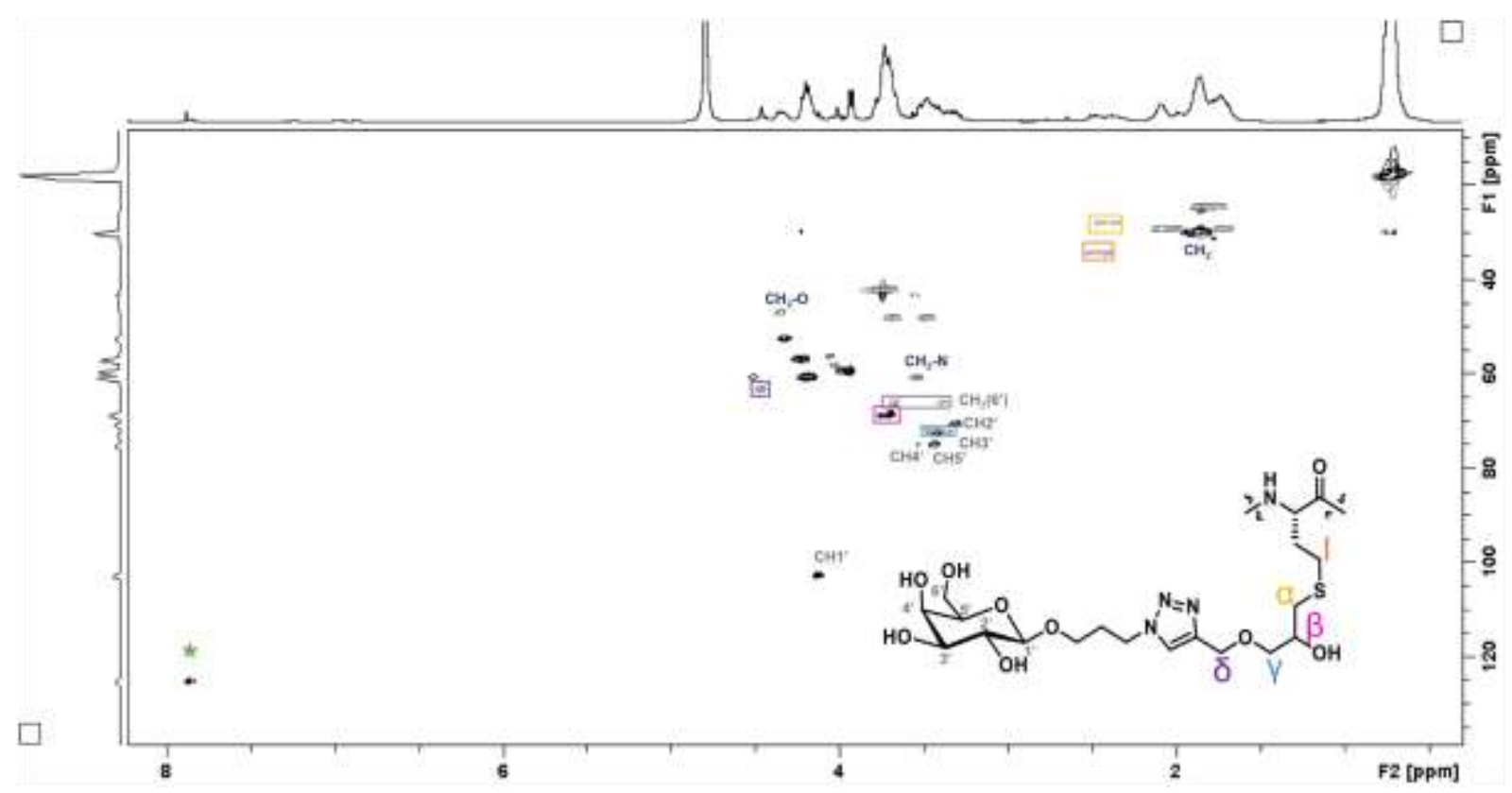

Figure S38. 2D NMR spectrum of compound $\underline{\mathbf{3 c}}$ in $\mathrm{D}_{2} \mathrm{O}, \mathrm{HSQC}$.

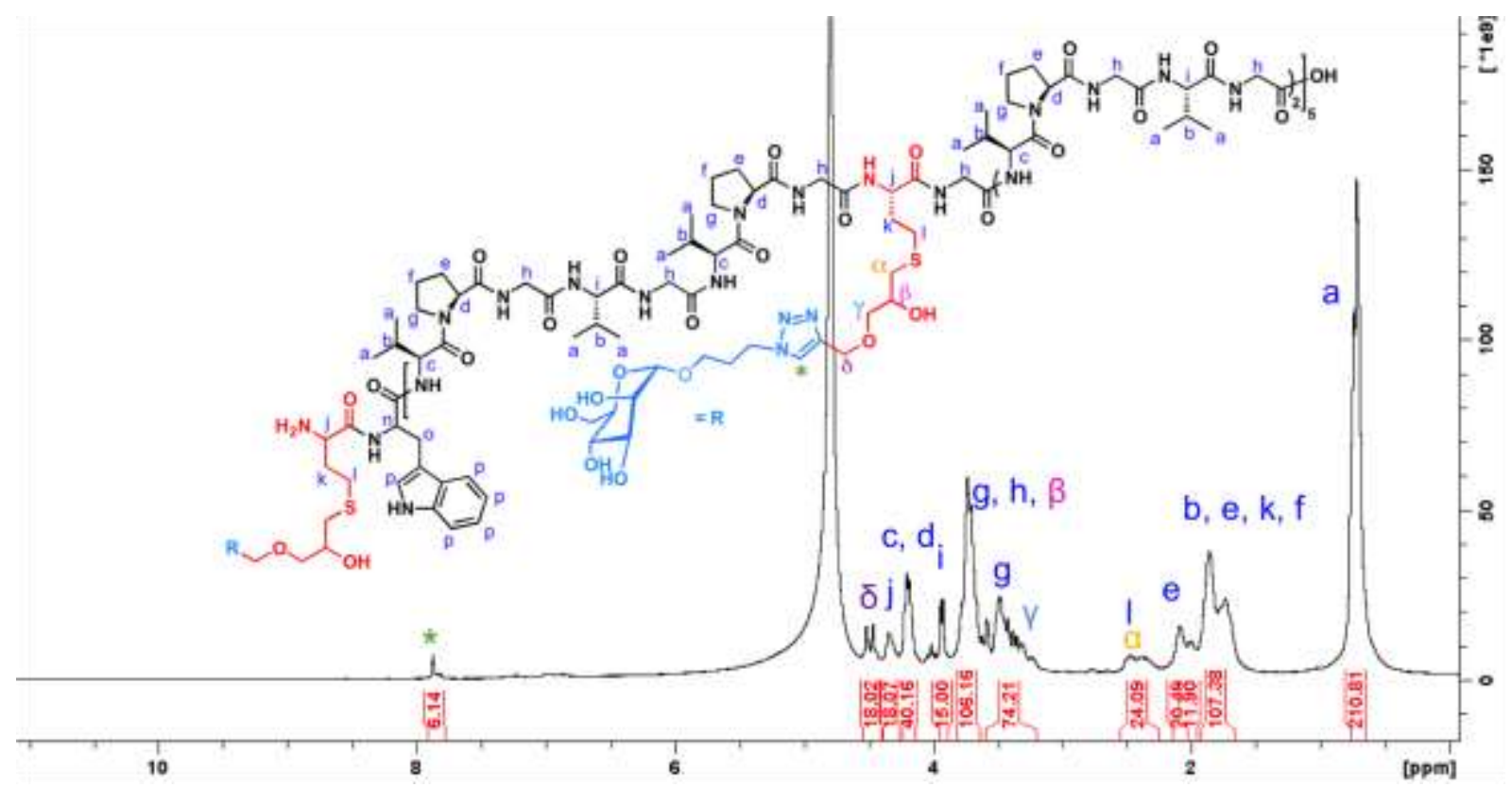

Figure S39. ${ }^{1} \mathrm{H}$ NMR spectrum of compound $\underline{\mathbf{3 d}}$ in $\mathrm{D}_{2} \mathrm{O}$. 


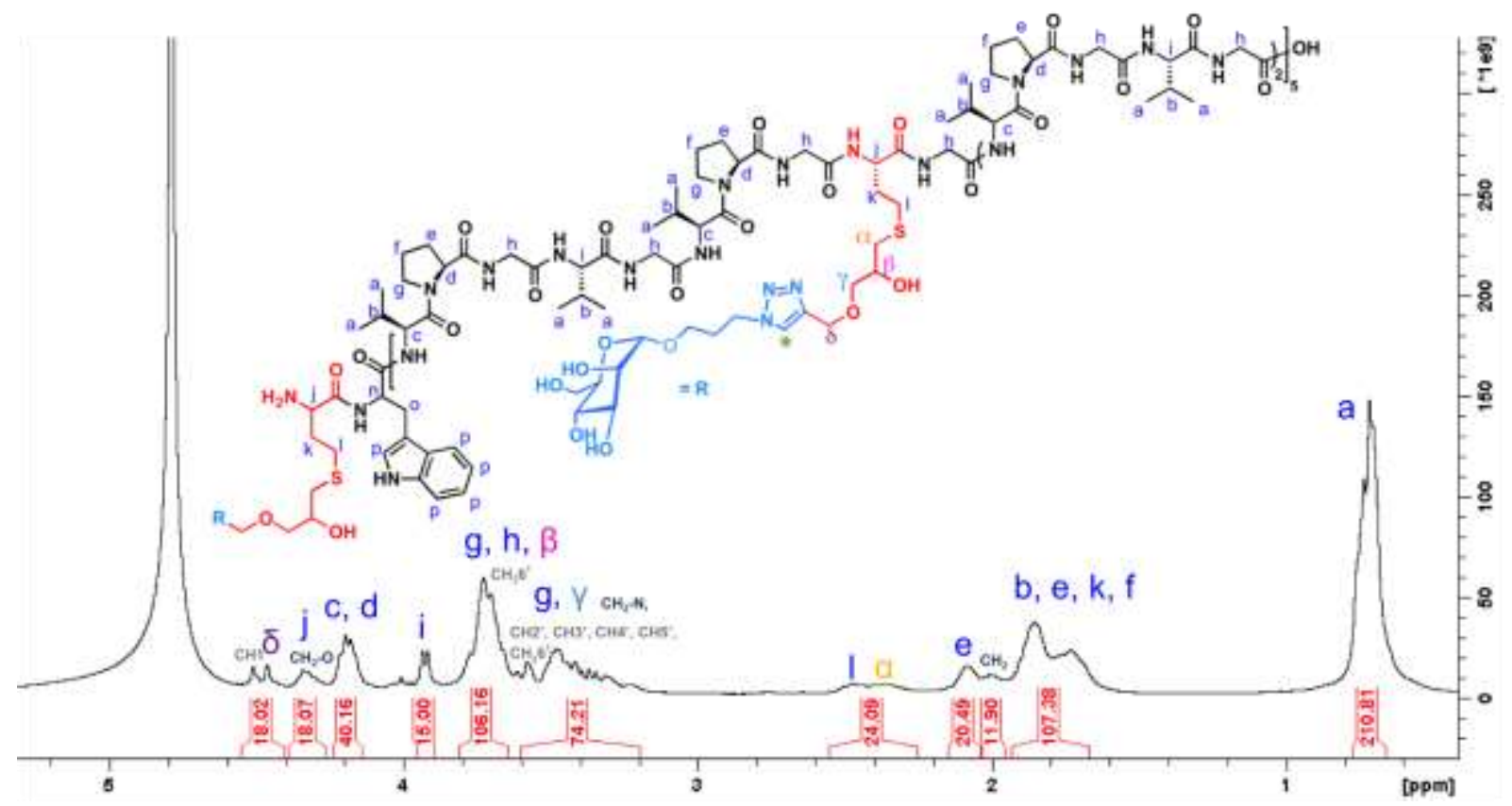

Figure S40. ${ }^{1} \mathrm{H}$ NMR spectrum of compound $\underline{\mathbf{3 d}}$ (zoom) in $\mathrm{D}_{2} \mathrm{O}$.

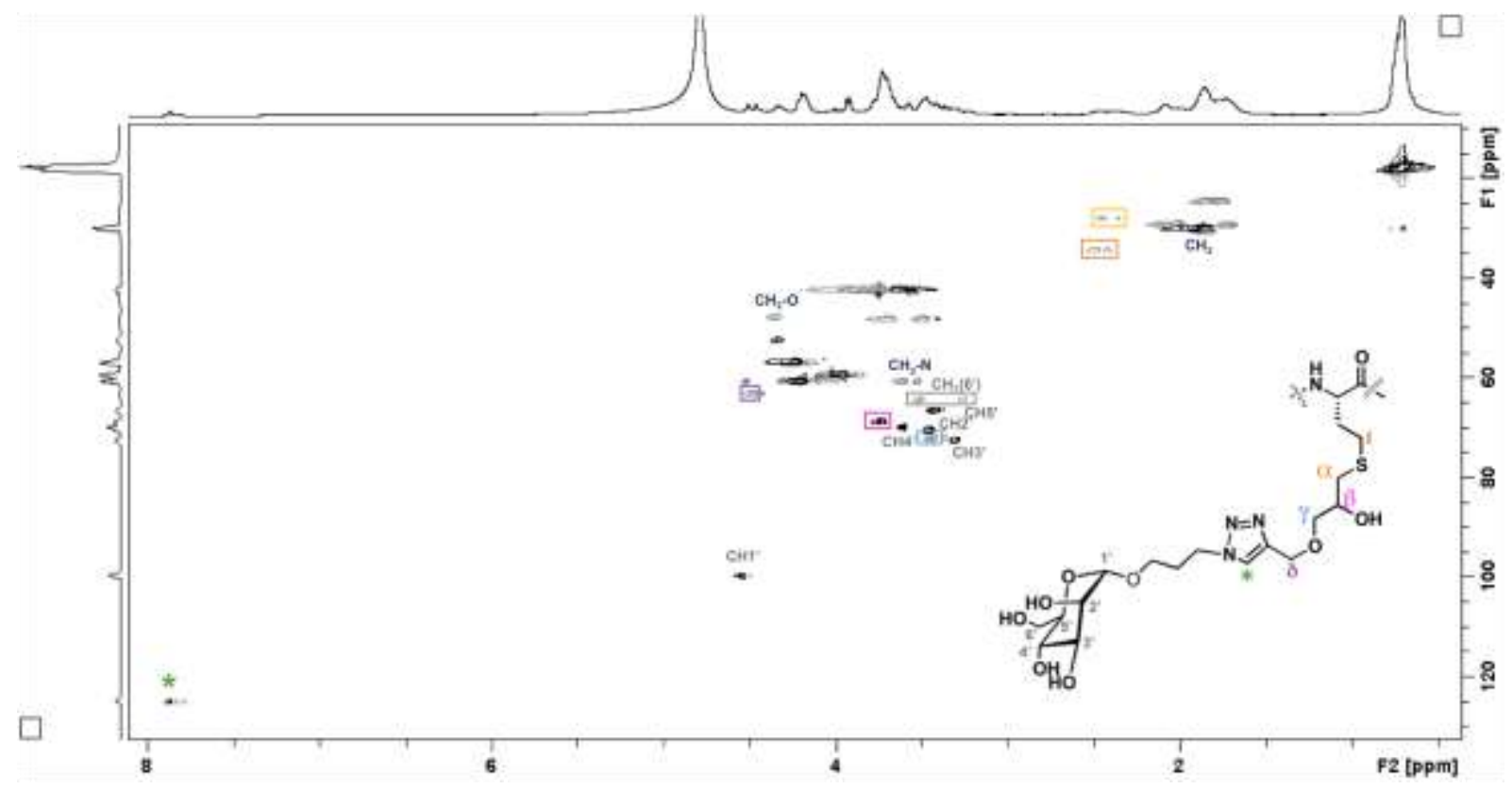

Figure S41. 2D NMR spectrum of compound $\underline{\mathbf{3 d}}$ in $\mathrm{D}_{2} \mathrm{O}, \mathrm{HSQC}$. 


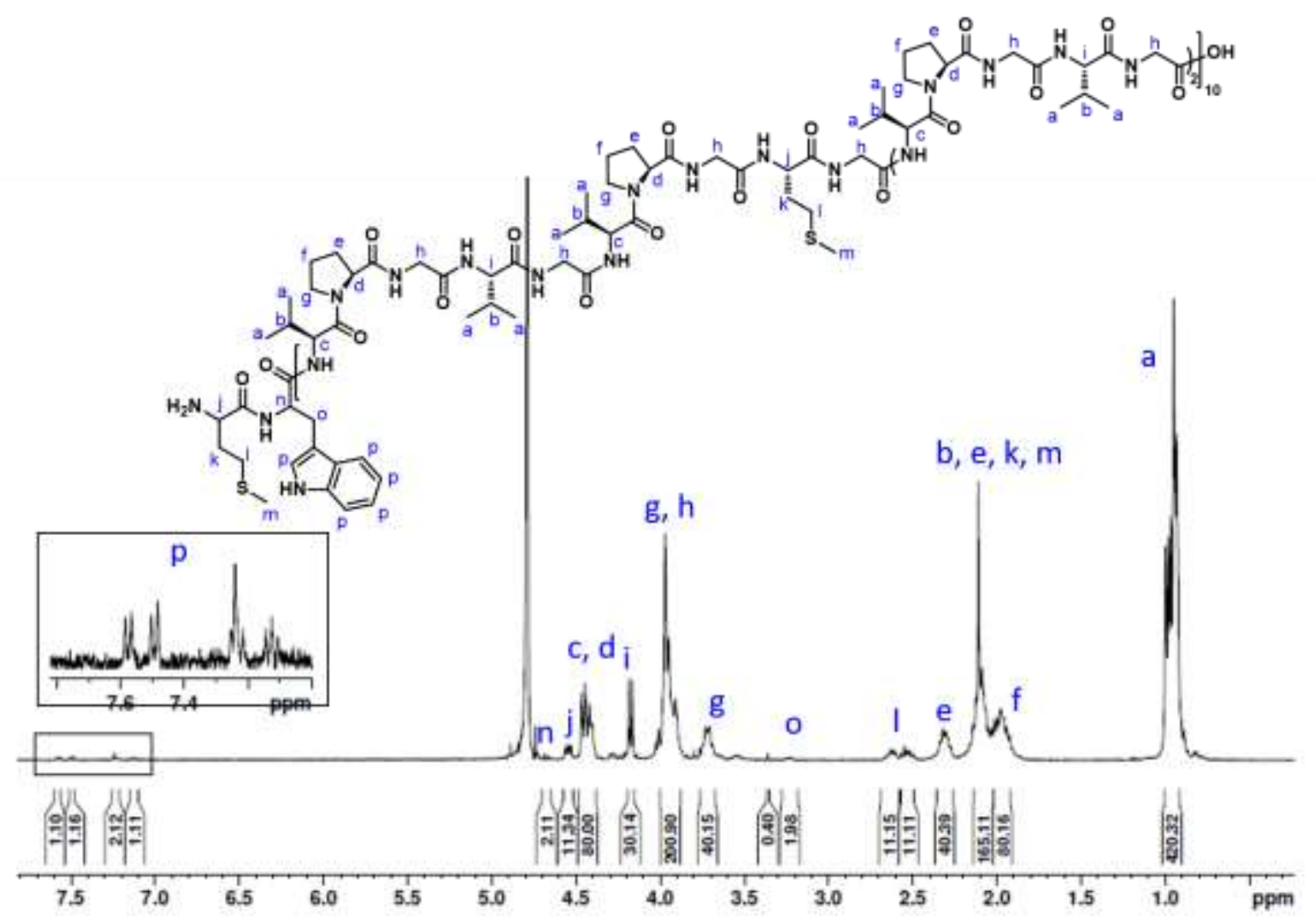

Figure S42. ${ }^{1} \mathrm{H}$ NMR spectrum of ELP $\left[\mathrm{M}_{1} \mathrm{~V}_{3}-40\right]$ in $\mathrm{D}_{2} \mathrm{O}$.

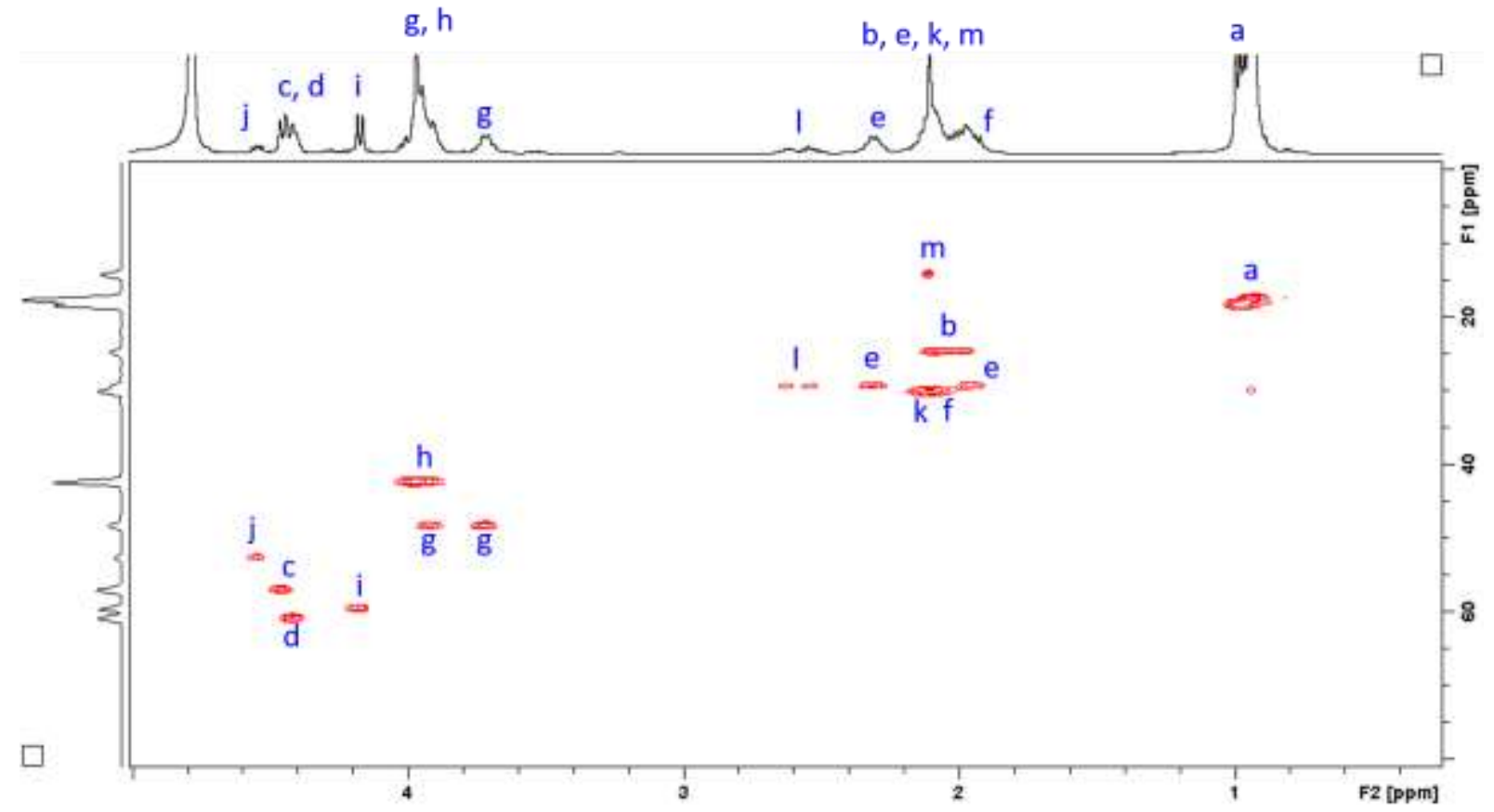

Figure S43. 2D NMR spectrum of ELP $\left[\mathrm{M}_{1} \mathrm{~V}_{3}-40\right]$ in $\mathrm{D}_{2} \mathrm{O}$, HSQC. 


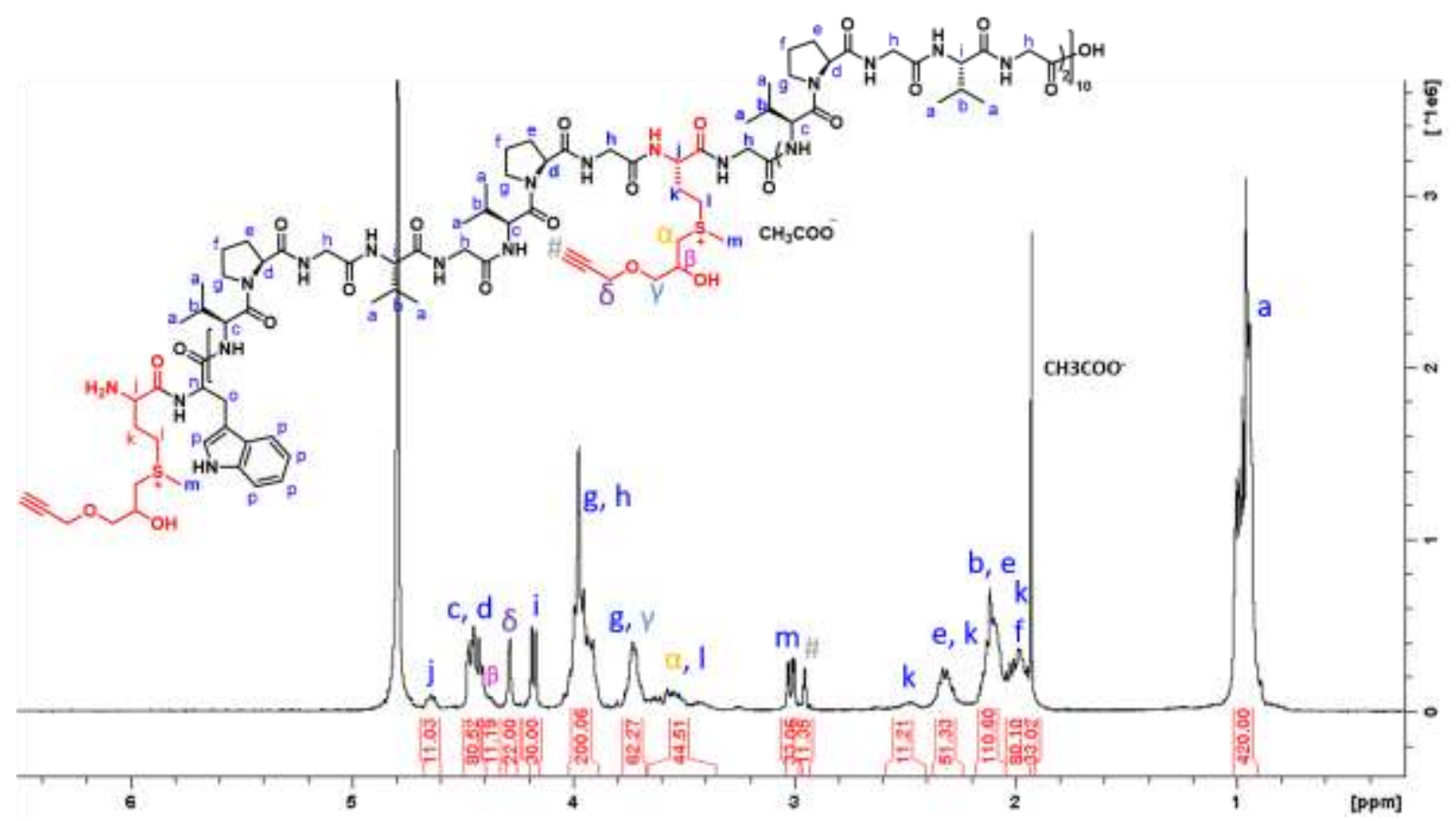

Figure S44. ${ }^{1} \mathrm{H}$ NMR spectrum of $\operatorname{ELP}\left[\mathrm{M}(\mathrm{Alk})_{1} \mathrm{~V}_{3}-40\right]$, $\underline{\mathbf{2}}$, in $\mathrm{D}_{2} \mathrm{O}$.

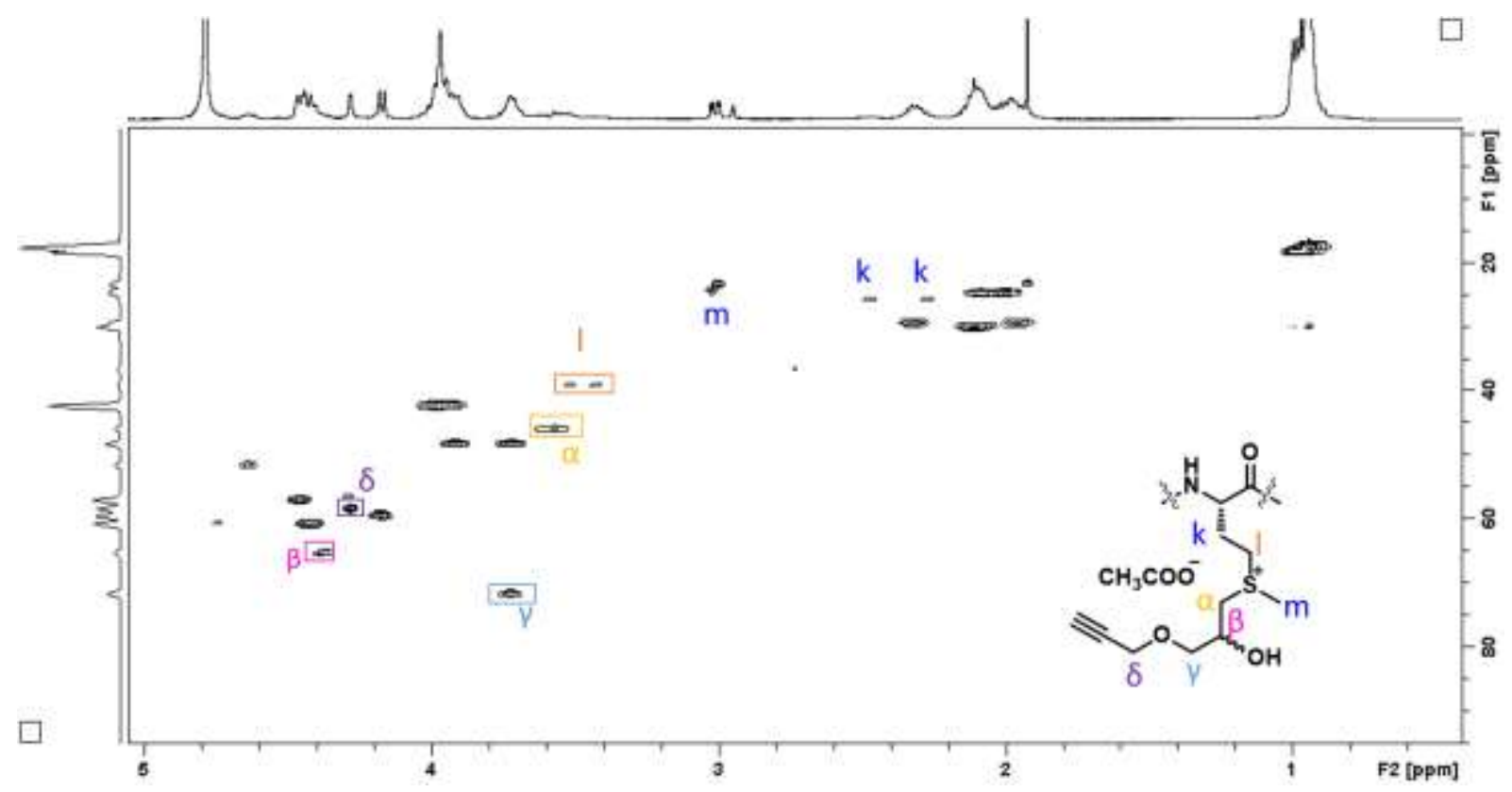

Figure S45. 2D NMR spectrum of ELP[M(Alk) $\left.)_{1} \mathrm{~V}_{3}-40\right]$, $\underline{\mathbf{2}}$, in $\mathrm{D}_{2} \mathrm{O}$, HSQC. 


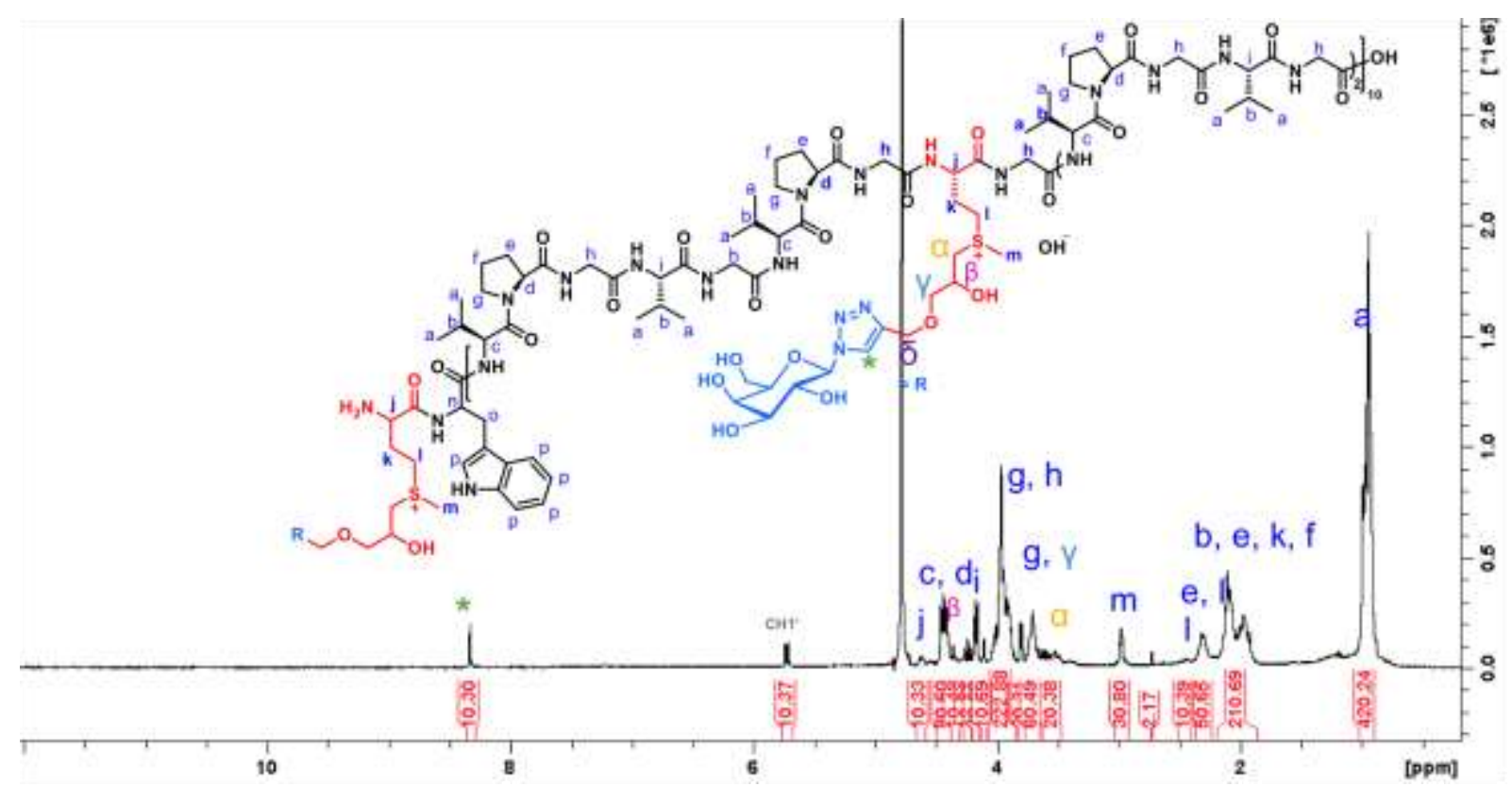

Figure S46. ${ }^{1} \mathrm{H}$ NMR spectrum of compound $\underline{\mathbf{2 a}}$ in $\mathrm{D}_{2} \mathrm{O}$.

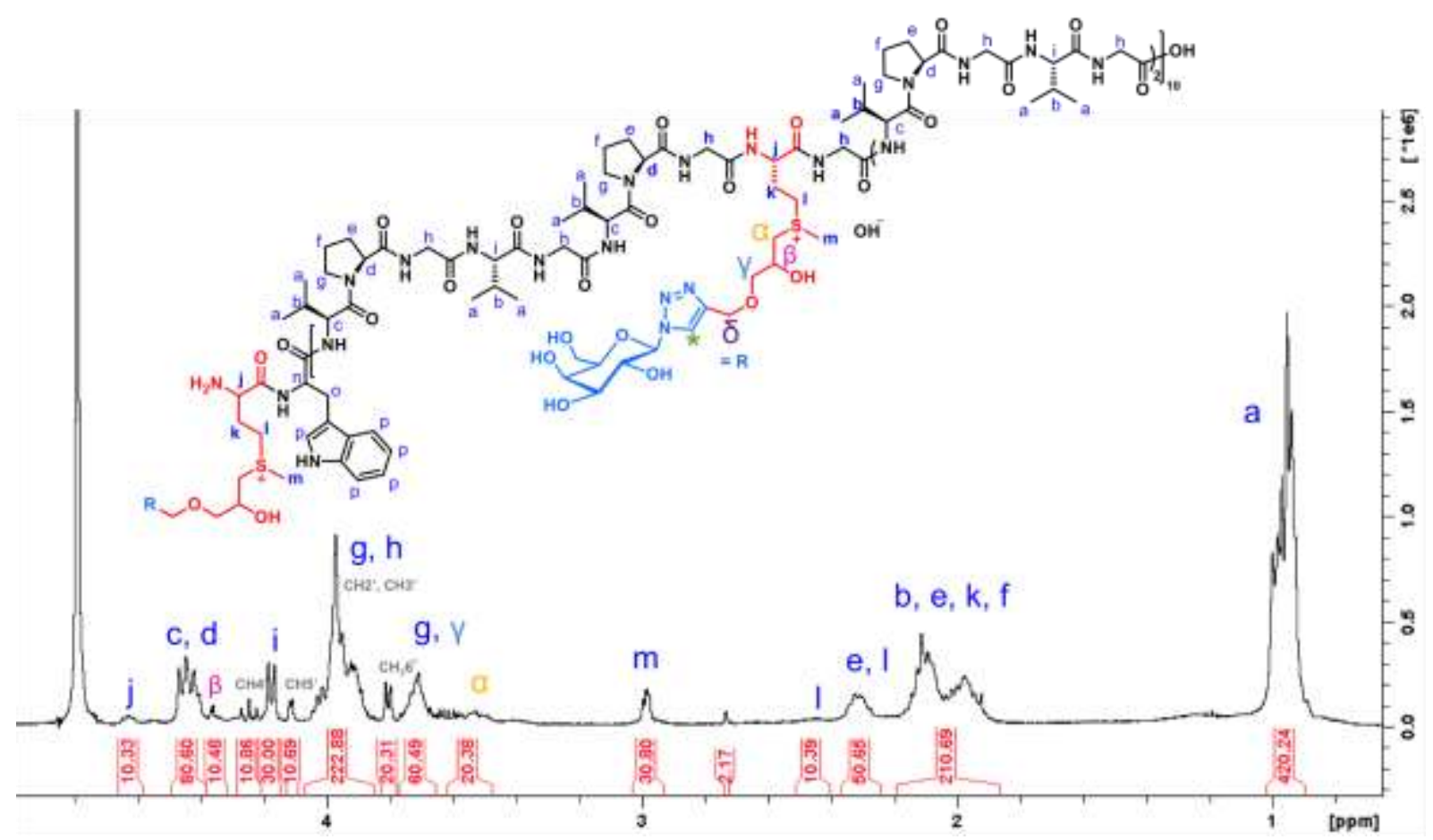

Figure S47. ${ }^{1} \mathrm{H}$ NMR spectrum of compound $\underline{\mathbf{2 a}}$ (zoom) in $\mathrm{D}_{2} \mathrm{O}$. 


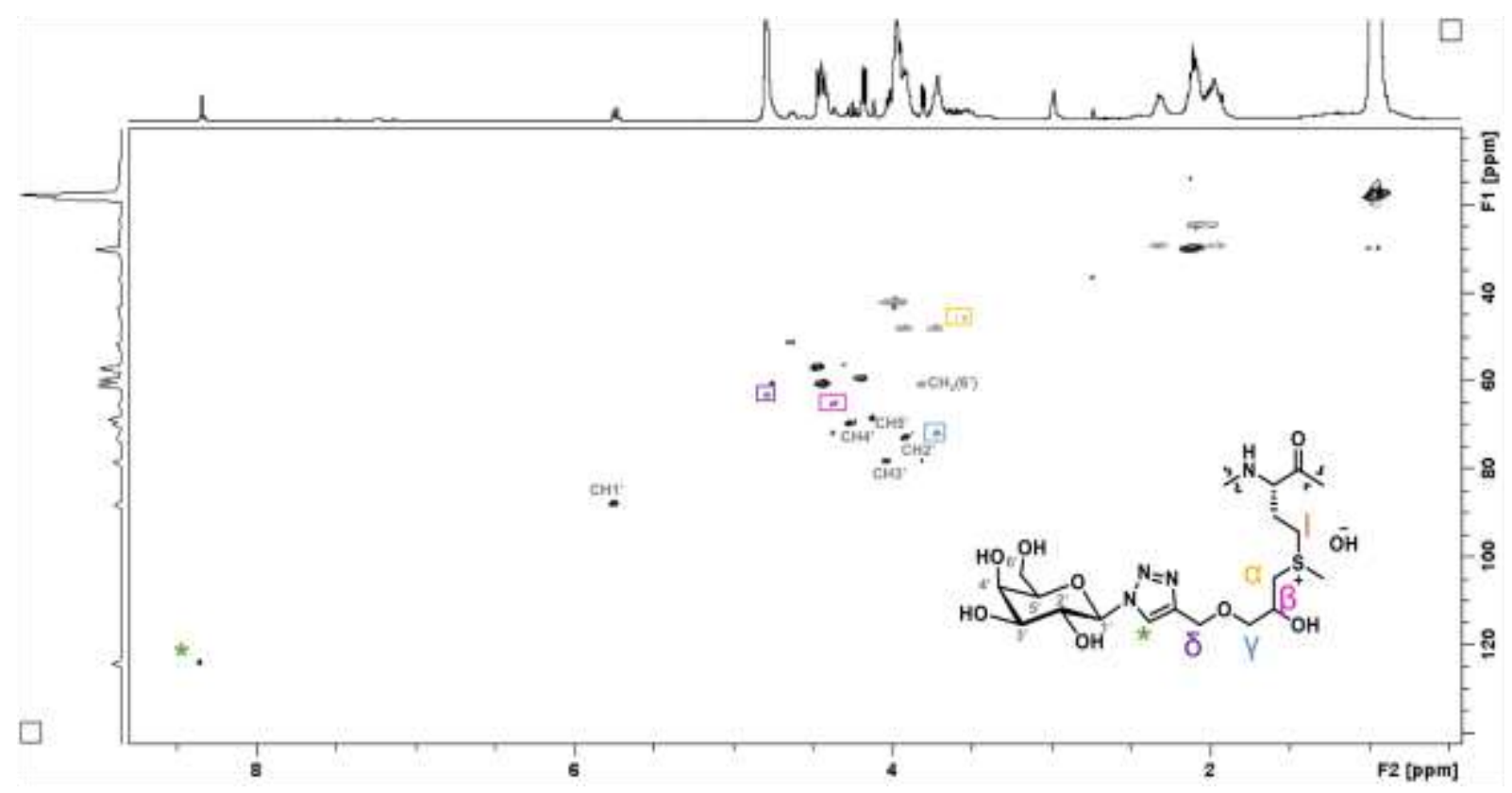

Figure S48. 2D NMR spectrum of compound $\underline{\mathbf{2 a}}$ in $\mathrm{D}_{2} \mathrm{O}$, HSQC.

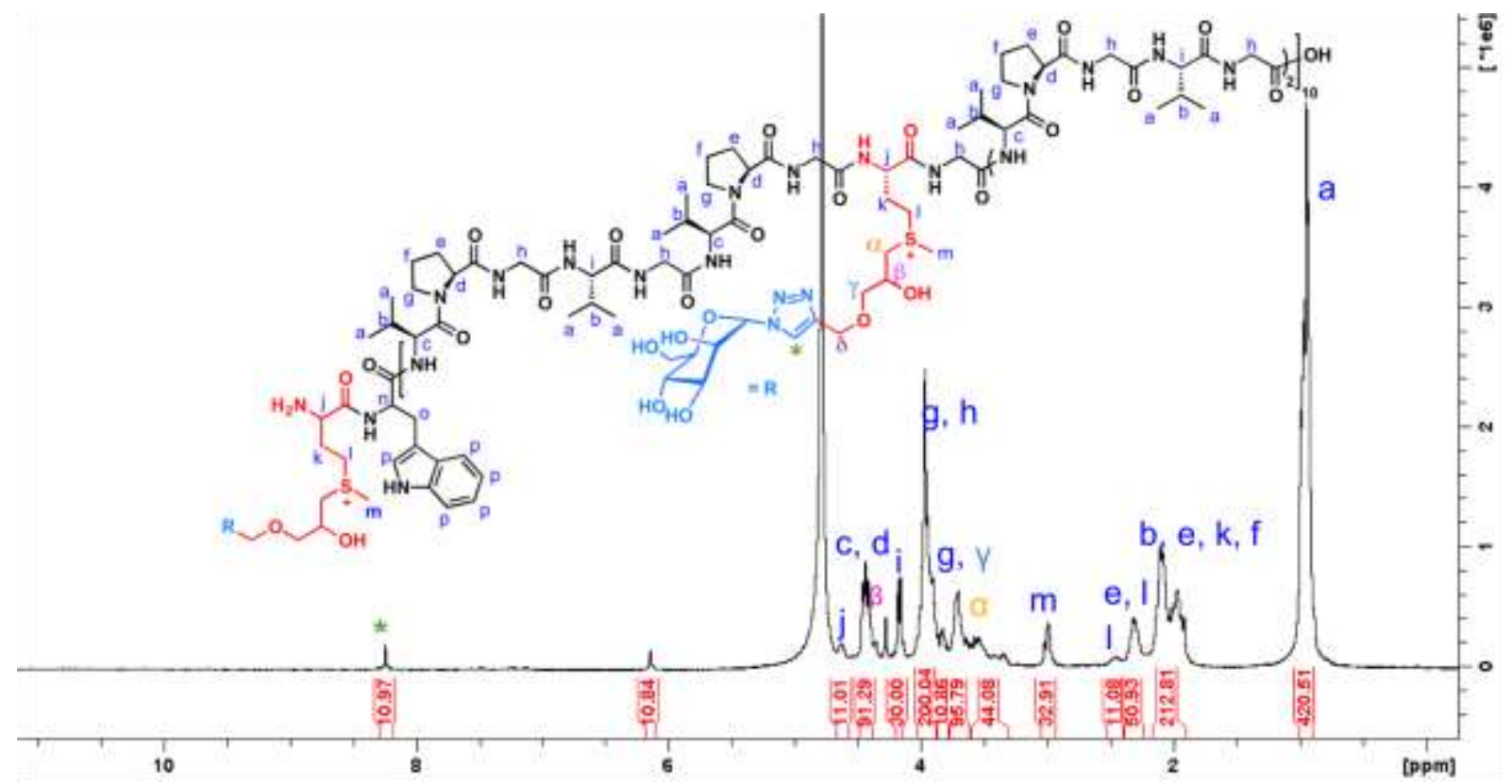

Figure S49. ${ }^{1} \mathrm{H}$ NMR spectrum of compound $\underline{\mathbf{2 b}}$ in $\mathrm{D}_{2} \mathrm{O}$. 


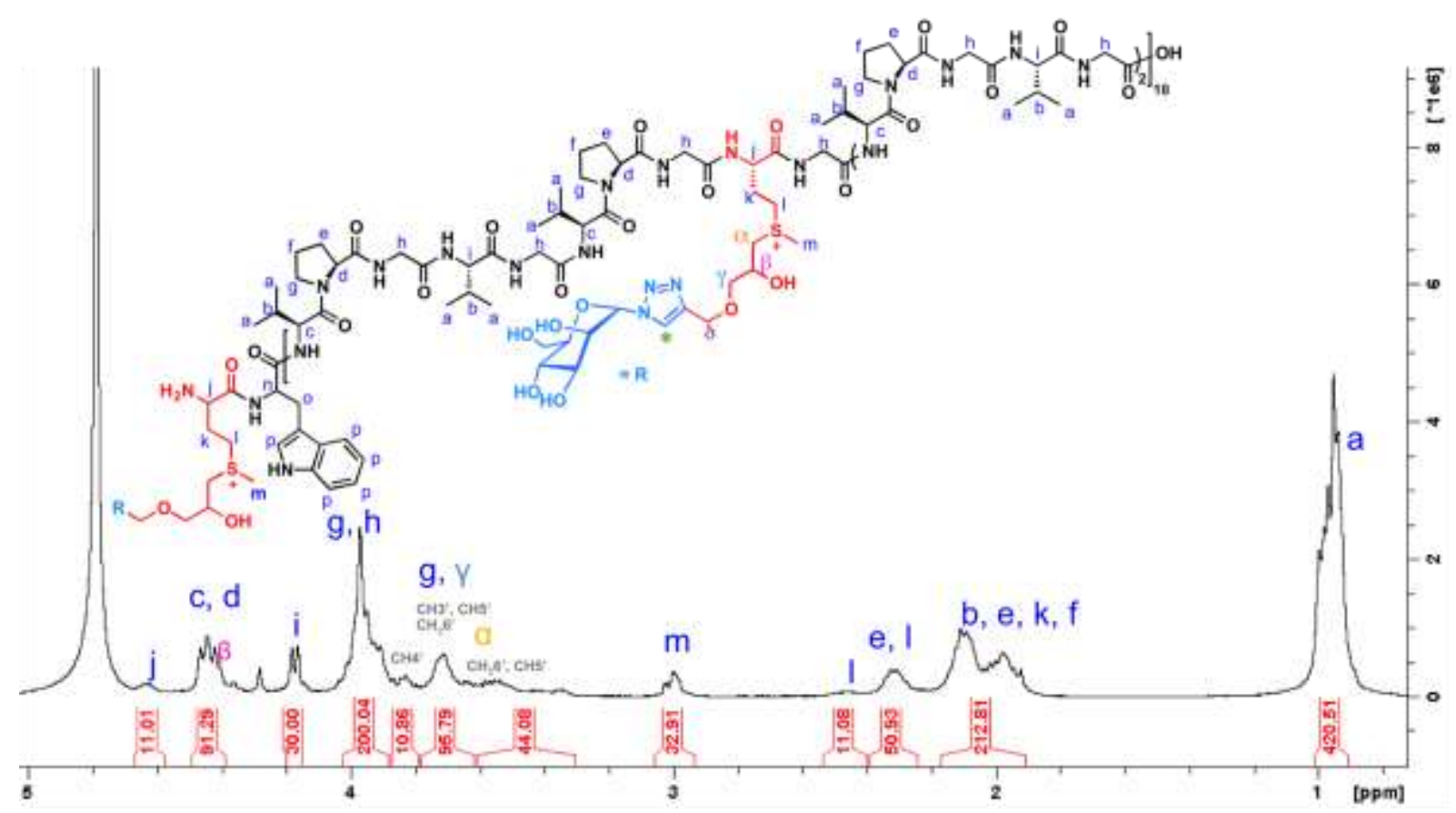

Figure S50. ${ }^{1} \mathrm{H}$ NMR spectrum of compound $\underline{\mathbf{2 b}}$ (zoom) in $\mathrm{D}_{2} \mathrm{O}$.

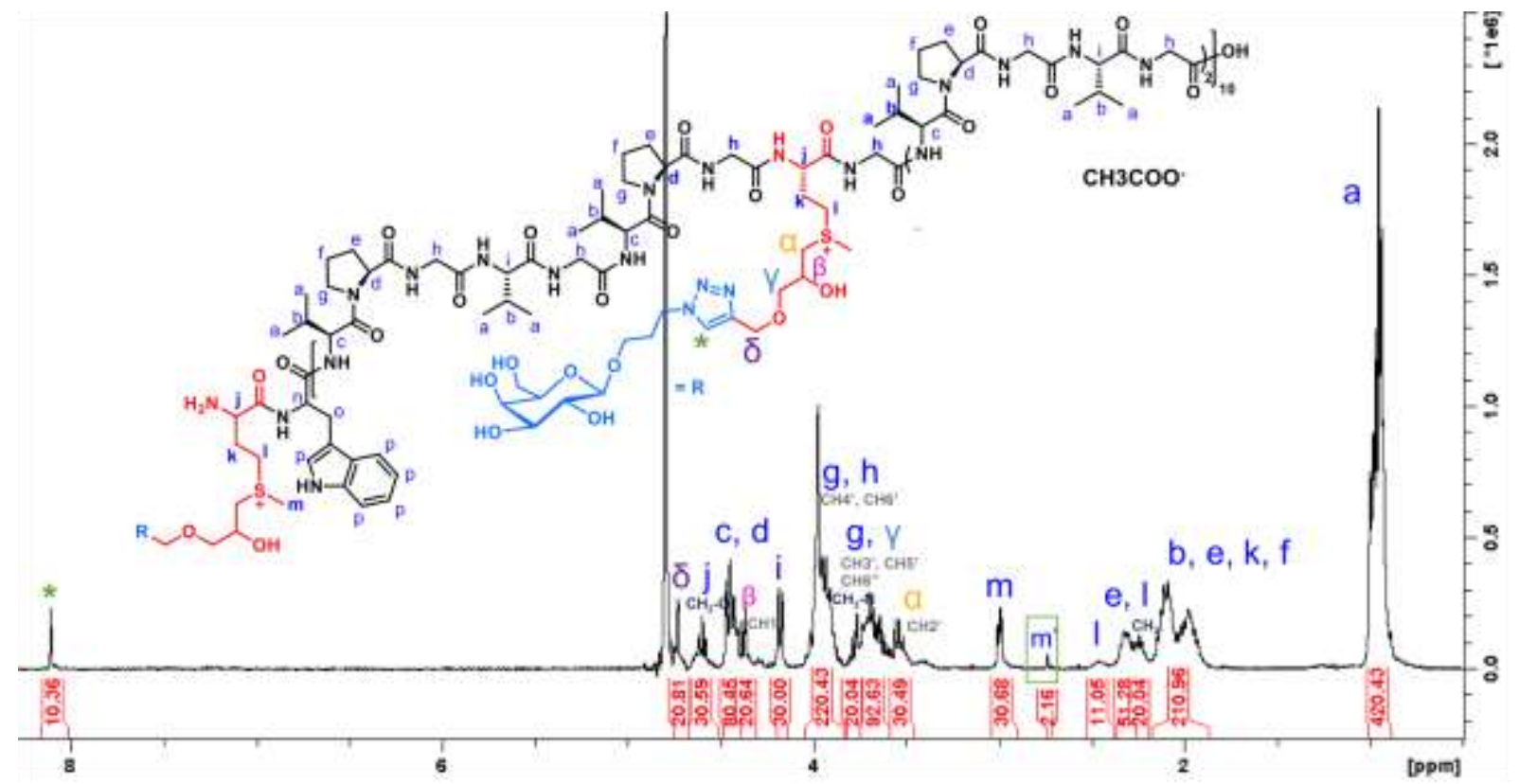

Figure S51. ${ }^{1} \mathrm{H}$ NMR spectrum of compound $\underline{\mathbf{2 c}}$ in $\mathrm{D}_{2} \mathrm{O}$. 


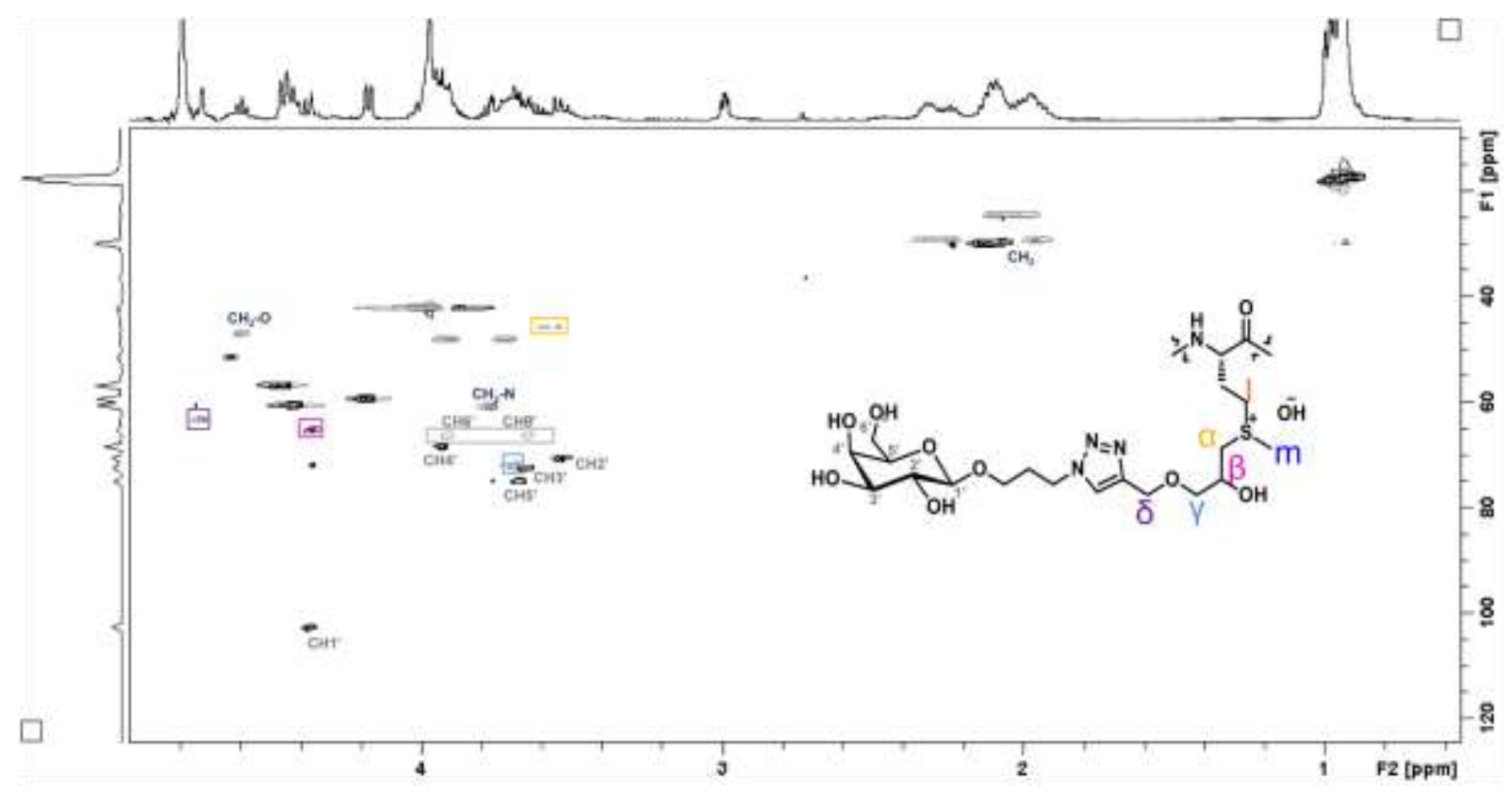

Figure S52. 2D NMR spectrum of compound $\underline{\mathbf{2 c}}$ in $\mathrm{D}_{2} \mathrm{O}, \mathrm{HSQC}$.

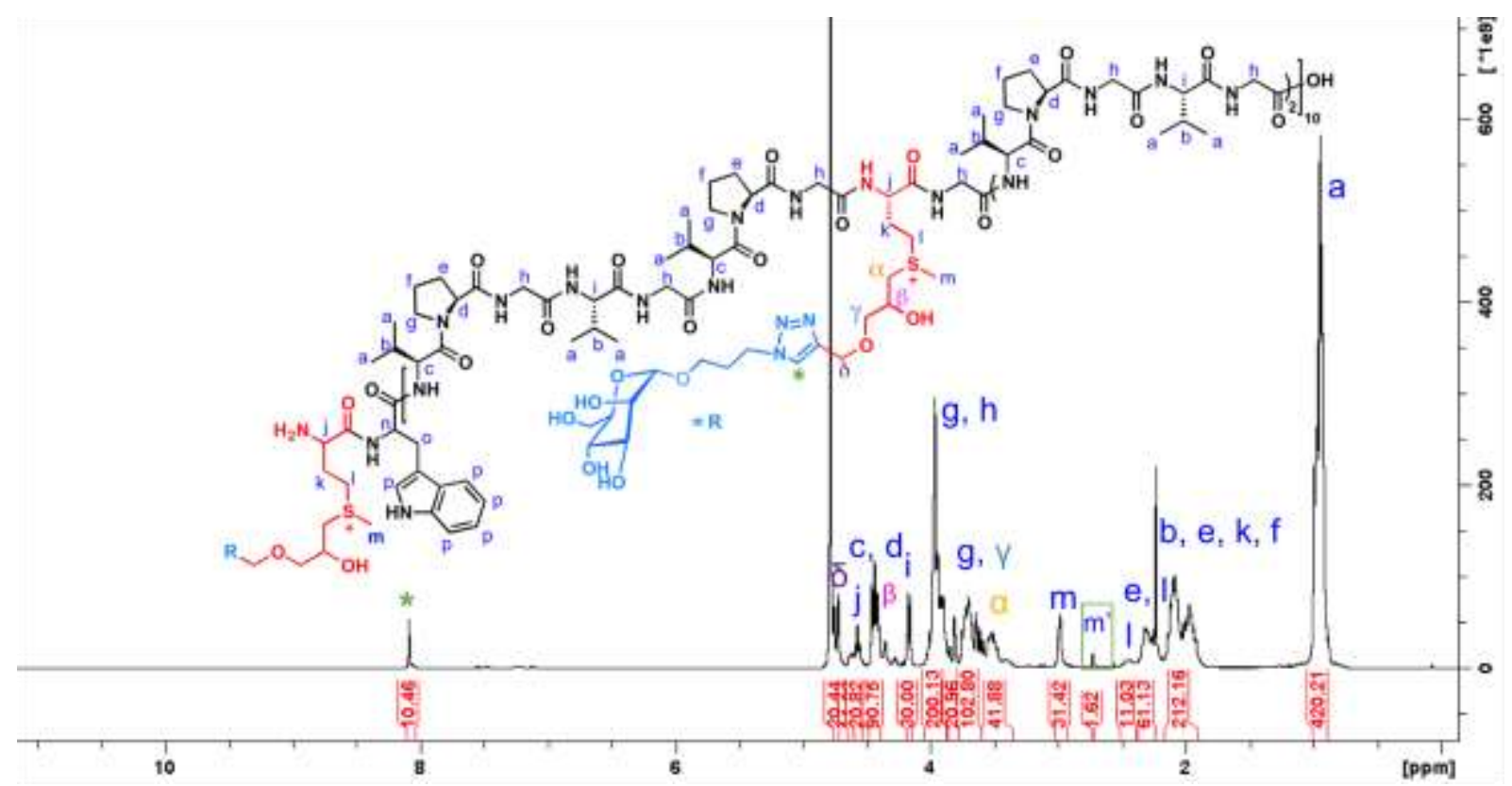

Figure S53. ${ }^{1} \mathrm{H}$ NMR spectrum of compound $\underline{\mathbf{2 d}}$ in $\mathrm{D}_{2} \mathrm{O}$. 


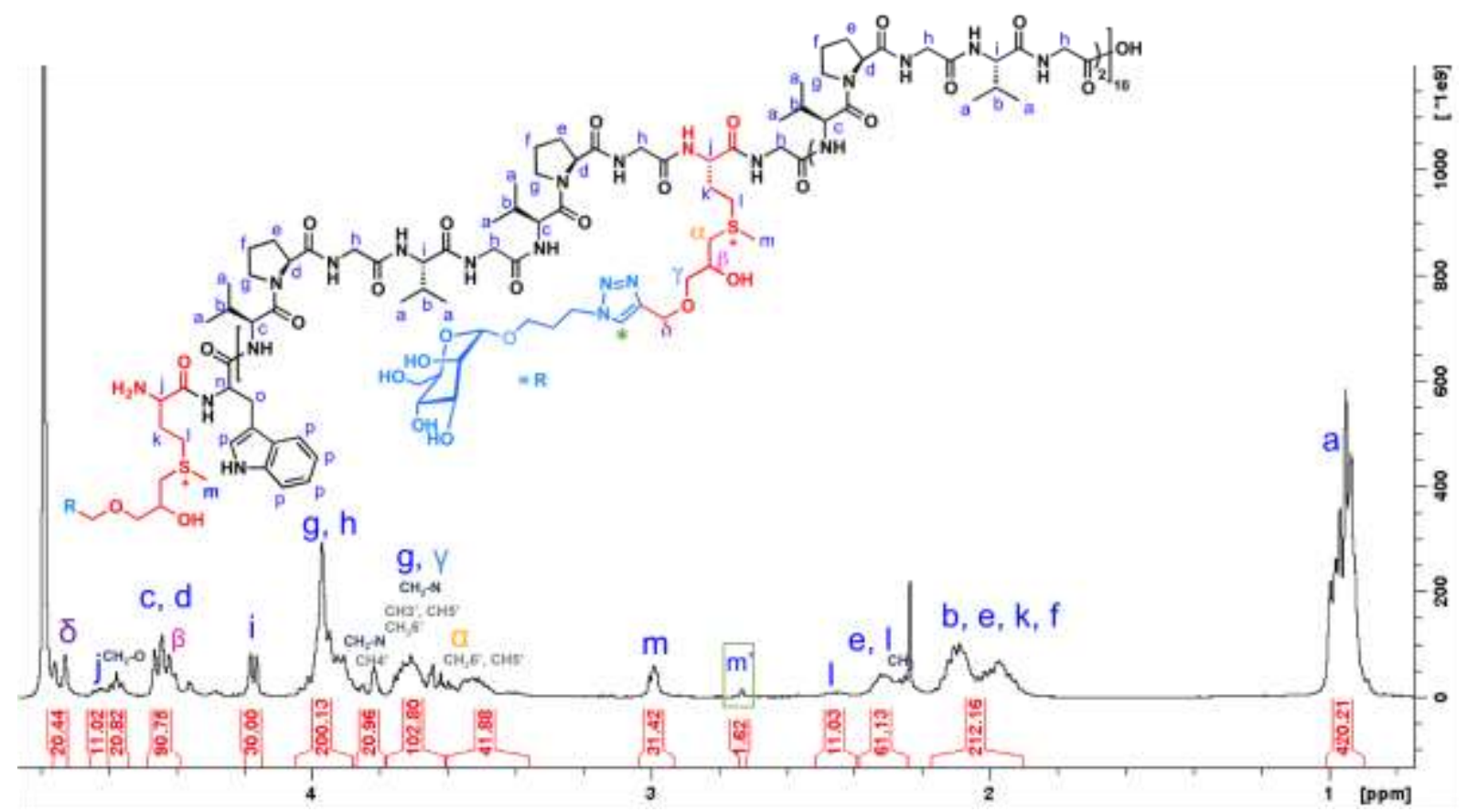

Figure S54. ${ }^{1} \mathrm{H}$ NMR spectrum of compound $\underline{\mathbf{2 d}}$ (zoom) in $\mathrm{D}_{2} \mathrm{O}$.

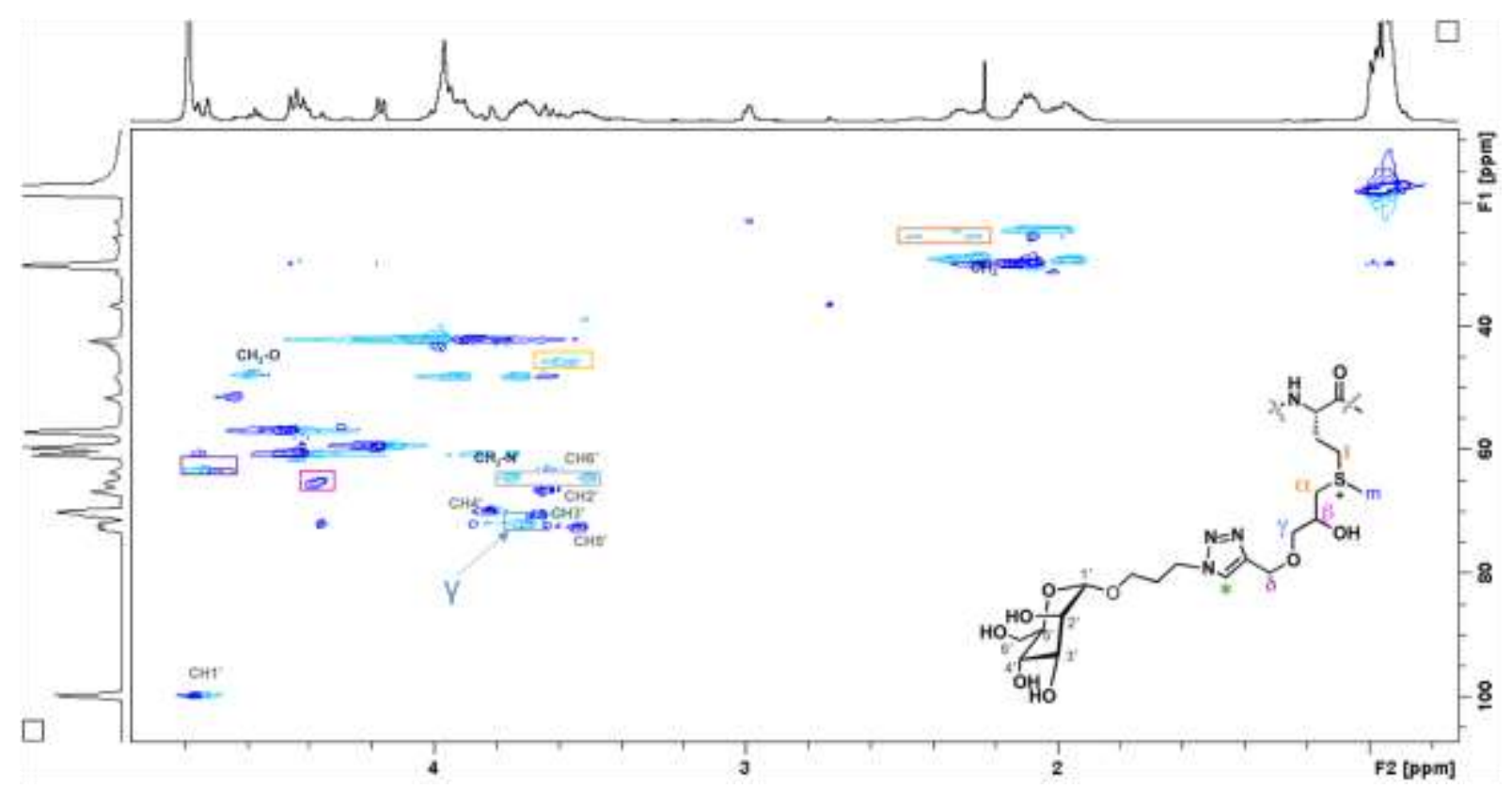

Figure S55. 2D NMR spectrum of compound $\underline{\mathbf{2 d}}$ in $\mathrm{D}_{2} \mathrm{O}, \mathrm{HSQC}$. 


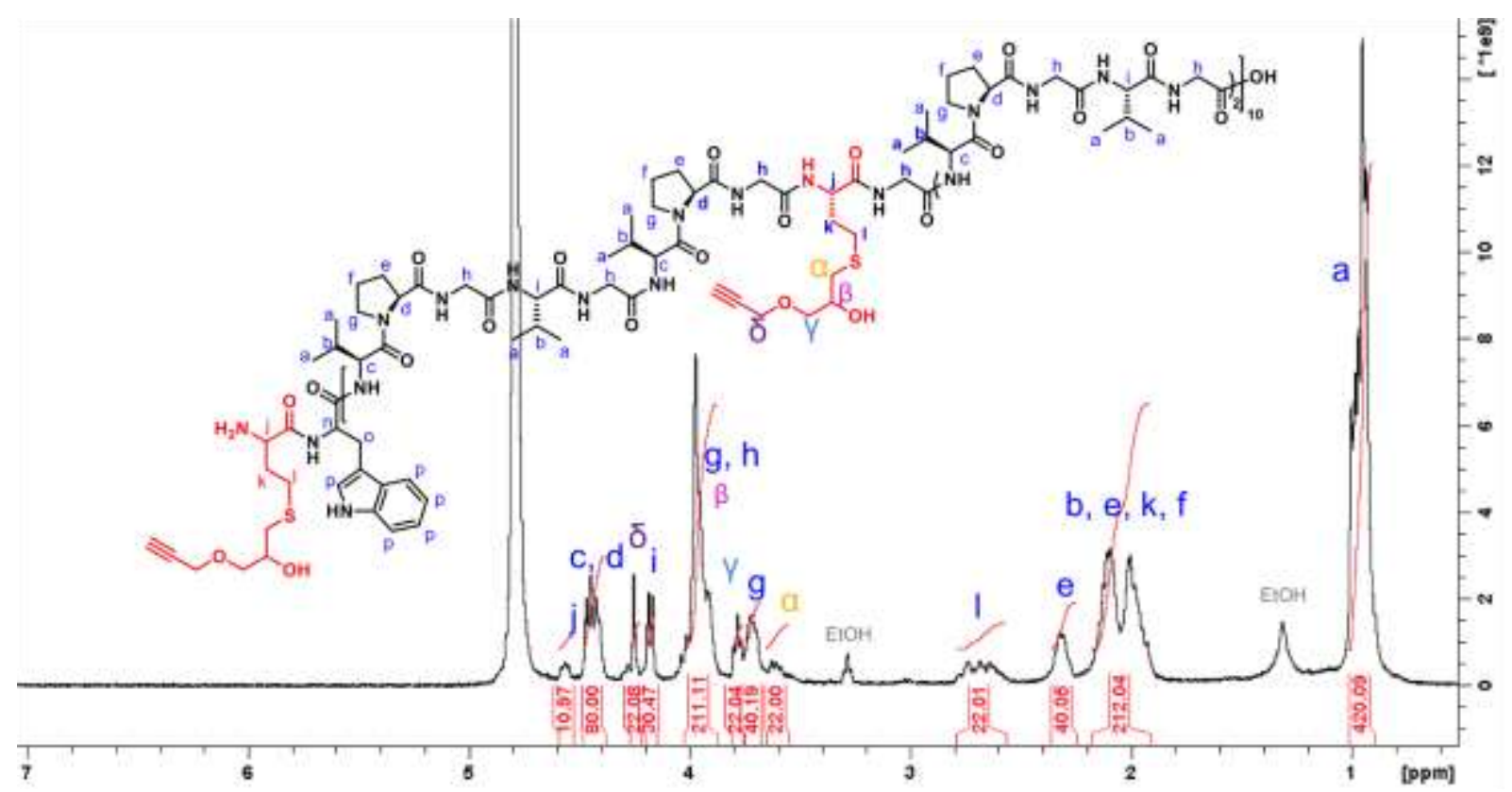

Figure S56. ${ }^{1} \mathrm{H}$ NMR spectrum of $\operatorname{ELP}\left[\mathrm{M}(\operatorname{DemAlk}){ }_{1} \mathrm{~V}_{3}-20\right]$, $\underline{\mathbf{4}}$, in $\mathrm{D}_{2} \mathrm{O}$.

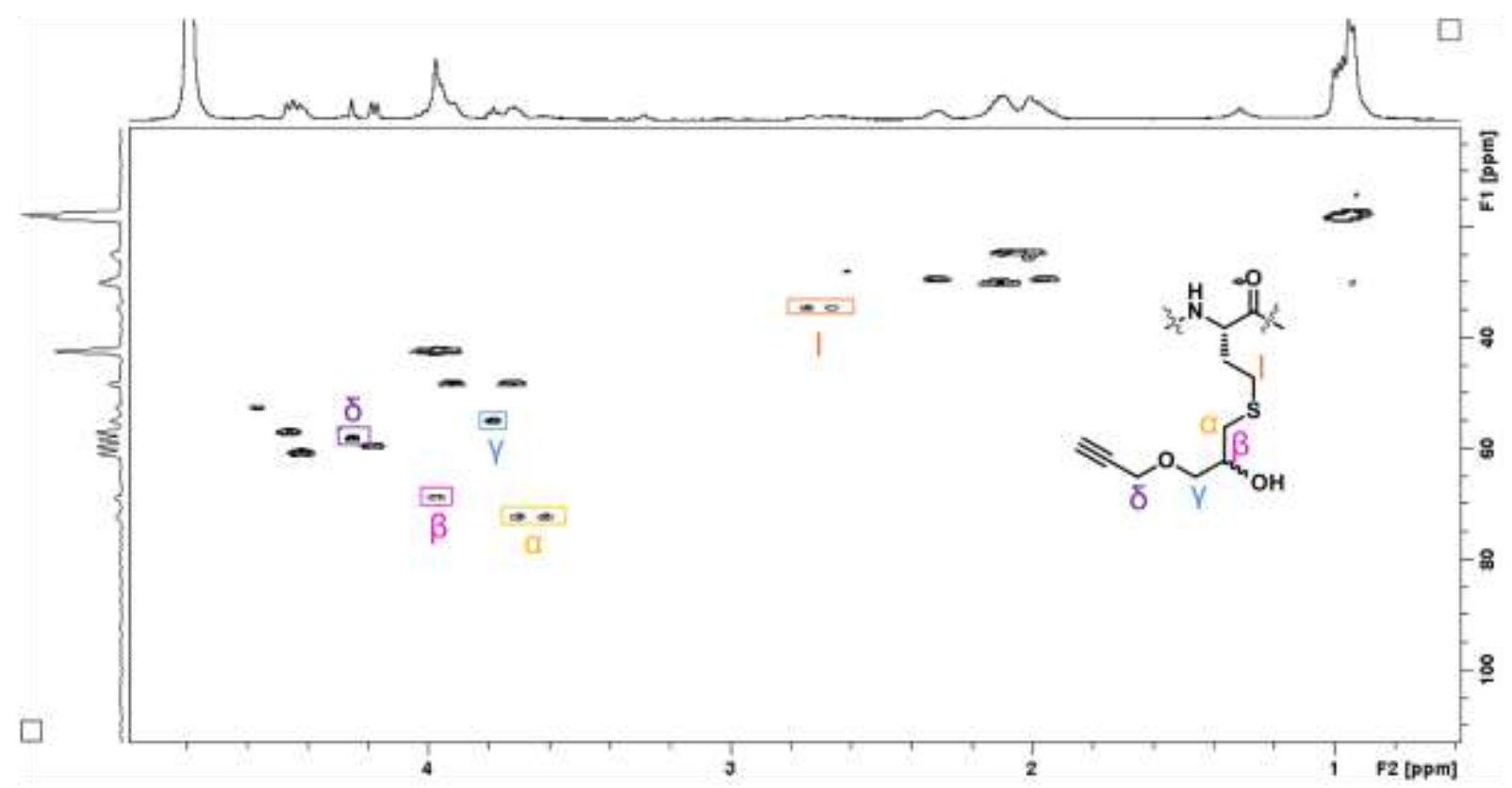

Figure S57. 2D NMR spectrum of $\operatorname{ELP}\left[\mathrm{M}(\text { DemAlk })_{1} \mathrm{~V}_{3}-20\right]$, $\underline{\mathbf{4}}$, in $\mathrm{D}_{2} \mathrm{O}, \mathrm{HSQC}$. 


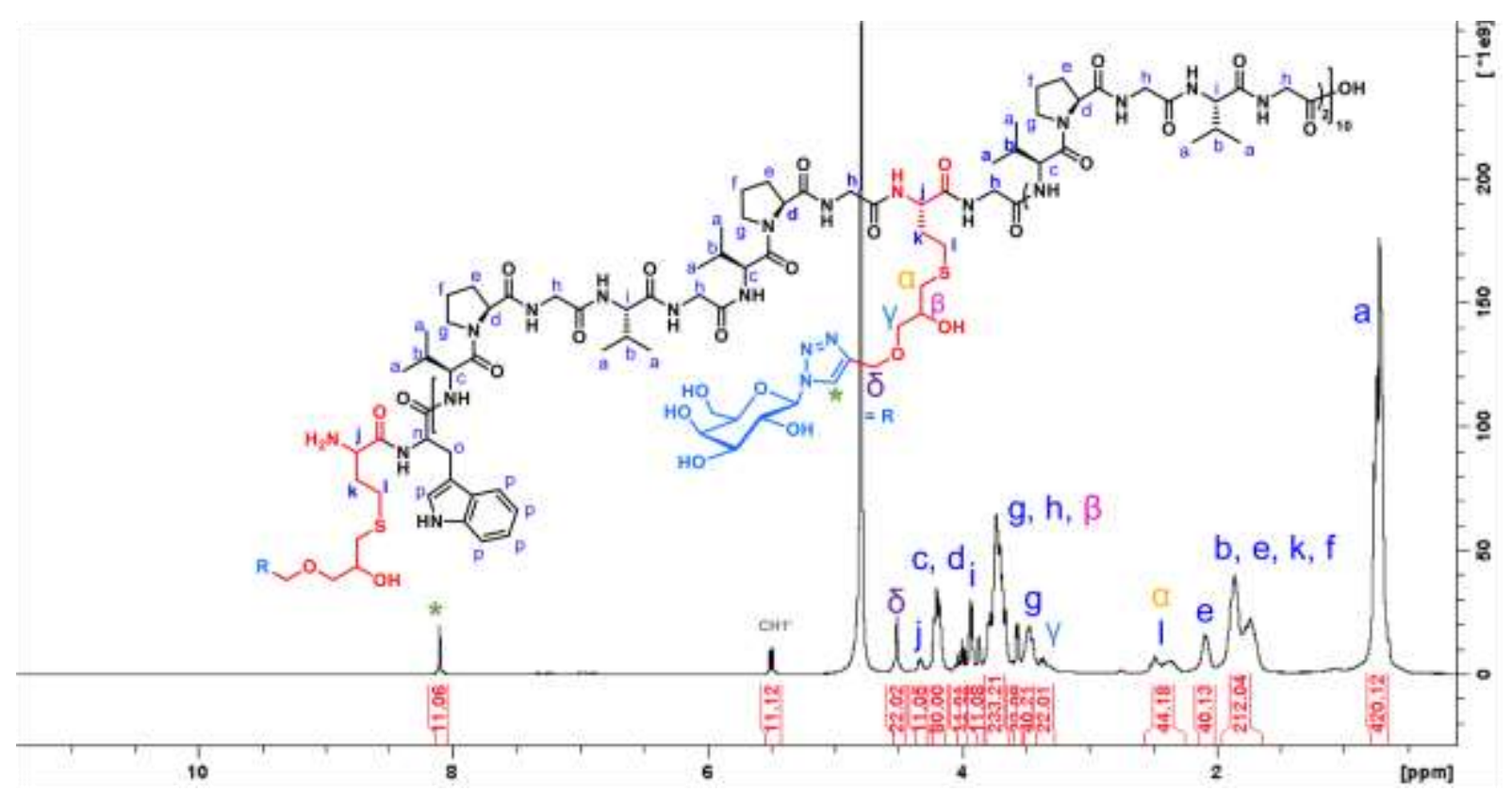

Figure S58. ${ }^{1} \mathrm{H}$ NMR spectrum of compound $\underline{\mathbf{4 a}}$ in $\mathrm{D}_{2} \mathrm{O}$.

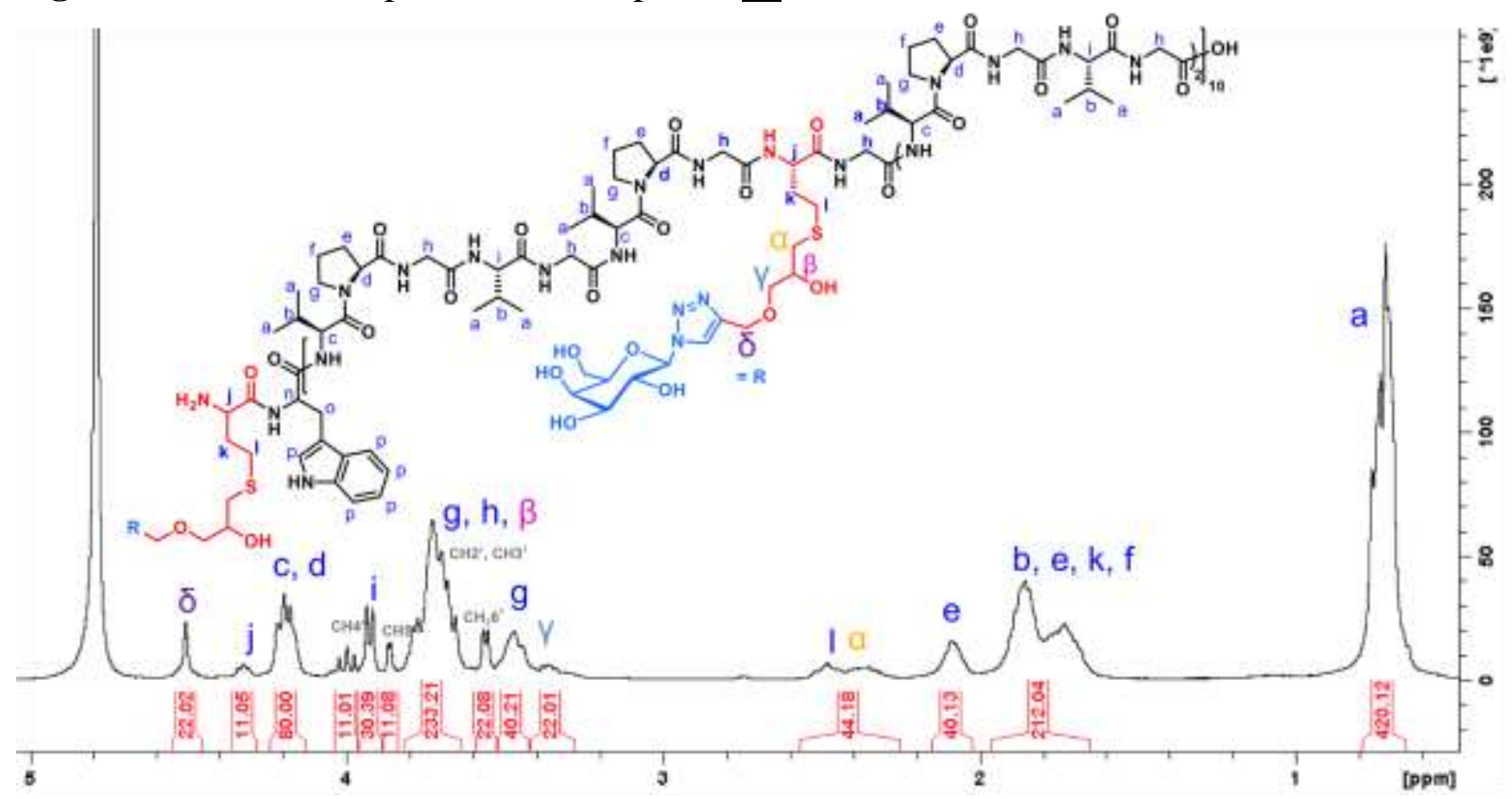

Figure S59. ${ }^{1} \mathrm{H}$ NMR spectrum of compound $\underline{\mathbf{4 a}}$ (zoom) in $\mathrm{D}_{2} \mathrm{O}$. 


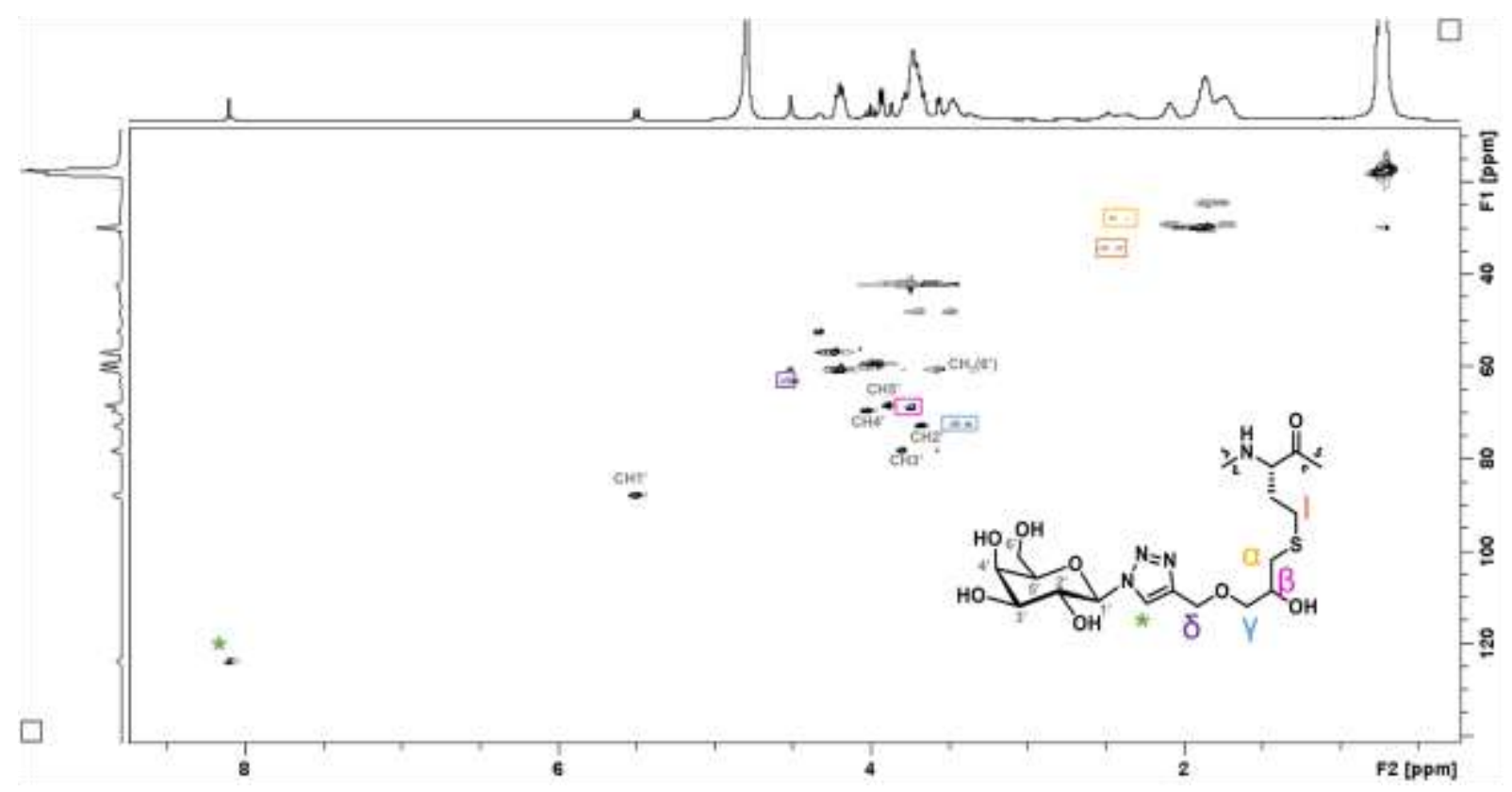

Figure S60. 2D NMR spectrum of compound $\underline{4 a}$ in $\mathrm{D}_{2} \mathrm{O}$, HSQC.

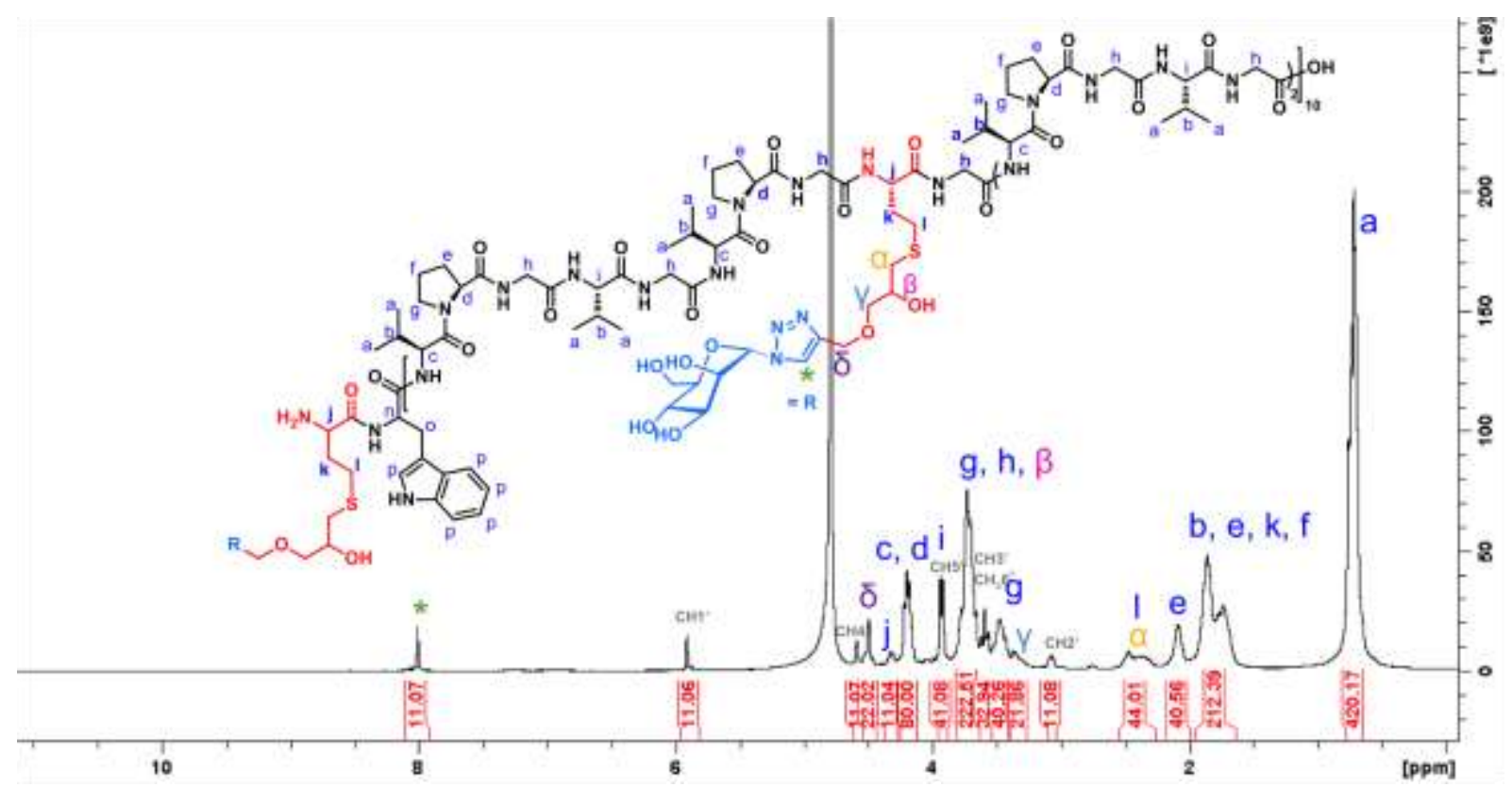

Figure S61. ${ }^{1} \mathrm{H}$ NMR spectrum of compound $\underline{\mathbf{4 b}}$ in $\mathrm{D}_{2} \mathrm{O}$. 


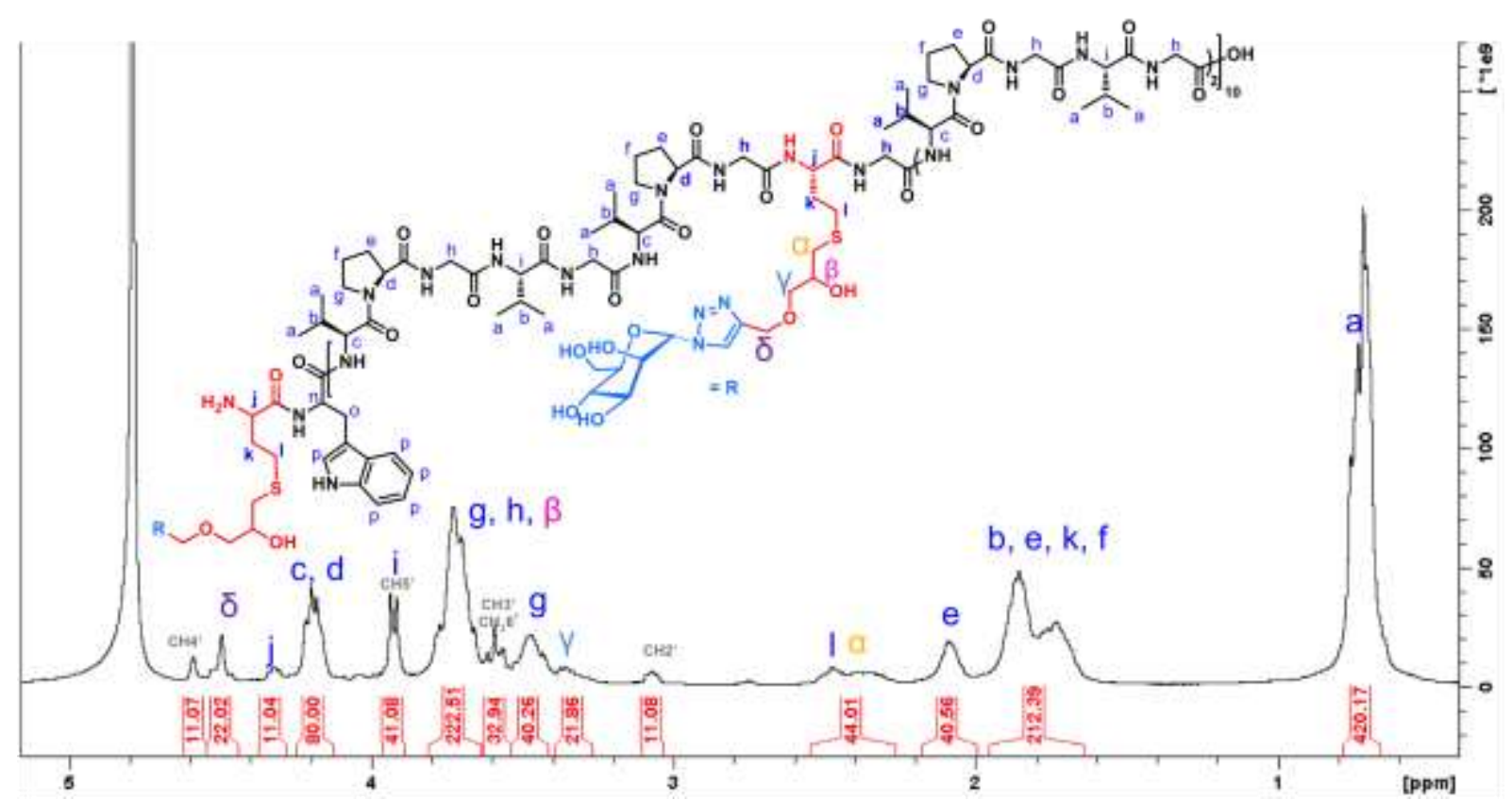

Figure S62. ${ }^{1} \mathrm{H}$ NMR spectrum of compound $\underline{\mathbf{4 b}}$ (zoom) in $\mathrm{D}_{2} \mathrm{O}$.

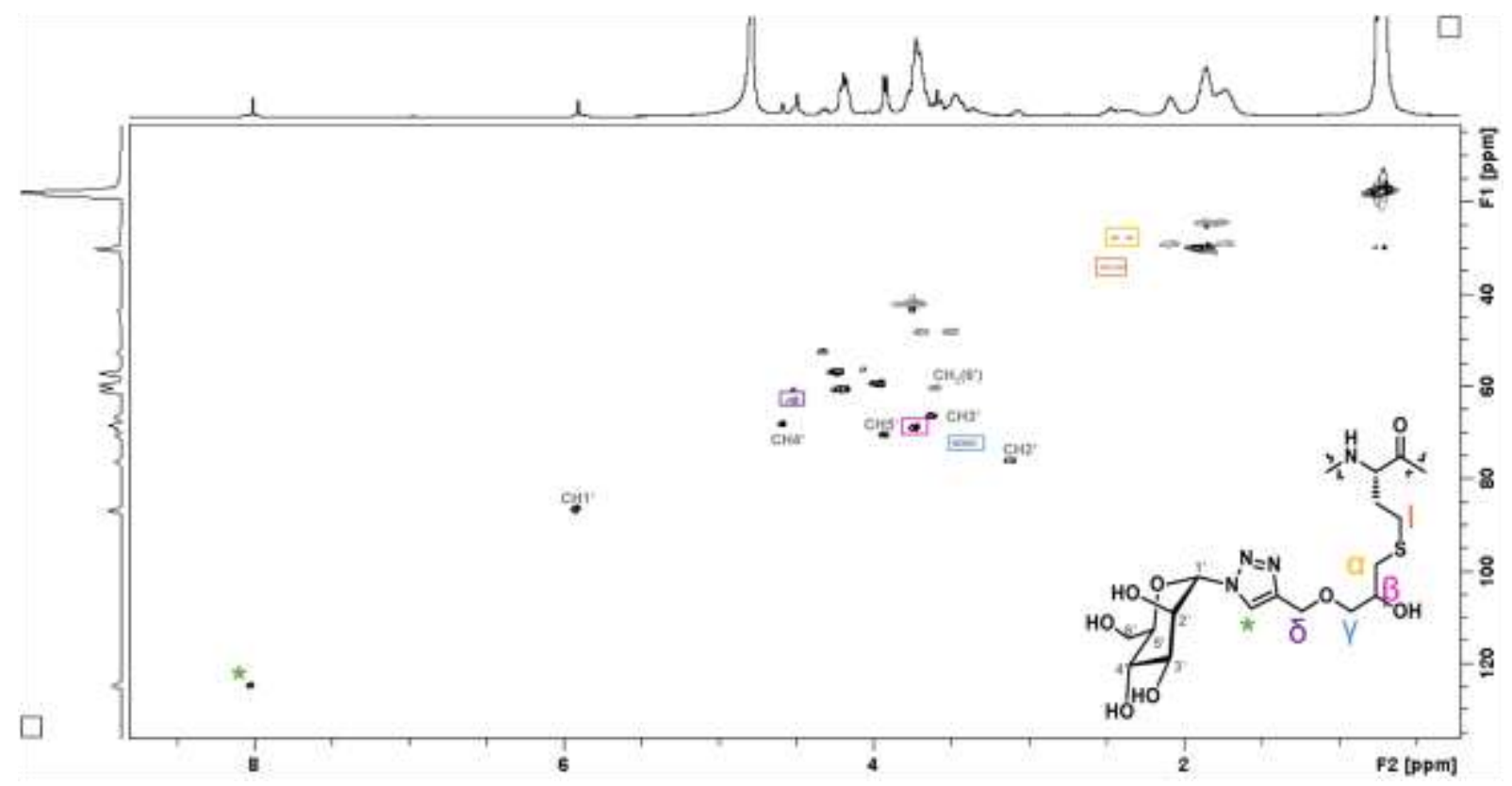

Figure S63. 2D NMR spectrum of compound $\underline{4 \mathbf{b}}$ in $\mathrm{D}_{2} \mathrm{O}$, HSQC. 


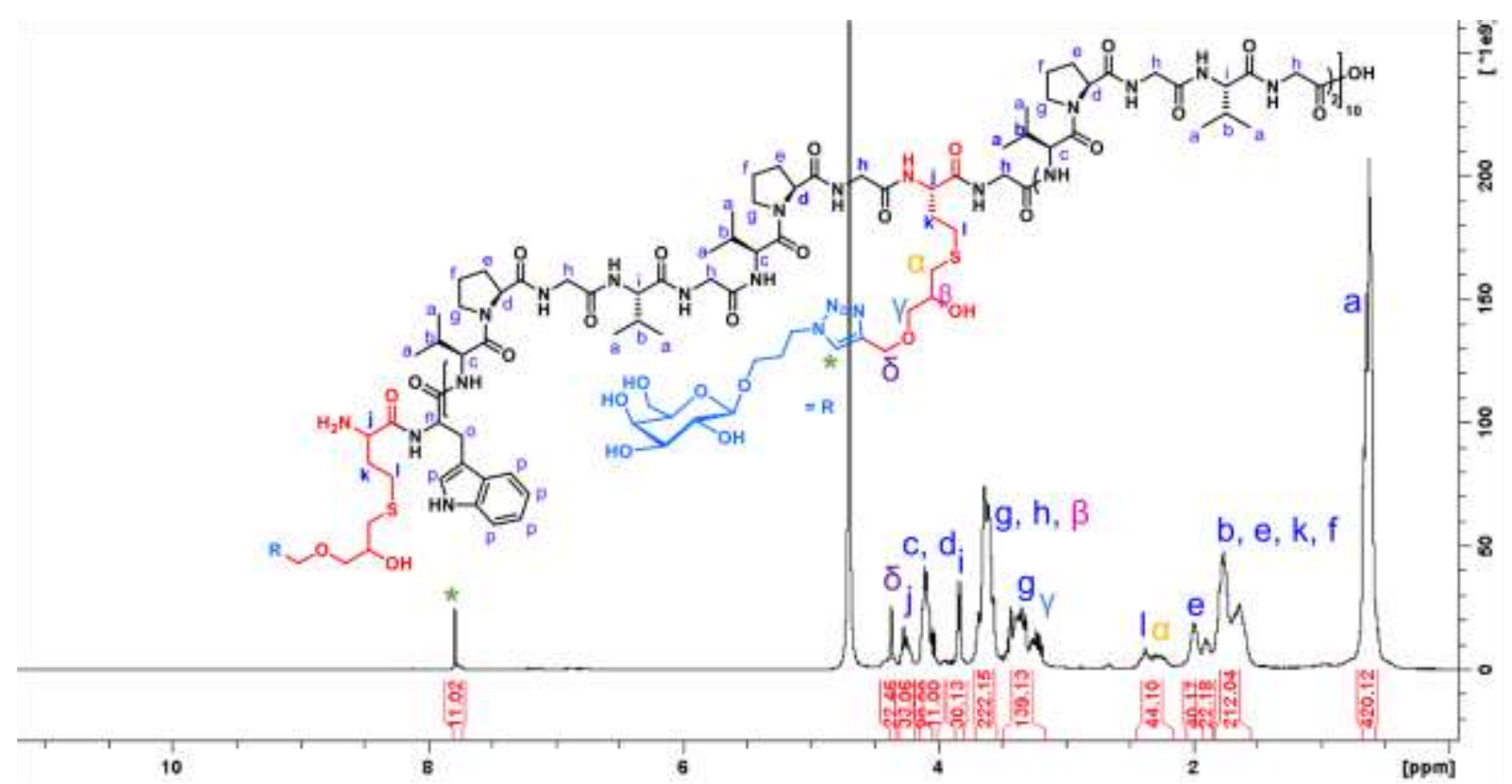

Figure S64. ${ }^{1} \mathrm{H}$ NMR spectrum of compound $\underline{\mathbf{4 c}}$ in $\mathrm{D}_{2} \mathrm{O}$.

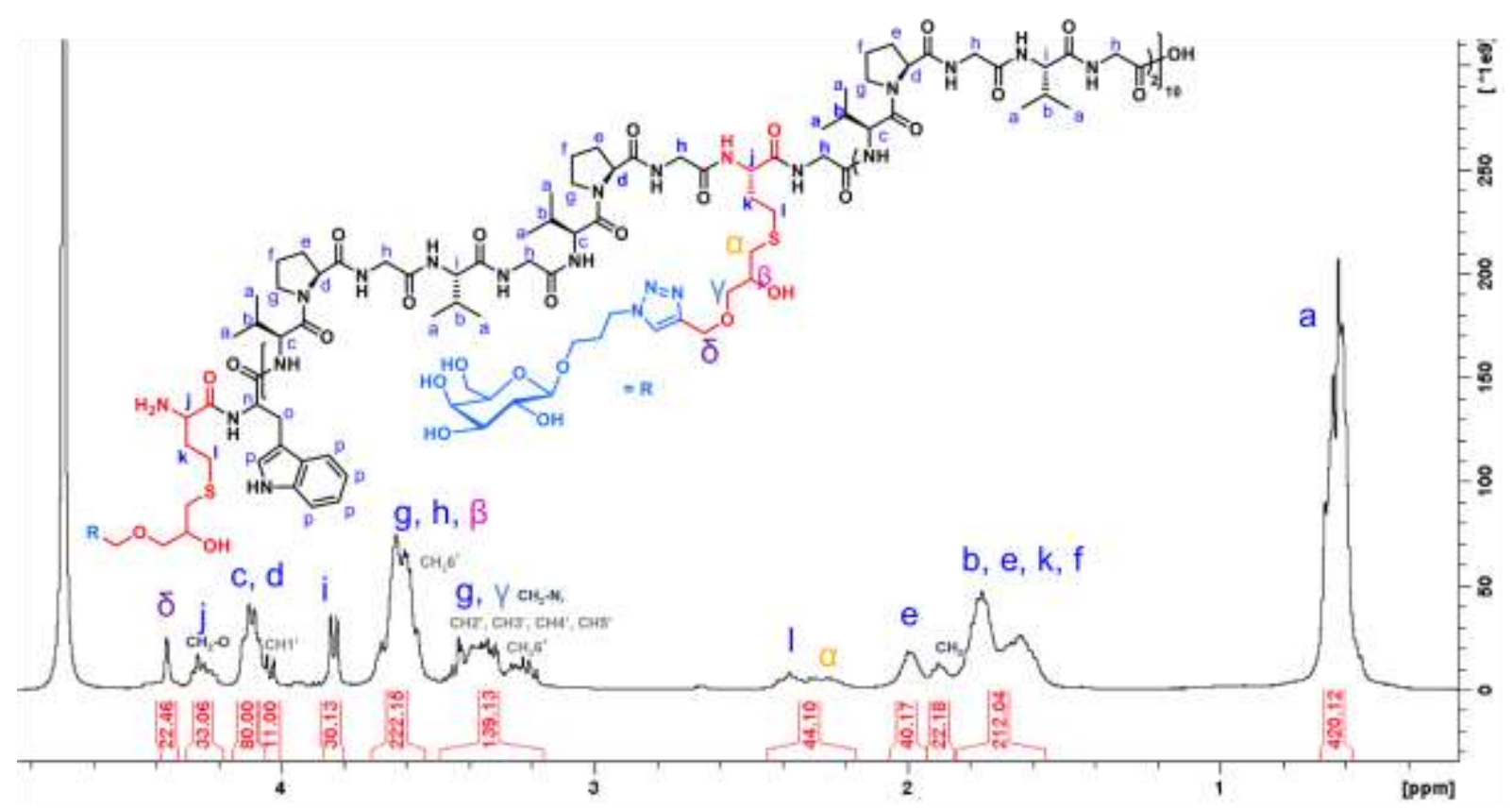

Figure S65. ${ }^{1} \mathrm{H}$ NMR spectrum of compound $\underline{\mathbf{4 c}}$ (zoom) in $\mathrm{D}_{2} \mathrm{O}$. 


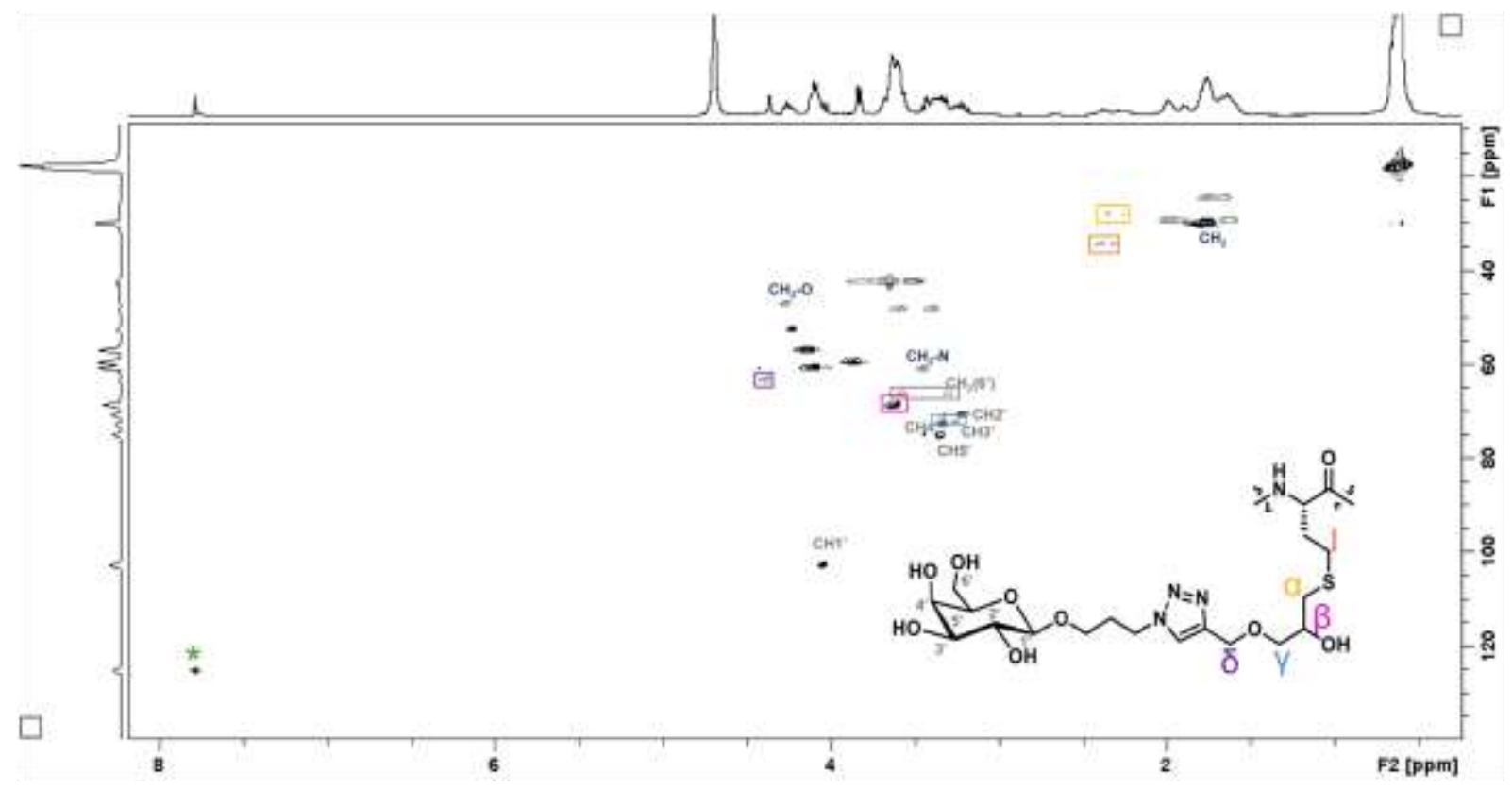

Figure S66. 2D NMR spectrum of compound $\underline{4 \mathbf{c}}$ in $\mathrm{D}_{2} \mathrm{O}, \mathrm{HSQC}$.

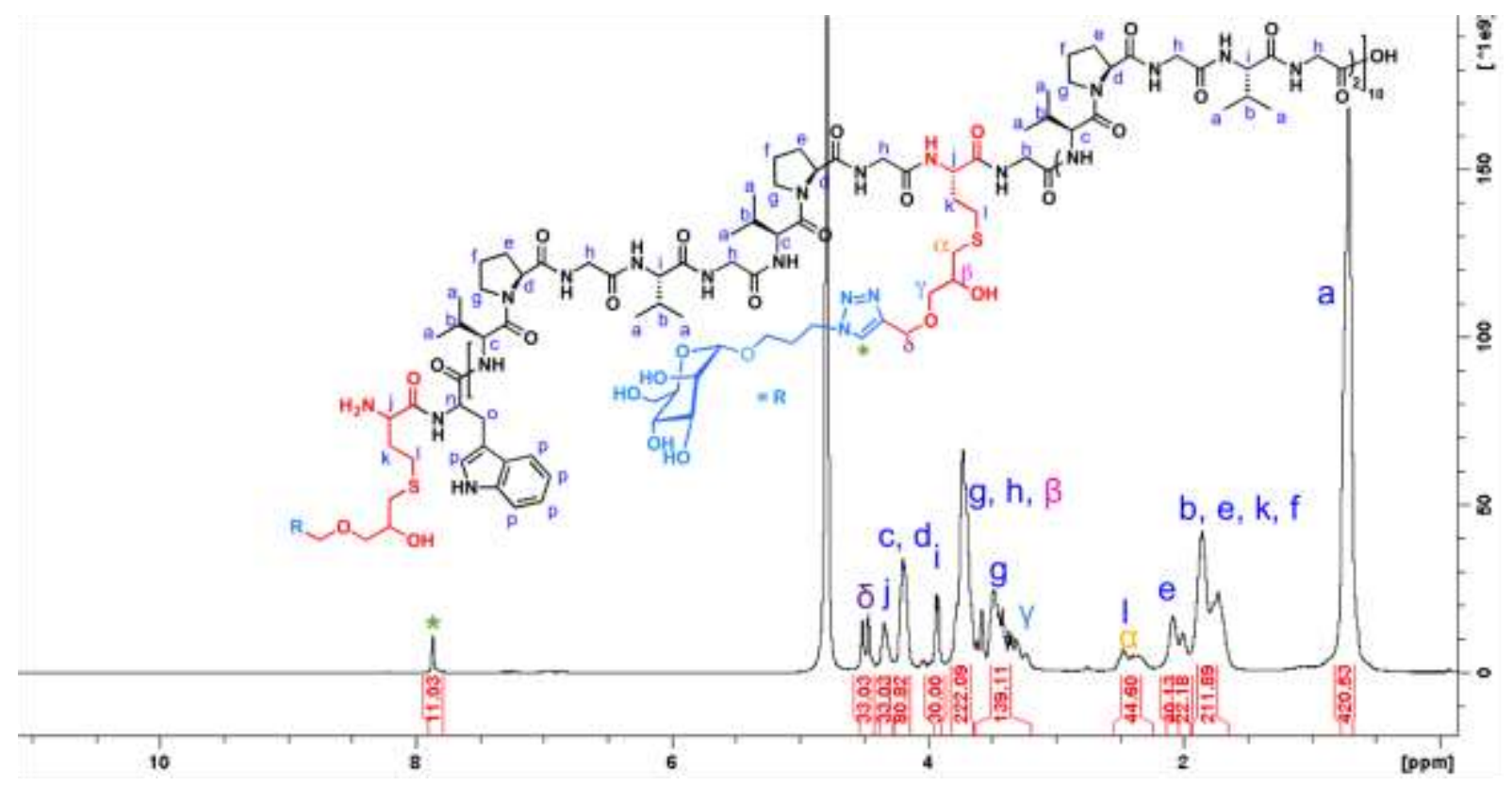

Figure S67. ${ }^{1} \mathrm{H}$ NMR spectrum of compound $\underline{\mathbf{4 d}}$ in $\mathrm{D}_{2} \mathrm{O}$. 


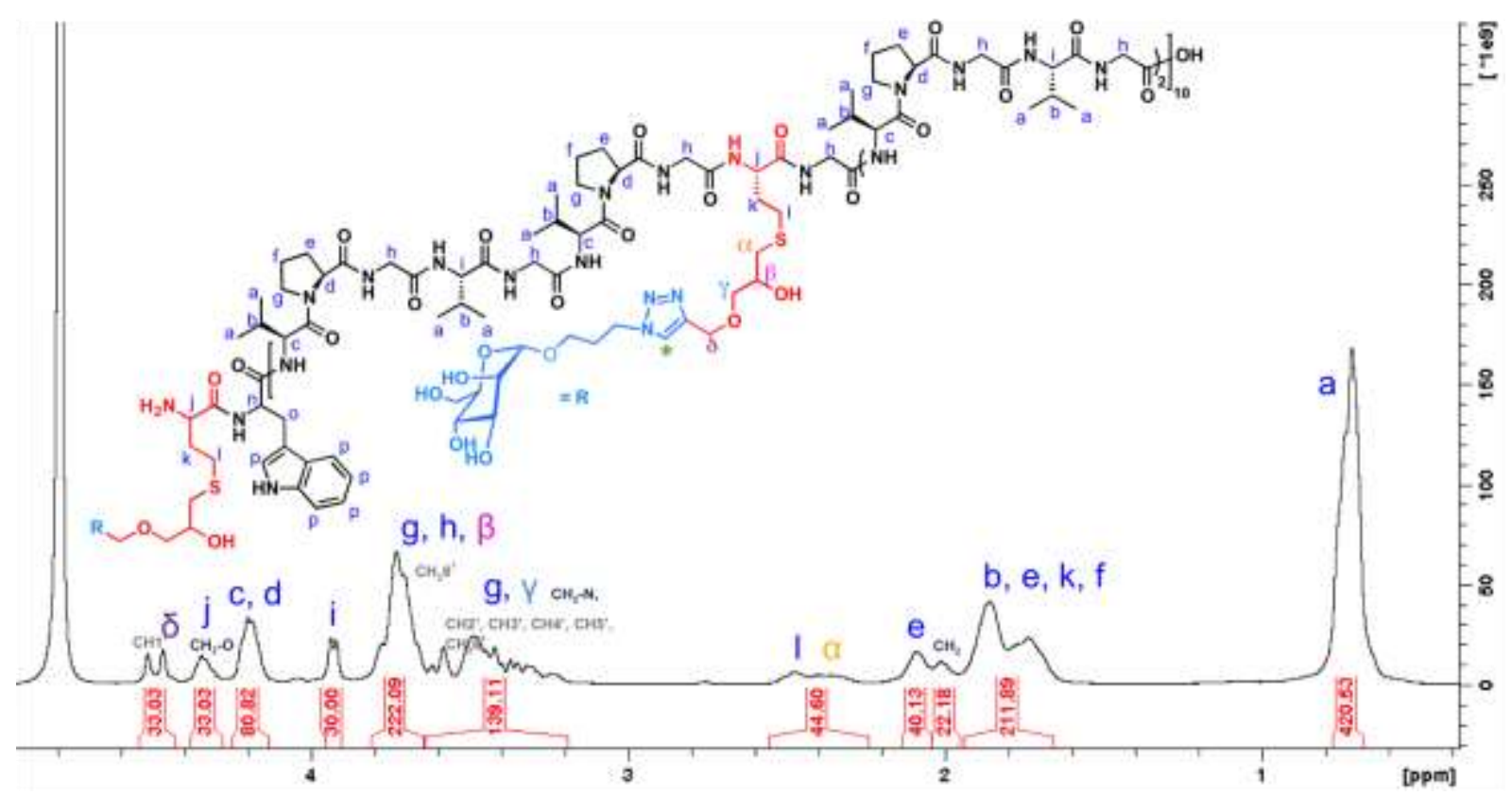

Figure S68. ${ }^{1} \mathrm{H}$ NMR spectrum of compound $\underline{4 \mathbf{d}}$ (zoom) in $\mathrm{D}_{2} \mathrm{O}$.

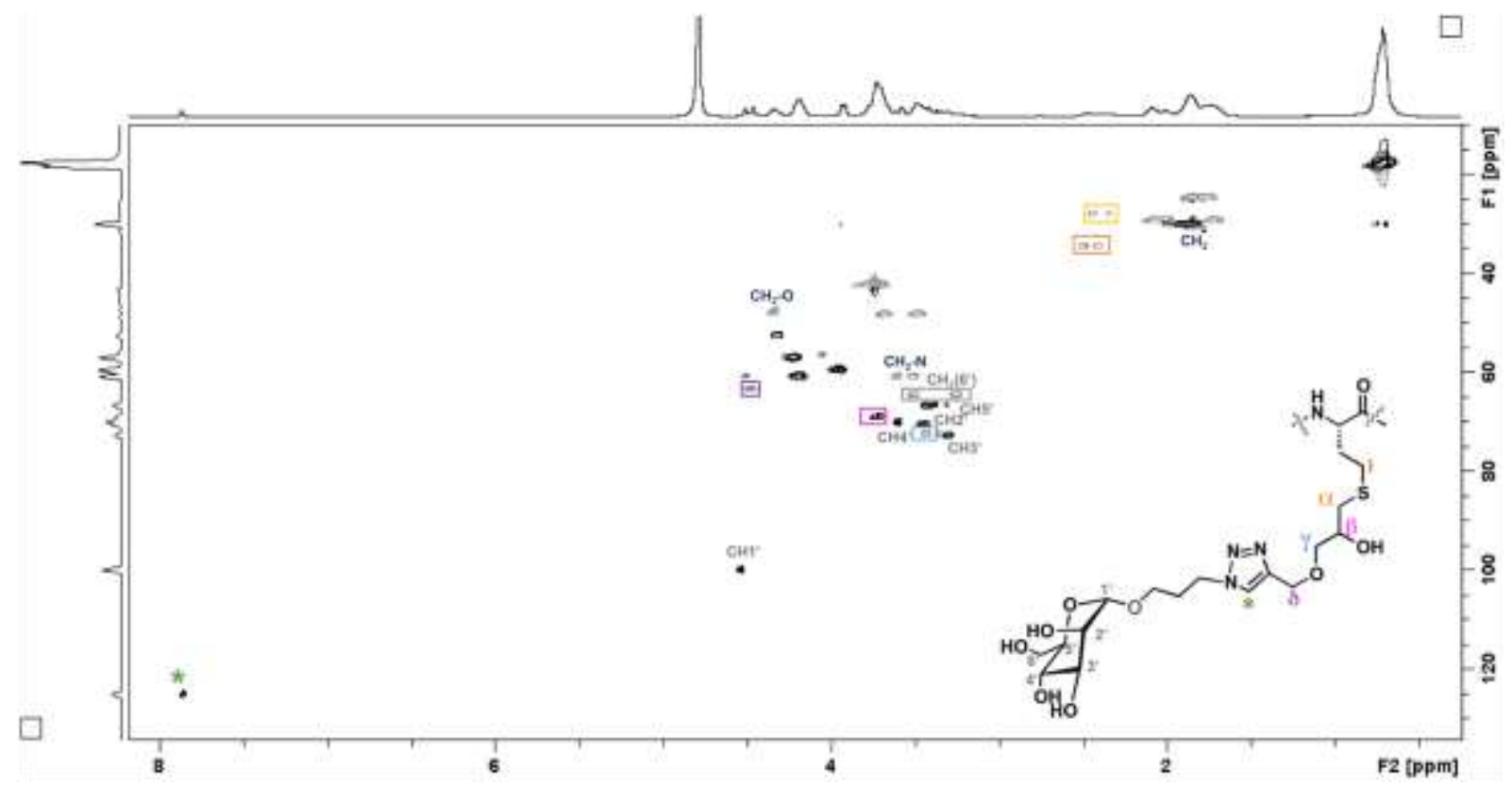

Figure S69. 2D NMR spectrum of compound $\underline{\mathbf{4 d}}$ in $\mathrm{D}_{2} \mathrm{O}$, HSQC. 

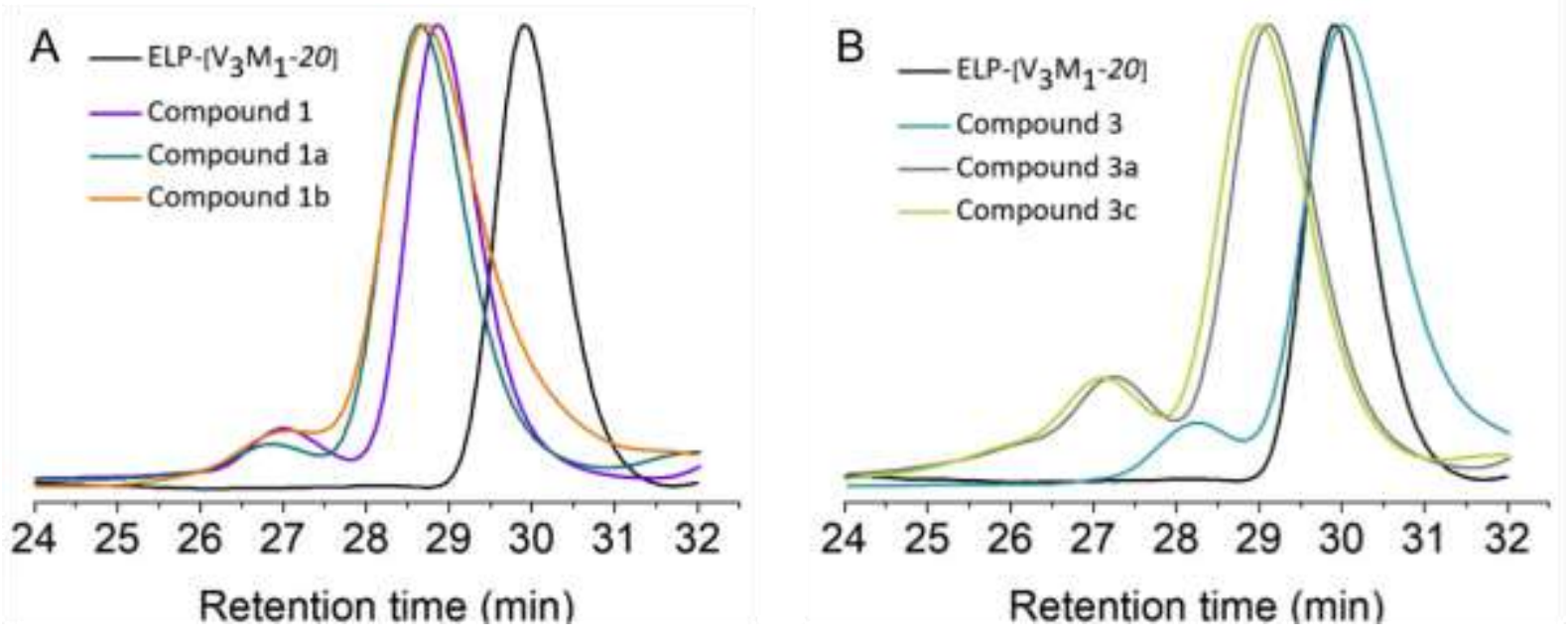

Figure S70. Size exclusion chromatography traces of ELP-[ $\left[\mathrm{M}_{1} \mathrm{~V}_{3}-20\right]$ for comparison with those of (A) compounds $\underline{\mathbf{1}}, \underline{\mathbf{1 a}}, \underline{\mathbf{1 b}}$, and (B) compounds $\underline{\mathbf{3}}, \underline{\mathbf{3 a}}, \underline{\mathbf{3}}$ in AcOH/Ammonium Acetate/ACN (RI detection).
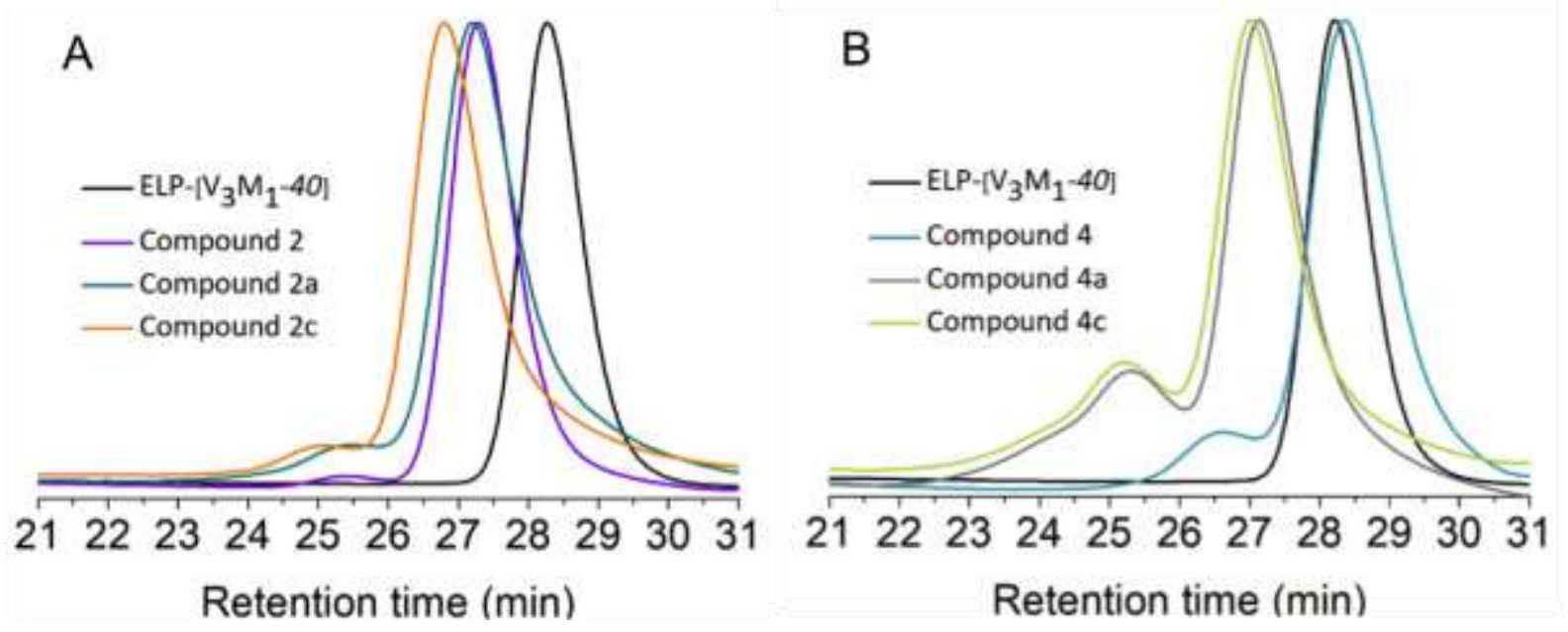

Figure S71. Size exclusion chromatography traces of ELP- $\left[\mathrm{M}_{1} \mathrm{~V}_{3}-40\right]$ for comparison with those of (A) compounds $\underline{\mathbf{2}}, \underline{\mathbf{2 a}}, \underline{\mathbf{2 c}}$ and (B) compound $\underline{\mathbf{4}}, \underline{\mathbf{4 a}}, \underline{\mathbf{4 c}}$ in AcOH/Ammonium Acetate/ACN (RI detection). 

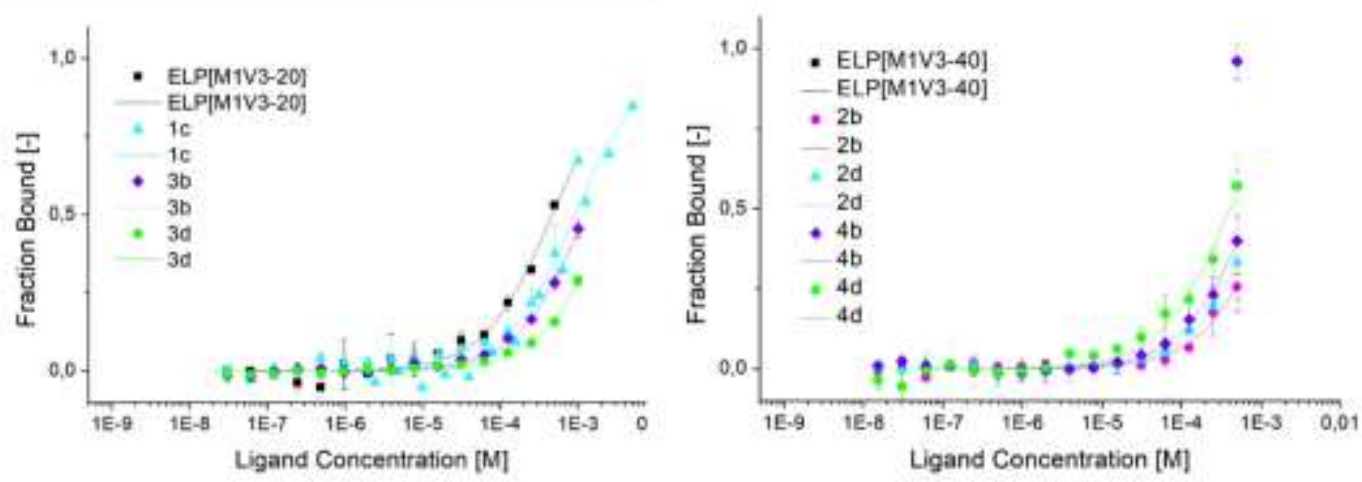

Figure S72. Thermophoretic analysis of interactions between lectin $\mathrm{RCA}_{120}$ and control ligands (mannose derivatives) in Tris buffer at $22^{\circ} \mathrm{C}$.

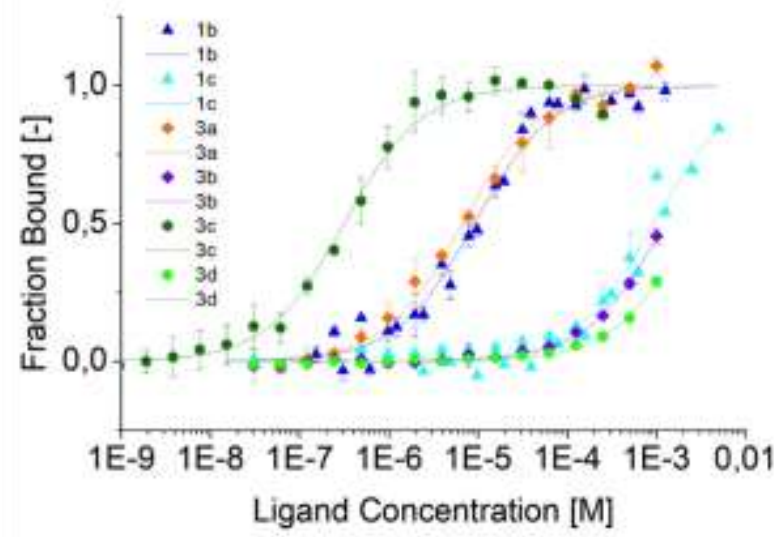

Figure S73. Thermophoretic analysis of interactions between lectin $\mathrm{RCA}_{120}$ and ligands $\underline{\mathbf{1 b}}$, $\underline{\mathbf{3 a}}$ and $\underline{\mathbf{3 c}}$ as compared to control ligands $\underline{\mathbf{1 c}}, \underline{\mathbf{3 b}}$ and $\underline{\mathbf{3 d}}$ in Tris buffer at $22^{\circ} \mathrm{C}$. 